\title{
norden
}

\section{Information on Chemicals in Electronic Products}

A study of needs, gaps, obstacles and solutions to provide and access information on chemicals in electronic products

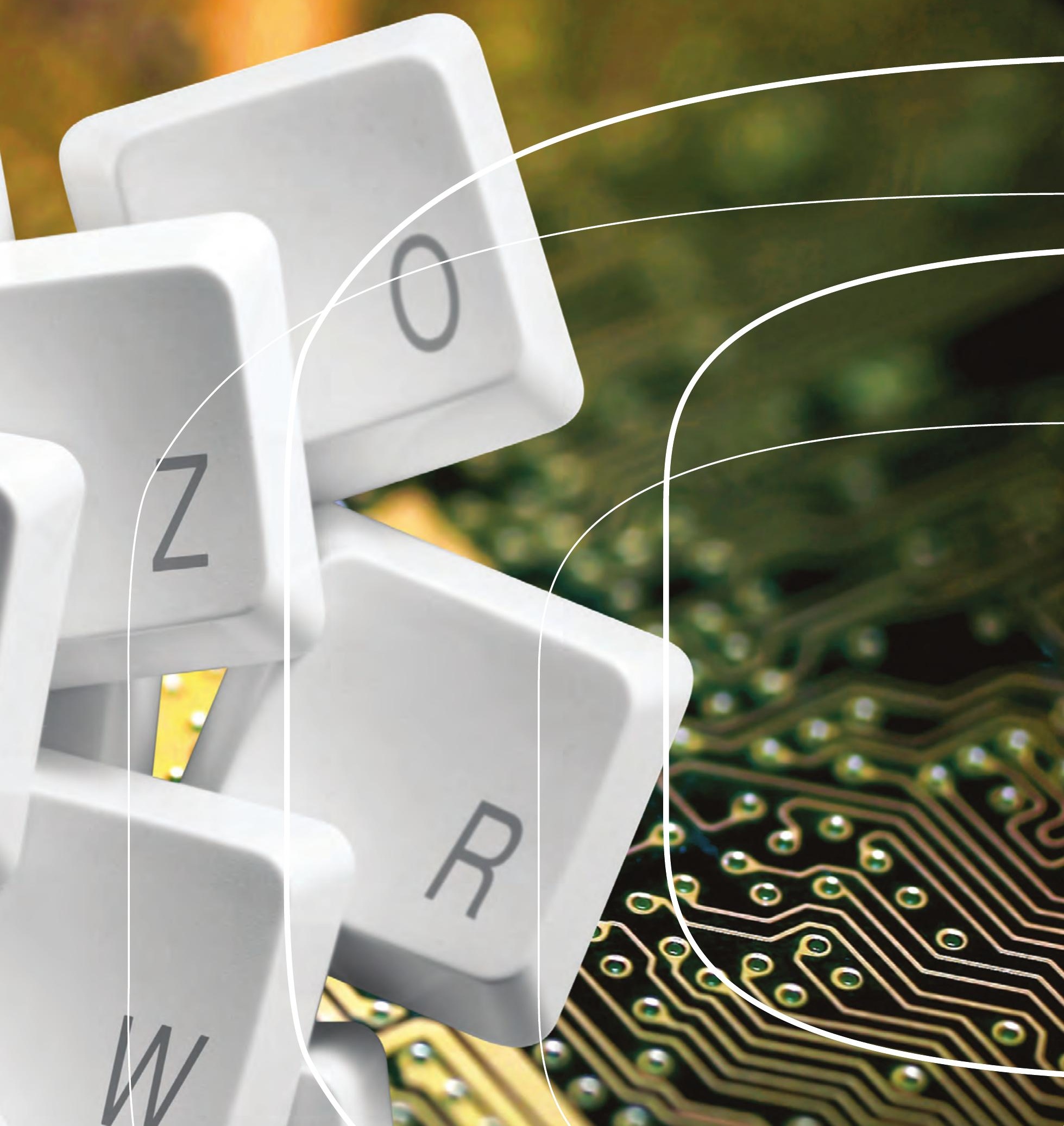


enorden 



\section{Information on Chemicals in Electronic Products}

A study of needs, gaps, obstacles and solutions to provide and access information on chemicals in electronic products

Main Authors:

Nardono Nimpuno, ChemSec, Sweden and Caroline Scruggs, Stanford University, United States

Contributing Authors:

Magnus Bengtsson, Shiko Hayashi and Yoshiaki Totoki, IGES, Japan,

Maren Urban Swart, DanWatch, Denmark

Research assistant:

Mia Tholin, ChemSec, Sweden

TemaNord 2011:524 
Information on Chemicals in Electronic Products

A study of needs, gaps, obstacles and solutions to provide and access information on chemicals in electronic products

TemaNord 2011:524

(C) Nordic Council of Ministers, Copenhagen 2011

ISBN 978-92-893-2218-8

This publication has been published with financial support by the Nordic Council of Ministers. But the contents of this publication do not necessarily reflect the views, policies or recommendations of the Nordic Council of Ministers.

Nordic Council of Ministers

Ved Stranden 18

DK-1061 København K

Phone (+45) 33960200

Fax (+45) 33960202

www.norden.org

\section{Nordic Council}

Ved Stranden 18

DK-1061 København K

Phone (+45) 33960400

Fax (+45) 33111870
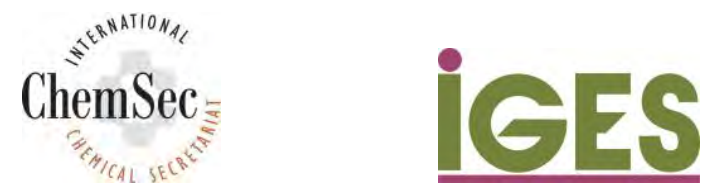

\section{Nordic co-operation}

Nordic co-operation is one of the world's most extensive forms of regional collaboration, involving Denmark, Finland, Iceland, Norway, Sweden, and three autonomous areas: the Faroe Islands, Greenland, and Åland.

Nordic co-operation has firm traditions in politics, the economy, and culture. It plays an important role in European and international collaboration, and aims at creating a strong Nordic community in a strong Europe.

Nordic co-operation seeks to safeguard Nordic and regional interests and principles in the global community. Common Nordic values help the region solidify its position as one of the world's most innovative and competitive. 


\section{Content}

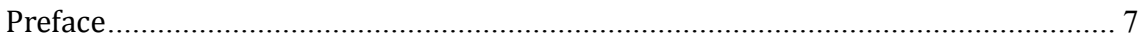

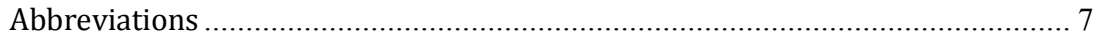

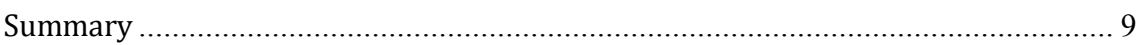

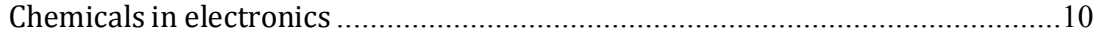

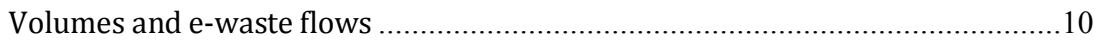

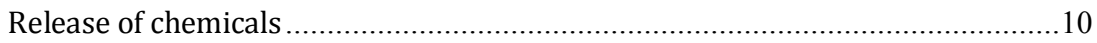

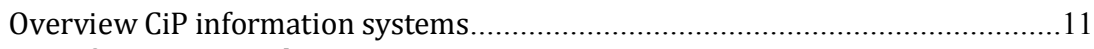

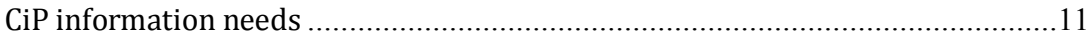

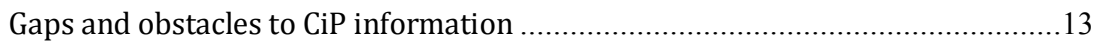

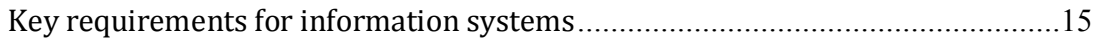

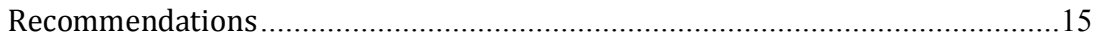

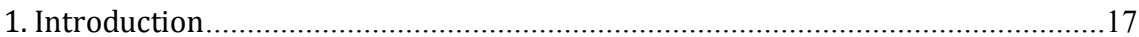

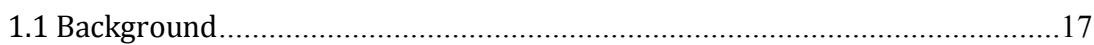

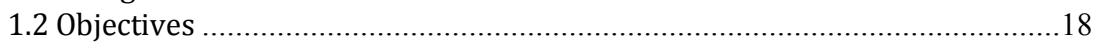

1.3 Previous work

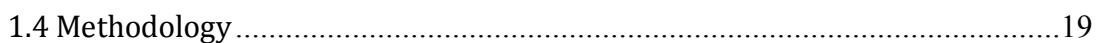

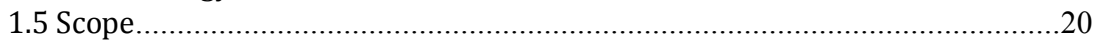

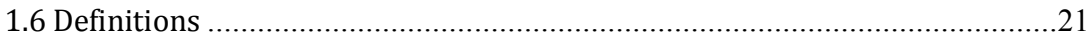

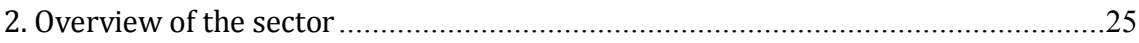

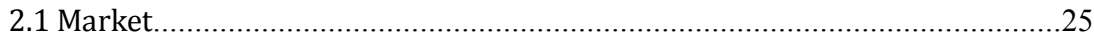

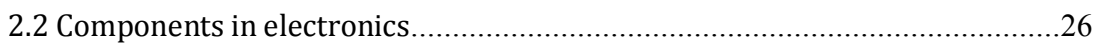

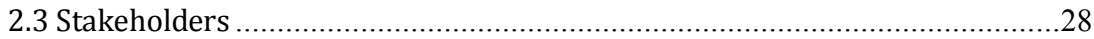

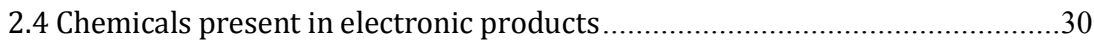

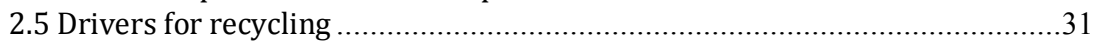

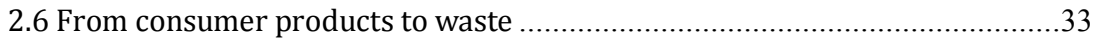

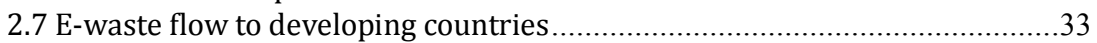

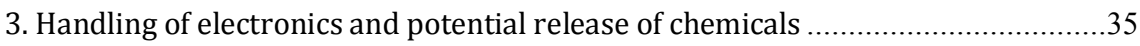

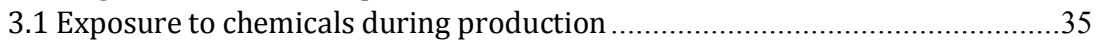

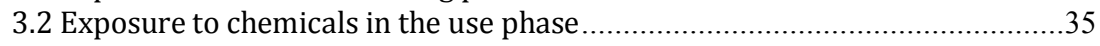

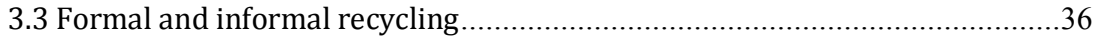

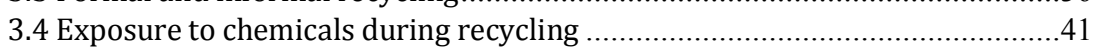

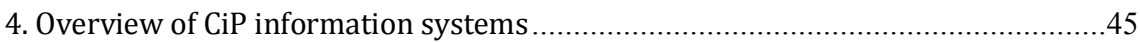

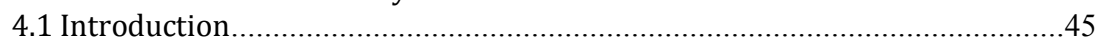

4.2 International industry systems for sharing information ..............................45

4.3 National/Regional regulation and initiatives...............................................46

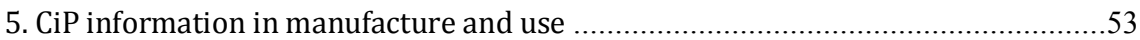

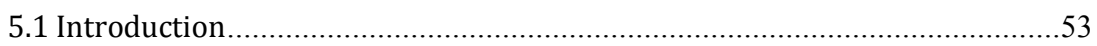

5.2 Needs and access to CiP Information in the product chain ...........................54

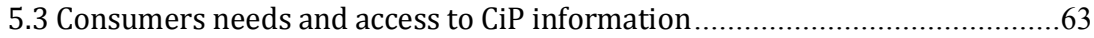

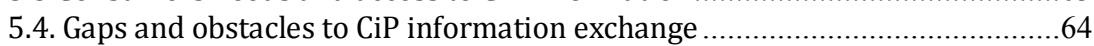

5.5 Potential means of addressing gaps and obstacles ..................................... 70

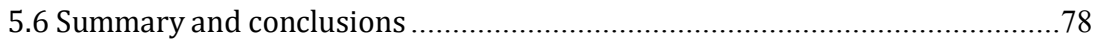

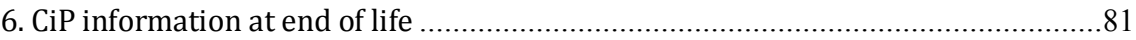

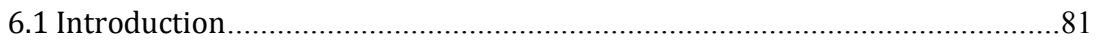

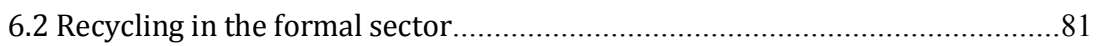

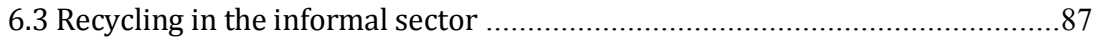




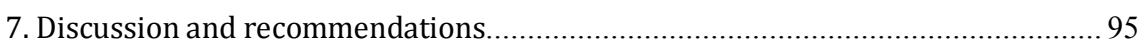

7.1 Needs for improved flow of CiP information............................................... 96

7.2 Gaps and obstacles in the flow of information on chemicals ........................ 97

7.3 Key requirements for information systems................................................ 100

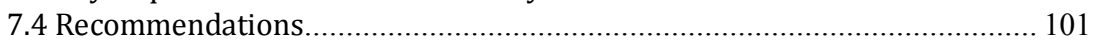

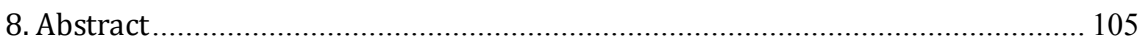

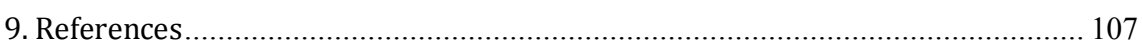

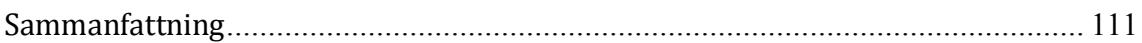

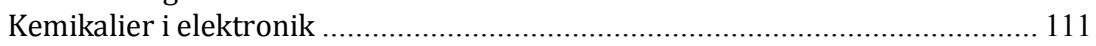

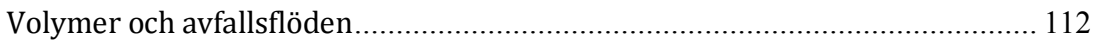

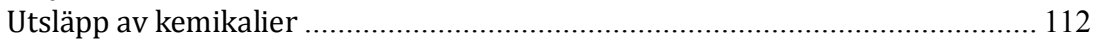

Översikt över informationssystem............................................................. 112

Behov av information om kemikalier i varor ................................................. 113

Hinder för flöde av CIP information.................................................................... 114

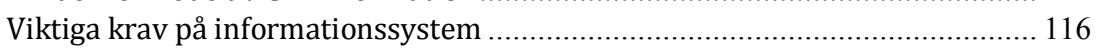

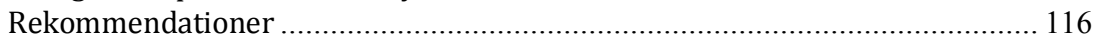

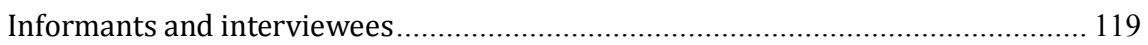




\section{Preface}

This report was commissioned by the United Nations Environment Program, UNEP, with funding from the Nordic Chemicals Group under the Nordic Council of Ministers. Responsibility for the content of this report rests with its authors.

In 2009, the second session of the International Conference on Chemicals Management, ICCM2, agreed to initiate a project on the emerging policy issue of Chemicals in Products to promote the implementation of Objective 15 (b) of the Strategic Approach to International Chemicals Management, SAICM. The Objective states that "information on chemicals throughout their life cycle, including, where appropriate, chemicals in products, is available, user friendly, adequate and appropriate to the needs of all stakeholders...". UNEP was invited to lead and facilitate the project. Recommendations for further cooperative actions will be developed and reported to the SAICM open-ended working group, OEWG, in 2011, and to the ICCM3 in 2012 for its consideration.

The present report on electronics is one of four case studies performed within the project on Chemicals in Products. The other case studies concern toys, textiles and building products.

\section{Abbreviations}

\begin{tabular}{ll}
\hline BFR & Brominated Flame Retardants \\
CBI & Confidential Business Information \\
CiP & Chemicals in Products \\
CM & Contact Manufacturer \\
EPR & Extended Producer Responsibility \\
GPS & Global Portal Strategy \\
LCD & Liquid Crystal Display \\
MSDS & Material Safety Data Sheets \\
NDA & Non Disclosure Agreement \\
ODM & Original Design Manufacturer \\
OEM & Original Equipment Manufacturer \\
PAH & Polycyclic Aromatic Hydrocarbon \\
PBDD & Polybrominated Dibenzodioxin \\
PBDE & Polybrominated Diphenylether \\
PBDF & Polybrominated Dibenzofuran \\
PVC & Polyvinyl Chloride \\
REACH & Registration, Evaluation, Authorisation and Restriction of CHemicals \\
RoHS & Restriction of Hazardous Substances \\
RSL & Restricted Substances List \\
SAICM & Strategic Approach to International Chemicals Management \\
SVHC & Substances of Very High Concern \\
WEEE & Waste Electrical and Electronic Equipment Directive \\
\hline
\end{tabular}





\section{Summary}

Many chemicals used in the electronics sector have negative consequences for human and environmental health. Typical electronic waste handling practices in developing countries are detrimental to the health of workers, their environment, and their communities. There are welldocumented problems associated also with formal recycling in modern facilities, and the production phase is often problematic as well. In addition, it is becoming apparent that recycling of valuable materials must be made more efficient as the price of virgin materials, metals, and minerals increases and their availability decreases. All of these problems are exacerbated by the fact that there has been a rapid increase in sales of electronics products in the past several years, making e-waste one of the fastest-growing waste streams today.

To address the problems associated with exposure to chemical substances, the Strategic Approach to International Chemicals Management, SAICM, was adopted at the first International Conference on Chemicals Management, ICCM1, in February 2006. The overall objective of this international framework is to achieve the sound management of chemicals throughout their life cycles so that, by 2020, chemicals are used and produced in ways that lead to the minimisation of significant adverse effects on human health and the environment.

In 2009, the second session of the International Conference on Chemicals Management, ICCM2, agreed to initiate a project on the emerging policy issue of Chemicals in Products to promote the implementation of Objective 15 (b) of the Strategic Approach to International Chemicals Management, SAICM. The Objective states that "information on chemicals throughout their life cycle, including, where appropriate, chemicals in products, is available, user friendly, adequate and appropriate to the needs of all stakeholders..." UNEP was invited to lead and facilitate the project.

The present report on electronics is one of four case studies performed within the project on Chemicals in Products. The other case studies concern toys, textiles and building products.

The aim of this report is to:

- describe the extent to which existing information systems meet the needs of different stakeholder groups for minimizing potential risks of chemicals in electronic products

- highlight information gaps, and

- identify obstacles and potential solutions to optimize flow of information. 
38 interviews with stakeholders surrounding the electronics sector were conducted. With regards to manufacturers engaged, a focus was put on mobile phones and personal computers, (PCs), as these are product segments at the forefront of technological development and innovation. Due to consumer demand for new products with the latest technology there is quick turnover of these products on the market. In addition, mobile phones and PCs are widely used in industrialized countries and prevalent in developing countries, are highly significant from a waste and recycling perspective.

\section{Chemicals in electronics}

Computers and mobile phones can contain over one thousand different substances. The main hazardous substances that could be found in electronic products are: lead, mercury, cadmium, zinc, yttrium, chromium, beryllium, nickel, brominated flame retardants, antimony trioxide, halogenated flame retardants, tin, polyvinyl chloride (PVC) and phthalates. In addition, electronic products contain valuable metals such as gold and copper that are valuable for recyclers to extract. Plastics recycling is also steadily increasing.

\section{Volumes and e-waste flows}

UNEP has estimated that consumers globally bought almost 900 million mobile phones in 2006 and over a billion in 2007. A considerable share of these products end up in household waste-streams, or are wastehandled through environmentally unsound practices. Up to 75 percent of the e-waste generated in Europe and around 80 percent of the ewaste generated in the United States goes unaccounted for. A vast amount of this e-waste is being exported to developing countries.

Typical electronic waste handling practices in developing countries are detrimental to the health of workers, their environment and their communities. The lower cost of waste handling in developing countries is a powerful incentive for this export. It is estimated that the wastehandling/recycling costs for PCs and mobile phones are ten times higher in the US or the EU than in e.g. India or Nigeria.

\section{Release of chemicals}

Data is continuously emerging on negative consequences for human health and the environment of hazardous chemicals throughout the life cycle of electronics products. Studies have demonstrated that electronics 
workers are highly exposed to carcinogens and reproductive toxicants during manufacture. Substances include solvents, heavy metals and epoxy resins. Other studies have demonstrated potential release of e.g. polybrominated dibenzofurans (PBDFs) in the use-phase of electronics. PBDFs are breakdown products of polybrominated diphenyl ethers (PBDEs), commonly used as a flame retardant in electronics.

Studies on release pathways and exposure to workers in recycling facilities in developed countries have also documented the release of hazardous chemicals from e-waste.

The rudimentary informal sector recycling techniques common in developing countries, coupled with the amounts of e-waste processed, have already resulted in adverse environmental and human health impacts in developing countries including China, India, Nigeria, the Philippines and Ghana.

\section{Overview CiP information systems}

Over the last few years a number of policy initiatives on chemicals in products and end-of-life treatment of electronics have been developed. Most notable are the policy developments in the European Union where the RoHS and WEEE directives and the REACH regulation have had a strong impact on the way electronic products are designed, how they are collected and treated at end-of-life, and how information on hazardous substances is generated and shared. Other regions and countries such as the USA, South Korea, China and Japan have since followed suit.

Industry-wide initiatives have been set up which are international in their scope. These include the Joint Industry Guide (JIG), the IEC material declaration standards and the GPS chemicals portal.

\section{CiP information needs}

The companies participating in this study try to stay ahead of global regulations and voluntarily restrict chemicals that they think may be regulated in the future. One of the most common and important uses of $\mathrm{CiP}$ information systems cited by interviewees was to keep up to date on the latest information on chemical hazards and risks. The interviewees each described a different set of CiP information systems that they find valuable in trying to advance product safety. Based on the CiP information systems they find valuable, each company creates its own restricted substance list to keep undesirable chemicals and materials out of its products. In addition, a few companies require full materials disclosure from their suppliers.

Many of the interviewed companies tend to interact primarily with the adjacent actor in the supply chain. The brand owners were the most 
likely to be involved in multiple stages of product development and disposal across the supply chain. Upstream actors described how they provided their customers with relevant information about their products, but actors farther downstream felt that essential data was unavailable, indicating that information is lost in the supply chain.

In order to minimize any potential risks to human or environmental health, electronics stakeholders in different stages of the life cycle of products need information on what chemicals are present in products, their properties, use and potential risks.

Companies expressed a need for increased flow and transparency to help reduce their costs when planning, designing and carrying out production. There is a need to be able foresee any potential future business risks as well as opportunities. This can include upcoming regulation on chemicals used in production, future preferences, demands and expectations of customers and consumers, future challenges in performance of their products, in the manufacture of their products, the availability of materials and components for their products and any present or future liability for the fate of these products. Protection of the workforce is also largely dependent on an understanding of the chemicals present in production. All this is dependent on the availability of adequate CiP information.

Agreement on what chemicals should be reported, and what information should be made available, would in many cases help companies obtain the needed and relevant chemicals-related information.

Authorities such as customs officials need access to relevant information in their efforts to control the flow of discarded electronics. In addition, in order to develop appropriate policies and measures, authorities need information about the chemicals used in products on the market.

Recyclers extracting valuable material from e-waste need to know where hazardous chemicals can be found in the products they receive, as well as information on the content of valuable material. At end-of-life, improved information can contribute to increased and more environmentally-sound recycling, with more efficient extraction of valuable metals.

It should be noted that in general, recyclers are not aware of the environmental risks of their activity. This results in reduced demand for information. Recyclers seem to think that there is no particular risk to the environment or human health in the recycling process as long as they adhere to general regulations. Accordingly, there is a need for awareness-raising on the chemicals present in products, associated hazards and risks, and the role recyclers might have in contributing to or addressing problems related to chemicals in products.

The low awareness of risks especially applies to e-waste handlers in developing countries and information on associated hazards and risks are seen as important. In addition, intervention and economic support is required to provide feasible alternatives to inappropriate waste handling practices in the informal sector. 
Consumers in general assume that the products they purchase and use are safe for them as well as for the environment. Therefore, consumers in general might not feel an urgent need for CiP information. Provision of information about hazards and risks from chemicals in products would provide consumers with the opportunity to make informed choices about the products they buy.

Awareness about the presence of hazardous chemicals in products would also give designers, companies in the supply chain and public purchasers the ability to make informed choices about the products they purchase, which could potentially be advantageous to products with better environmental profile.

In addition, upstream actors have expressed a strong need for information about where their products end up and how they are handled. Accordingly, improved information flow upstream the product life cycles on how products are used and handled at all stages would help designers and formulators make informed decisions when designing, developing and improving products. With better information on exposure, the development of products with improved environmental performance is promoted, which contributes to less toxic material to handle in recycling and decreased release of toxics into the environment.

\section{Gaps and obstacles to CiP information}

There are overarching, industry-wide systems developed to facilitate exchange of information. The companies interviewed in this study take part in such joint collaborations. There are also regional and national rules and policies that regulate the flow of information on chemicals in electronics. However, as many companies feel that these systems are not sufficient to meet their particular information needs, they often develop their own approach, complementing the joint industry systems and regulatory frameworks with internal systems for substance restrictions, information exchange, supply chain management etc.

A number of gaps and obstacles in the flow of information on chemicals have been described in this report.

- The gap between upstream manufacturers of chemicals and the information needs further downstream. Upstream manufacturers of chemicals and material pass on the information they consider relevant, but they seem to have limited knowledge on applications and downstream exposure pathways. Thus downstream manufacturers often feel that there is a gap at the beginning of the product chain, where the information made available and fed into the system is not the relevant or sufficient information.

- The gap along the supply chain to the final brand owners. Upstream actors described how they provided their customers with relevant 
information about their products, but actors farther downstream felt that needed data was unavailable, indicating that communication of data or information needs may be obstructed through the supply chain. It is likely that a deal of information is lost in the numerous steps in the product chain between the chemicals industry and OEMs/brandowners.

- The gap between the production-phase and the recycling phase. From the perspective of manufacturers, the general perception is that feedback is not communicated from recyclers on the needs they might have, and information requests from recyclers are very rare. Recyclers on the other hand express that producers often seem to have limited knowledge of recycling and that end-of-life considerations are not incorporated in the product design and material composition of electronics.

- The gap between the formal product chain and informal wastehandlers in developing countries. Information systems are in general not designed to take into account conditions in developing countries. For example, information to workers engaged in informal recycling in developing countries must take into account factors such as low level of literacy, lack formal education or organisation.

- The gap between information provided for intended use and the information needs arising from unintended use. In general, information is provided considering the intended use of products. However, considering the large volumes of e-waste being handled in substandard conditions, what type of $\mathrm{CiP}$ information that is fed in to the system upstream should also take into account information needs that arise from unintended, but highly probable, handling.

- The gap between what information is needed (relevant) and available. Stakeholders have been emphasizing that the information provided should only be the relevant information. However, due to the gaps in information flow, information that is relevant to a particular actor in the life cycle might not be available at that point in the life cycle. A challenge is how to ensure that relevant information is available where needed at every step of the life cycle.

- One of the obstacles to CiP information discussed by interviewees was lack of agreement about what constitutes proprietary information. Many stakeholders said claims that information is proprietary block their ability to determine product contents or chemical uses. They also suspect frequent misuse of the claims. Claiming that information is proprietary also impedes upstream communication of information. While understanding the necessity for businesses to protect sensitive information, interviewees have discussed examples of how to nonetheless deal with sensitive information in a manner that meets the needs of providers as well as recipients of information. A sincere and open discussion is needed among stakeholders about what really is and is not proprietary. 
Recipients need to be able to show suppliers that data can be protected. Ways must also be found to provide the information needed by different actors to conduct proper risk management in their particular stage of the life cycle.

\section{Key requirements for information systems}

A set of key characteristics of well-functioning information systems for chemicals in products were pointed out by interviewees contributing to this study:

- Information must flow down the product chain, but also travel up the product chain;

- Relevant information must be available when the particular need for that particular type of information arises;

- The information generated and provided must take into account not only the intended use or handling of a product, but also the likely or probable fate of that product;

- The information provided must be comprehensible, accessible and appropriate for the particular stakeholder who needs the information for safe handling of the product in the particular stage of the life cycle of that stakeholder.

\section{Recommendations}

Interviewees discussed the usefulness of a harmonized global standard as well as platforms for sharing CiP information. The common theme among interviewees was that there are too many information systems and too many lists available, making it difficult to keep up with all of the information and make decisions about which chemicals are actually of real concern in products.

Companies throughout the product chains have described a need for a common list of chemicals of concern to be agreed upon which would simplify design and operation and reduce costs throughout the industry. Such a list should include what chemicals to provide information on as well the content of such information. In order to provide any added value, the list should go beyond merely listing already banned or otherwise regulated chemicals, but also take into account broader needs for CiP information among companies and other stakeholders such as regulatory authorities.

Introducing an obligation to provide information on the product and its effects at all stages of its life cycle, including relevant information on chemicals, is another solution discussed. One example is legislation on 
Extended Producer Responsibility, which would include informative responsibility.

Furthermore, certification systems for recycling are proposed as constructive tools for tracking materials, increasing transparency in the waste phase and increasing awareness about chemicals in e-waste management.

Other solutions proposed are improving the tools required for facilitating the transfer of information on chemicals in products. These include the further development of standard formats for collecting and communicating chemicals-related data, software packages to support such standards, and escort information systems to allow product content to be tracked through the product chain.

In addition, other solutions are discussed concerning joint avoidance lists for the sector, standards and labels for eco-design, information campaigns aimed at consumers, information campaigns for stakeholders in developing countries, and measures to promote safe and profitable ewaste handling in developing countries. Although some of these solutions seemingly go beyond CiP information systems and information flow, the availability of CiP information is a precondition for developing such solutions that reduce risks from electronics throughout the entire life cycle. 


\section{Introduction}

\subsection{Background}

At a global scale evidence is mounting that many chemicals used in the electronics sector have negative consequences for human and environmental health. Typical electronic waste handling practices in developing countries are detrimental to the health of workers, their environment, and their communities. There are well-documented problems associated also with formal recycling in modern facilities, and the production phase is often problematic as well. In addition, it is becoming apparent that recycling of valuable materials must be made more efficient as the prices of virgin materials, metals, and minerals increase and their availability decreases. All of these problems are exacerbated by the fact that there has been a rapid increase in sales of electronics products in the past several years, making e-waste one of the fastest growing waste stream today.

To address the problems associated with exposure to chemical substances, the Strategic Approach to International Chemicals Management, SAICM, was adopted at the first International Conference on Chemicals Management, ICCM1, in February 2006. The overall objective of this international framework is to "achieve the sound management of chemicals throughout their life cycles so that, by 2020, chemicals are used and produced in ways that lead to the minimization of significant adverse effects on human health and the environment."1

The second International Conference on Chemicals Management, ICCM2, was held in May 2009. It was agreed to initiate a project on Chemicals in Products, CiP, to promote the implementation of Objective 15 (b) of the SAICM Overarching Policy Strategy. This objective states that information on chemicals throughout their life cycle, including, where appropriate, chemicals in products, should be available, accessible, user friendly, adequate and appropriate to the needs of all stakeholders. ${ }^{2}$

UNEP was invited to lead and facilitate the CiP project and to report on the project implementation and its outcomes to the SAICM OpenEnded Working Group in mid 2011 and to ICCM3 in mid 2012. Further, it was agreed that the project should:

1 UNEP 2006. Strategic Approach to International Chemicals Management -SAICM texts and resolutions of the International on Chemicals Management. p.14

2 UNEP 2006 p. 16 
- Collect and review existing information on information systems pertaining to chemicals in products including but not limited to regulations, standards and industry practices;

- Assess that information in relation to the needs of all relevant stakeholders and identify gaps;

- Develop specific recommendations for actions to promote implementation of the Strategic Approach with regard to such information, incorporating identified priorities and access and delivery mechanisms.

A needs survey among SAICM stakeholders was conducted to identify priority product sectors. At a scoping meeting held in December 2009, toys, building products, textiles and electronics were identified as priority sectors. For each sector a case study was to be carried out.

This report is the outcome of the case study on electronic products. The electronics sector was considered important primarily due to the problems associated with electronic waste in developing countries and the rapid increase in use of electronic products. In the needs survey, stakeholders in the African region considered computers, mobile phones and other electronic goods to be an absolute top priority sector.

\subsection{Objectives}

The objectives of this case study are, in accordance with the aim of the CiP project, to identify to what extent existing information systems meet the information needs of different stakeholder groups for managing and/or minimizing potential risks of chemicals in electronic products, to highlight the information gaps, and to identify obstacles and potential solutions to optimize flow of information.

The objectives apply to all types of stakeholders, directly or indirectly connected to the various life cycle stages of electronic products. A key focus is on developing country issues, where environmental and health problems associated with electronic products to a large degree arise at the end of life stage of the products.

The project period is September 2010 - February 2011.

\subsection{Previous work}

Within the CiP project, several reports have already been produced. These previous reports constitute a basis for this case study, when looking deeper into the use of, needs for, and obstacles to information systems in the electronic sector.

In particular, the following CiP reports have laid the groundwork for this case study: 
Toxic Substances in Articles: The Need for Information by Massey et al. describe the problems of the lack of information on chemicals in articles, and explore the benefits of, and challenges with the development of an internationally standardized information system for the chemical contents of products. They emphasise that, when designing such a system, it would be necessary to make decisions about its scope. Some key issues to determine would be the needs of the various target audiences, which chemicals, products and information to include and in what format information should be provided. ${ }^{3}$

Becker's Survey of SAICM Focal Points on the Need for Information on Chemicals in Products presents the results of a survey about CiP information that was conducted among SAICM focal points and other experts in October 2009. The aim of the survey was to collect information on existing information systems, needs for information and views about what product groups to prioritize in the CiP project. The survey had global reach and gathered 43 responses. The results demonstrate a strong unfilled need for information on chemicals in products. ${ }^{4}$

In Chemicals in Products - An overview of existing systems for providing information regarding chemicals in products and of stakeholders' needs for such information, Kogg and Thidell use Becker's report as an important source in providing an overview of existing CiP information systems and stakeholder needs. They conclude that the information needs of stakeholders are very diverse, and stress the difficulties of reconciling the need for a harmonized and user-friendly CiP information system with the need to adapt information to different stakeholders' needs. $^{5}$

\subsection{Methodology}

38 interviews were conducted with stakeholders in the value chain of electronic products. Included were representatives from the product chain (i.e. chemical producers, components manufacturers and brand owners) as well as consultants, NGOs, consumer groups, recyclers and electronics waste handlers. Interviews performed with stakeholders in the product chain were focused on mobile phones and personal computers (PCs) specifically. (See list of informants.)

The Institute for Global Environmental Studies (IGES) has been conducting extensive research in Japan on the environmental impacts of electronics during production and waste management phases. In carrying out this work, IGES has studied the waste management and recycling

\footnotetext{
${ }^{3}$ Massey et al. 2008, p. 14

4 Becker 2009

5 Kogg \& Thidell 2010
} 
industry, most notably in Japan, but also to some extent in Korea, China, the United States and the European Union.

IGES has been instrumental in this report by providing a large share on the background information on information systems for chemicals in the life cycle of electronics.

In addition, a bulk of the information in the section on formal recycling is based on IGES' research with a particular focus on the situation in Japan. The empirical research on the waste management practices in Japan consists of document analysis and face-to-face interviews with 14 representatives of the recycling industry, electronics manufacturers and industry associations. ${ }^{6}$

The research laying the basis for the section on informal e-waste management consists of document analysis and in-depth interviews with stakeholders engaged in the e-waste issue in Nigeria, Ghana, Thailand and the Philippines. A bulk of these interviews were carried out by DanWatch. In addition, input has been provided by Public Interest Organisation members of the International POPs Elimination Network (IPEN). Stakeholders in India and Latin America were contacted for the study, but due to the time-constraints of this project it was not possible for them to contribute via interview.

Other sources of information used in developing this case study were the previous CiP reports described in chapter 1.3.

\subsection{Scope}

The scope of the study is limited to electronic products, specifically to mobile phones and PCs, and to information related to chemicals that are used in such products. The various chemicals that are mentioned herein are those identified by the stakeholders. Different chemicals are important to different stakeholders, so, for example, the same chemicals of primary concern to components manufacturers may not be those of primary concern to recyclers.

By selecting companies in the supply chain of mobile phones and PCs as interviewees, a certain focus is intentionally put on these product groups. Information from other stakeholders in the value chain, though, pertains to electronic products more generally. The reason that some stakeholders provide more general information is because information about specific product groups does not usually exist, especially at the end-of-life phase.

The PC and mobile phone product segments are at the forefront of technological development and innovation. These products have been selected as significant for this case study because of their quick turnover

6 IGES 2009; IGES 2010 
on the market due to consumer demand for new products with the latest technology. In addition, mobile phones and PCs are widely used in industrialized countries and prevalent in developing countries, and they are highly significant from a waste and recycling perspective.

In parallel with identifying Chemicals in Products as a priority area, a so-called emerging policy issue, ICCM2 also identified three other emerging issues. These are Lead in Paint, Hazardous Substances within the Life Cycle of Electrical and Electronic Products and Nanotechnologies and Manufactured Nanomaterials.

Of particular relevance for this CiP electronics project is the SAICM project on Hazardous Substances within the Life Cycle of Electrical and Electronic Products. As these two projects partially overlap, the authors of this report would like to express the ambition to coordinate them. Accordingly, key stakeholders to the project on Hazardous Substances within the Life Cycle of Electrical and Electronic Products have been contacted to ensure coordination between the two projects.

\subsection{Definitions}

For consistency in the SAICM CiP reports, the definitions of terms used in this report follows definitions made in previous CiP-reports to the greatest possible extent. A major part of the following definitions are directly, or with some modifications, from the Kogg and Thidell report.

\subsubsection{Confidential Business Information (CBI) / Proprietary Information}

CBI and proprietary information is information that companies wish to keep confidential. Typically, companies declare certain information CBI if they believe it will harm their business if it is disclosed.

The United States Environmental Protection Agency, EPA, defines CBI as:

\footnotetext{
"Any information that pertains to the interests of a business, developed or acquired by that business, [...] which contains trade secrets or commercial or financial information that is privileged or confidential"7
}

According to Objective 15 (c) of the SAICM Overarching Policy Strategy, information on chemicals relating to the health and safety of humans and the environment should not be regarded as confidential. ${ }^{8}$

7 US Environmental Protection Agency 2009. http://www.epa.gov/region4/ris_training/p7.htm 8 UNEP 2006. p. 17 


\subsubsection{Downstream/Upstream actors}

A number of stakeholders have in the input to this study used the terms downstream and upstream actor. Rather than being used with an absolute definition, such as Downstream User of Substances as defined by $\mathrm{REACH}$, the terms are used in a relative way. Downstream or upstream actors are those actors in the life cycle of a given product who are in a position farther down, (customers, clients, recyclers) or farther up (manufacturers, suppliers, materials producers) the product chain than relative to the actor in question.

It should be noted here that normally retailers or consumers are not included in the scope of these terms.

\subsubsection{Electronic products}

In this report, the term electronics/electronic products is used to cover both electrical and electronic equipment, often referred to as EEE. The European WEEE directive provides a helpful definition:

\footnotetext{
"electrical and electronic equipment" or "EEE" means equipment which is dependent on electric currents or electromagnetic fields in order to work properly and equipment for the generation, transfer and measurement of such currents and fields [...] and designed for use with a voltage rating not exceeding $1000 \mathrm{~V}$ for alternating current and $1500 \mathrm{~V}$ for direct current."
}

In their contribution to this report different stakeholders have been using different terms such as electronics devices, electric home appliances, electronics etc. Sometimes, these terms are used interchangeably. In other cases, a more specific term is used, to cover a limited range of products, e.g. electric home appliances, or a specific type of product, such as PCs.

\subsubsection{E-waste}

Similarly, the term $e$-waste is used in this report to cover waste from the range of electronics and electrical products, usually described as WEEE, i.e. Waste Electrical and Electronics Equipment.

\subsubsection{Information needs}

Information needs is defined as relevant information that the stakeholders require in order to minimise risks to human health and the environment posed by chemicals. It is important to emphasise that stakeholders

${ }^{9}$ Directive 2002/96/EC of the European Parliament and of the Council of 27 January 2003 on waste electrical and electronic equipment, WEEE, Article 3 
might not always know what information they need to minimise these risks. Nevertheless, such information is also considered to be an information need.

\subsubsection{Product chain}

The product chain consists of the actors involved at each step of the product life cycle.

\subsubsection{Product life cycle}

The product life cycle encompasses all stages of a product's development, including research and design, extraction of (raw-) materials, production, marketing, use, disposal and recycling.

\subsubsection{Stakeholder}

The term stakeholder, as used in this report, is anyone who has, or could have, an interest in knowing about chemicals in products. This includes, but is not limited to:

- Individuals in their capacities as consumers, parents, employees and citizens

- Private enterprises across all sectors

- Non-governmental organisations with an interest in consumer safety, labour rights and protection, environment, health, development and trade

- Governmental agencies, including agencies working with issues related to chemicals, environmental protection, consumer protection, health, trade and customs.

- Public sector organisations, including health and emergency response services

These stakeholders can be divided into two broad groups: actors engaged in the product along its life cycle (e.g. producers, distributors, users, recyclers and waste handlers), and stakeholders outside the product chain (e.g. government and NGOs). ${ }^{10}$

\subsubsection{Supply chain}

The supply chain is the series of suppliers, usually upstream, that produce individual components which are combined to produce incremen-

10 Kogg \& Thidell 2010. p. 44 
tal products, such as the different components of an electronics device, which are eventually combined into a final product.

\subsubsection{CiP information systems}

CiP information systems refers to any type of systematic information transfer that is formalized, recurring and provides information regarding:

- any or all chemicals in products/articles, potentially together with a tool or guidelines for the interpretation of the information.

- health and/or environmental performance of a product/article based at least in part on chemical content (in contrast to, for example, energy use or resource depletion);

- chemicals which are excluded from products/articles (as with ecolabels and restricted substances lists).

Other kinds of information can also be of great relevance, such as in what country a product is produced and how to handle a product at different stages of its life cycle (e.g. use and end of life phases). This does not provide any information about chemical content but can still be very important for minimising chemicals-related risks.

\subsubsection{Value chain}

The value chain describes the full range of activities that companies and workers engage in in the value creation process that brings a product from its conception to its end use and beyond. This includes activities such as design, production, marketing, distribution and support to the final consumer. As consumers engage as active stakeholders in the economy (e.g. through NGOs or consumption choices) they become an integral part of the value creation process and can thus be part of the value chain. 


\section{Overview of the sector}

\subsection{Market}

Worldwide PC shipments were estimated to total 84.3 million units in the first quarter of 2010, a 27.4 percent increase from the first quarter of 2009. Table 2.1 shows how the shipments are divided between the largest PC companies. (Please note that the figures in table 2.1 and 2.2 only provide quarter one numbers for each particular year.)

Table 2.1 Preliminary Worldwide PC Vendor Unit Shipment Estimates for 1Q10 (Thousands of Units)

\begin{tabular}{lrrrrr}
\hline Company & $\begin{array}{r}\text { 1Q10 } \\
\text { Shipments }\end{array}$ & $\begin{array}{r}\text { 1Q10 Market } \\
\text { Share (\%) }\end{array}$ & $\begin{array}{r}\text { 1Q09 } \\
\text { Shipments }\end{array}$ & $\begin{array}{r}\text { 1Q09 Market } \\
\text { Share (\%) }\end{array}$ & $\begin{array}{r}\text { 1Q09-1Q10 } \\
\text { Growth (\%) }\end{array}$ \\
\hline HP & 15,319 & 18.2 & 12,773 & 19.3 & 19.9 \\
Acer & 12,003 & 14.2 & 7,779 & 11.7 & 54.3 \\
Dell & 10,209 & 12.1 & 8,406 & 12.7 & 21.4 \\
Lenovo & 6,977 & 8.3 & 4,384 & 6.6 & 59.2 \\
ASUS & 4,647 & 5.5 & 2,164 & 3.3 & 114.8 \\
Toshiba & 4,623 & 5.5 & 3,404 & 5.1 & 35.8 \\
Others & 30,565 & 36.2 & 27,309 & 41.2 & 11.9 \\
Total & 84,344 & 100.0 & 66,220 & 100.0 & $\mathbf{2 7 . 4}$ \\
\hline
\end{tabular}

Source: Gartner, April 2010. http://www.gartner.com/it/page.jsp?id=1353330

Worldwide mobile phone sales to end users totalled 314.7 million units in the first quarter of 2010, a 17 per cent increase from the same period in 2009. Table 2.2 shows how the shipments are divided between the largest PC companies.

\begin{tabular}{|c|c|c|c|c|c|}
\hline Company & $\begin{array}{l}\text { 1Q10 } \\
\text { Units }\end{array}$ & $\begin{array}{r}1 Q 10 \text { Market } \\
\text { Share (\%) }\end{array}$ & $\begin{array}{l}1 Q 09 \\
\text { Units }\end{array}$ & $\begin{array}{r}1 Q 09 \text { Market } \\
\text { Share (\%) }\end{array}$ & Company \\
\hline Nokia & $110,105.6$ & 35.0 & $97,398.2$ & 36.2 & Nokia \\
\hline Samsung & $64,897.1$ & 20.6 & $51,385.4$ & 19.1 & Samsung \\
\hline LG & $27,190.1$ & 8.6 & $26,546.9$ & 9.9 & LG \\
\hline RIM & $10,552.5$ & 3.4 & $7,233.5$ & 2.7 & RIM \\
\hline Sony Ericsson & $9,865.6$ & 3.1 & $14,470.3$ & 5.4 & Sony Ericsson \\
\hline Motorola & $9,574.5$ & 3.0 & $16,587.3$ & 6.2 & Motorola \\
\hline Apple & $8,359.7$ & 2.7 & $3,938.8$ & 1.5 & Apple \\
\hline ZTE & $5,375.4$ & 1.7 & $3,369.6$ & 1.3 & ZTE \\
\hline G-Five & $4,345.0$ & 1.4 & & & G-Five \\
\hline Huawei & $3,970.0$ & 1.3 & $3,217.9$ & 1.2 & Huawei \\
\hline Others & $60,418.1$ & 19.2 & $44,972.2$ & 16.5 & Others \\
\hline Total & $314,653.50$ & 100.0 & $269,120.10$ & 100.0 & Total \\
\hline
\end{tabular}

Source: Gartner, 2010. http://www.gartner.com/it/page.jsp?id=1372013 
In $2007,52 \%$ of all mobile phones were produced in Mainland China.

There are 796 million mobile phone users in China ${ }^{11}$, which is about 60 percent of the population. Table 2.3 shows the market share per region for mobile phones sold during the fourth quarter of $2007^{12}$.

Table 2.3 Market share per region for mobile phones sold during the fourth quarter of 2007

$\begin{array}{lc}\text { Asia/Pacific } & 34 \% \\ \text { Eastern Europe/Middle East/Africa } & 19 \% \\ \text { Western Europe } & 17 \% \\ \text { North America } & 15 \% \\ \text { Latin America } & 12 \%\end{array}$

Source: Chan et al. 2008

\subsection{Components in electronics}

Electronic devices are manufactured, used, and waste-managed according to a life cycle, which can be described as in the figure below.

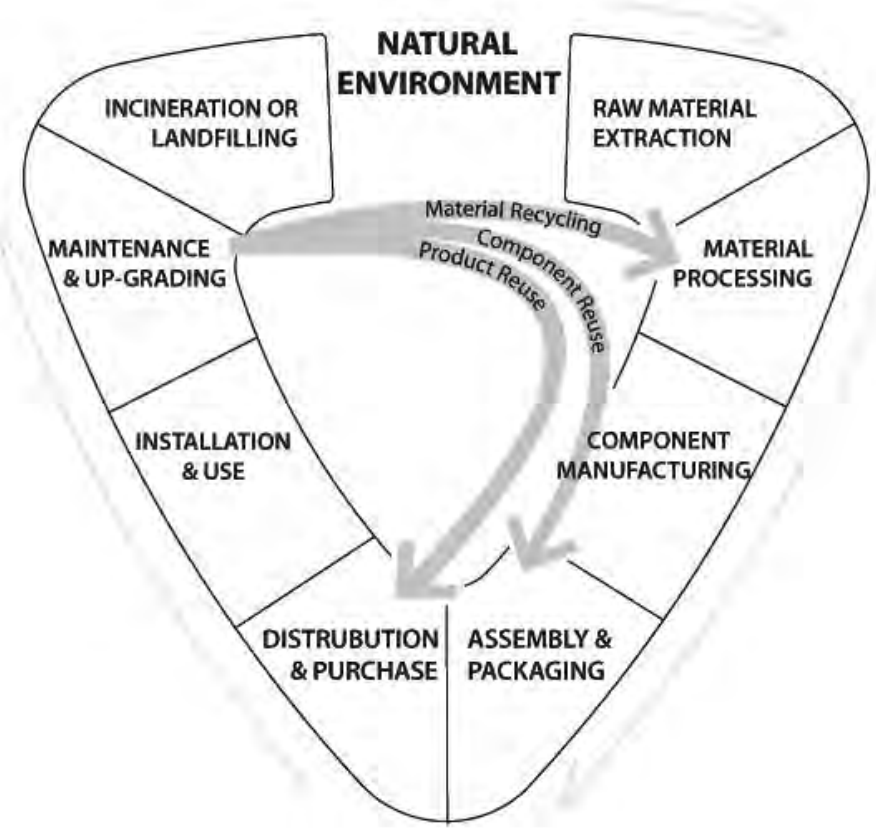

Figure 2.1 Product life cycle

Electronics products consist of components, from a few to several thousand, each of which has its own life cycle. Mobile phones can be said to consist of nine basic parts:

11 China Daily, 2010. http://www2.chinadaily.com.cn/china/2010-06/29/content_10036635.htm

12 Chan, Jenny. Haan, Esther de. et al. 2008 p.16 
- Circuit board/printed wiring board

- Liquid crystal display, LCD

- Battery

- Plastic casing

- Antenna

- Keypad

- Microphone

- Speaker

- Accessories (such as adapters, headsets, carrying cases, and decorative face plates)

An electronic device such as a laptop computer is made up of over a thousand separate components. The parts can be classified as follows:

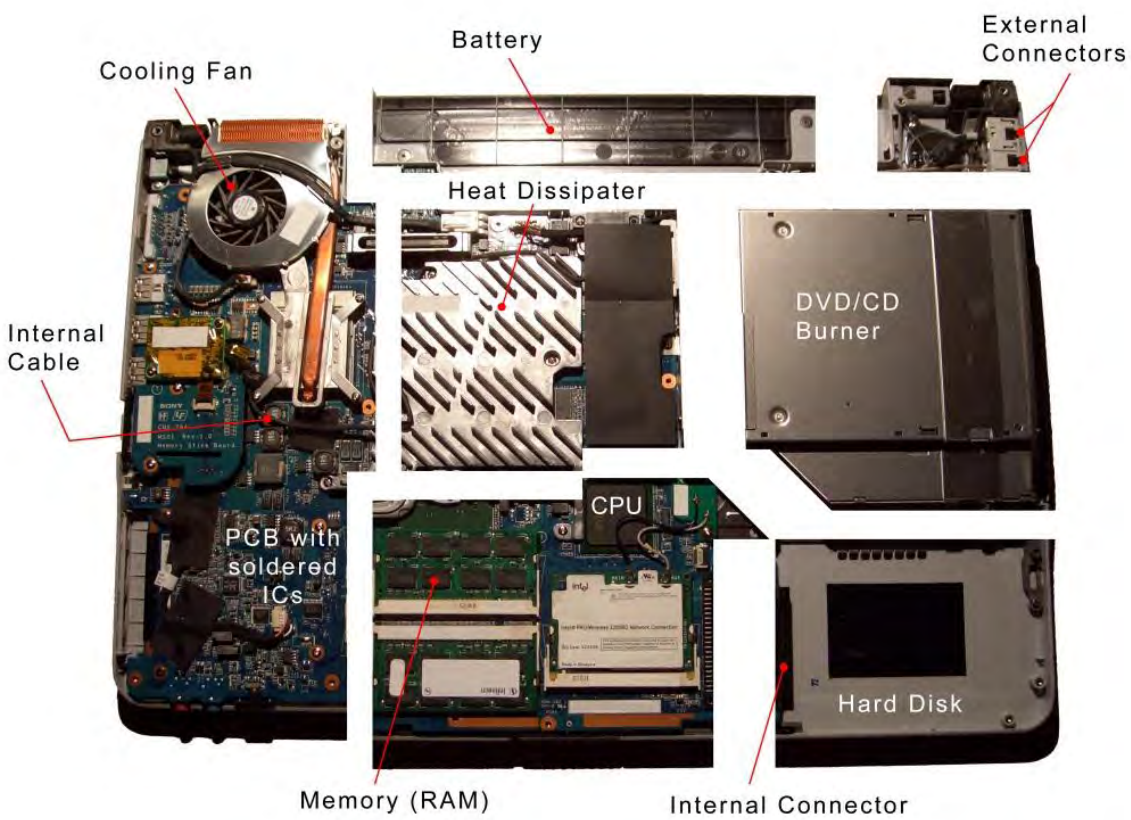

Figure 2.2. The inside of a generic laptop computer, artificially cut up in the main components/subparts

- Housing \& Input. The housing often is plastic, so are the input devices such as a keyboard or a mouse pad.

- Display Screen. Display screens are usually LCD screens. LCDs have displaced cathode ray tube (CRT) displays in most applications. In addition, OLED (organic light emitting diode) screens are becoming increasingly used. However CRTs are still common on the market, in second-hand markets and in e-waste.

- Semiconductor ICs. For example the CPU, memory and other specialized chips such as a wireless network chip. 
- Printed Circuit Board. These are rigid boards that all components are soldered on to. Printed Circuit Boards include motherboards and memory modules.

- Mass Storage. Often called a "hard disk drive", where most of the generated data such as the documents, images etc. and program files are stored.

- Optical Storage. Very similar to hard disk drives, with the addition of a laser based component which may use certain hazardous substance in the glass.

- Connectors. The connectors can be internal, such as the power supply to a hard disk drive, or external such as USB ports. Connectors need to be heat-resistant, able to withstand temperatures of up to $260^{\circ} \mathrm{C}$, in order to be soldered on to PCBs.

- Cabling (Internal and External). Internal cables connect components as shown in the example above. Cables are also used externally in the power cord.

Each of these components has its own life cycle, with different actors involved in the product chain.

\subsection{Stakeholders}

Whereas the product life cycle focuses on the different steps in the life of a product, the product chain concept focuses on the actors involved at each step of the product life cycle.

Supply chain is a term for the series of suppliers, usually upstream, that produce individual components that are combined to produce incremental products, such as the different components of an electronics device, which are eventually combined into a final product. Kogg and Thidell elaborate on the supply chain concept, demonstrating the complexity of the supply chain involving plethora of small and large companies that interact, horizontally up and down the supply chain, but even vertically among different suppliers, in supplying material, components and sub-components to each other, all feeding into the ultimate incremental development and manufacture of an end-product.13

Each actor in the supply chain of a product is a stakeholder in the development and manufacture of that particular product. The additional actors covered by the product chain, or the product life cycle ${ }^{14}$, are also stakeholders in the life cycle of any particular product. Each step of the product chain, such as eg Component Manufacturer, in turn consist of

\footnotetext{
${ }^{13}$ Kogg \& Thidell 2010. p. 46-49

14 Including stakeholders operating along or outside the product chain, such as waste handlers, consumers and governmental agencies.
} 
several sub-steps and actors, manufacturing sub-components and material, which feeds into the product chain.

A simplified manufacturing flow for a common electronic device including only Component Manufacturer and Product Manufacturer, may look like the following:

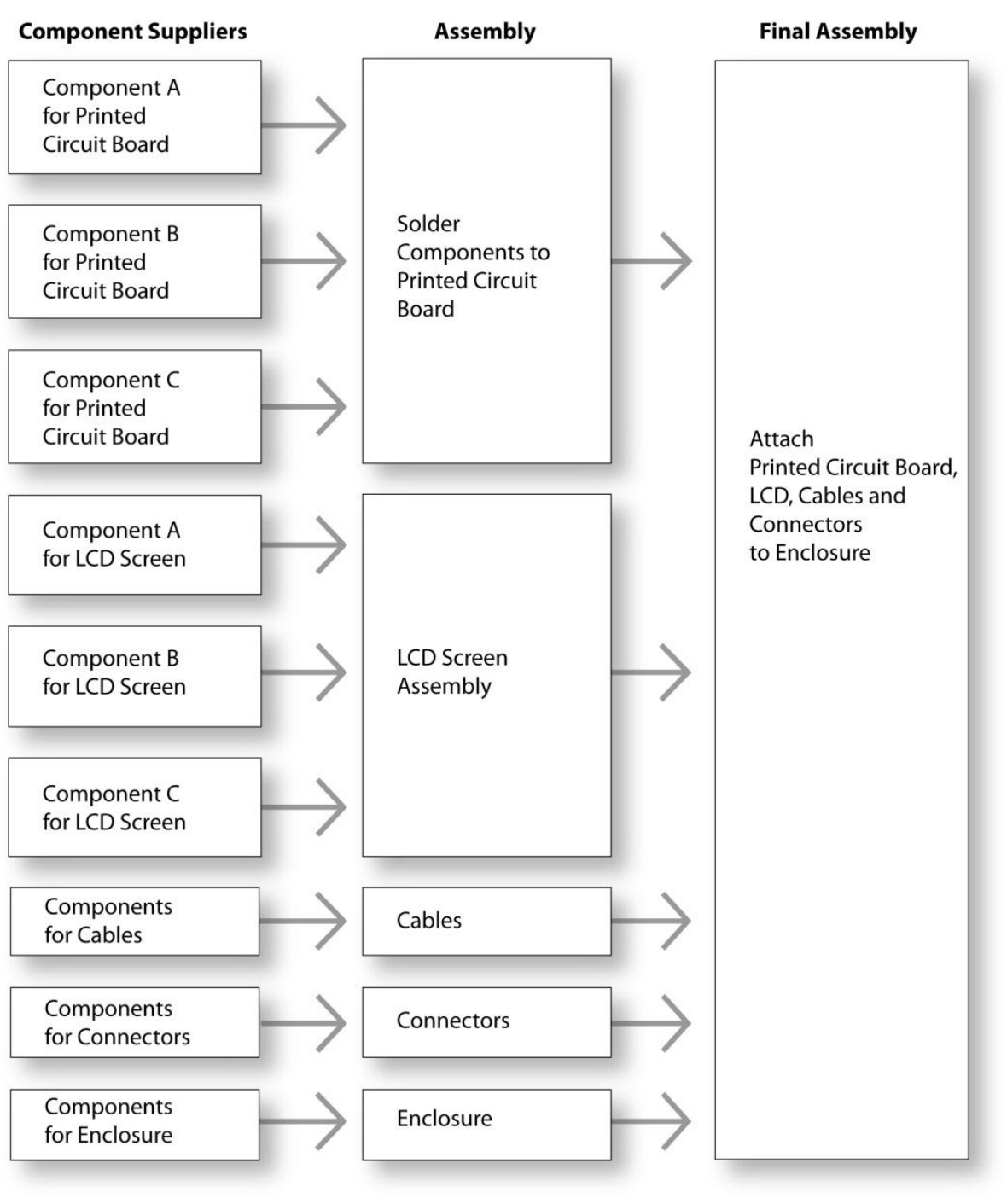

Figure. 2.3. Manufacturing flow for an electronic device

The example above is a simple two-layer supply chain consisting of suppliers and manufacturing facilities. Likewise, the other steps of the life cycle can be further refined and described in terms of more sophisticated distinctions between different paths or main-actors. For example, the end-of-life phase can be further divided into separate streams depending on whether the product is disposed of with household waste, or collected and dismantled and recycled, or incinerated, or maybe exported and waste-managed in an inappropriate manner, e.g. through back-yard burning. 
From the perspective of transferring information, each actor in the product chain has a role to play in passing on information to the next actor downstream, as well as communicate feedback and information on use and exposure etc. to their supplier upstream. Any actor not passing on relevant information (i.e. relevant at any point in the supply chain further downstream) creates a gap in the transfer of information in the supply chain. This study will focus on the following categories of actors as target-groups for the purpose of in-depth interviews on their perspective on information on chemicals in electronic products:

- Chemicals and/or material manufacturers

- Components manufacturers

- Producers of end-products, i.e. brand names and Original Equipment Manufacturers (OEMs)

- Consumers and public interest organizations

- Waste handlers, formal sector

- Waste-handlers, informal sector, often in developing countries

- Government Agencies

Each of these actors fall into one or several of the categories defined as stakeholders in chapter 1.6.

\subsection{Chemicals present in electronic products}

Analysis of the chemicals present in electronic products is not a simple matter. Computers and mobile phones can contain over one thousand different substances. ${ }^{15}$ Some of the materials used are valuable resources, such as gold, copper and silver. Other ingredients are hazardous. There are also cases where substances are hazardous as well as valuable, such as copper.

The main hazardous substances found in electronic products are: lead, mercury, cadmium, zinc, yttrium, chromium, beryllium, nickel, brominated flame retardants, antimony trioxide, halogenated flame retardants, tin, polyvinyl chloride (PVC) and phthalates.

The table below summarises the components in which these chemicals are most commonly used.

15 Sepulveda, A., M. Schluep, et al. 2010 


\begin{tabular}{|c|c|}
\hline \multirow[t]{2}{*}{ Printed circuit boards } & $\begin{array}{l}\text { In printed circuit boards, cadmium occurs in certain components. } \\
\text { Other hazardous metals such as chromium, lead, mercury, } \\
\text { beryllium, zinc and nickel may are also be present. }\end{array}$ \\
\hline & Brominated flame retardants and antimony trioxide are often used \\
\hline Liquid crystal displays, LCDs & $\begin{array}{l}\text { LCDs used in mobile phones and flat screen computer monitors may } \\
\text { contain mercury. }\end{array}$ \\
\hline Cathode ray tubes, CRTs & $\begin{array}{l}\text { Lead in the cone glass and cadmium/zinc/yttrium sulphide in the } \\
\text { fluorescent coating. }\end{array}$ \\
\hline Batteries & $\begin{array}{l}\text { Heavy metals such as lead, mercury and cadmium are present in } \\
\text { certain batteries. }\end{array}$ \\
\hline \multirow[t]{2}{*}{ Plastic casings } & $\begin{array}{l}\text { Plastics often contain halogenated flame retardants, many of which } \\
\text { are hazardous. }\end{array}$ \\
\hline & $\begin{array}{l}\text { Also, combustion of the plastics and halogenated flame retardants can } \\
\text { produce toxic substances. In addition, Antimony is often added to } \\
\text { enhance flame retardancy }\end{array}$ \\
\hline Components, such as switches & $\begin{array}{l}\text { Mercury is used in fluorescent lamps, and has historically been used in } \\
\text { thermostats, sensors, relays and switches, for example, on printed } \\
\text { circuit boards }\end{array}$ \\
\hline Solder & Can contain lead, tin and other metals. \\
\hline Internal and External Wiring & $\begin{array}{l}\text { Wiring is often coated in PVC which commonly contains numerous } \\
\text { additives, including heavy metal compounds and softeners such as } \\
\text { phthalates. Combustion of PVC can produce toxic substances. }\end{array}$ \\
\hline Semiconductors & $\begin{array}{l}\text { The semiconductor industry uses brominated flame retardants in } \\
\text { the plastic encapsulation material }\end{array}$ \\
\hline
\end{tabular}

Source: Adapted from Cui, J., Forsberg E. 2003

Electronics products also contain valuable metals such as gold and copper that are valuable for recyclers to extract. This is further described in the section below.

\subsection{Drivers for recycling}

Simple economics illustrate the why electronic waste is deemed so valuable: The economic level for a gold mine is approximately 5 grams $(0.18$ ounce) gold per tonne of ore. Discarded electronics, such as mobile phones, can yield 150 grams (5.3 ounce) or more per tonne, according to a study by Yokohama Metal Co Ltd. ${ }^{16}$ The same volume of discarded mobile phones also contains around $10 \%$ (100 kg/220,5 lb) of copper and $0,3 \%$ (3 kg /6.6 lb) of silver, among other metals. By comparison, Boliden reports an average copper content of $0,36 \%$ in the ore of their mine in Aitik, Sweden. ${ }^{17}$

The recovery of gold, silver, copper and palladium can thus be economically profitable, and these metals are therefore commonly recycled.

16 Yoshikawa 2008

17 Minde \& Liljeholm 2005 
Since these four metals represent more than $90 \%$ of the economic value of a typical printed circuit board, recycling companies have little incentive to target other substances. Metals such as indium and ruthenium, which are increasingly common in electronics, are thus not commonly recovered at present.

Manufacturers' pursuit of smaller and lighter electronic products with higher capacity has led to the introduction of an increasing number of rare materials, especially metals. For example, the composition of a processor from Intel Corporation has increased from 12 elements in 1980 to 16 elements in the 1990s, and 44 by 2000 . Currently, recycling companies can recover only a few of these elements.

Valuable metals are important to recycle from a strategic resource perspective. The global reserves of some of these elements are very small and the opportunities for finding good substitutes are limited. In the case of gold and silver, the electronics industry is only using a few percent of the global mining supply, but for some of the rare metals, such as indium and ruthenium, the electronics industry is the dominant user. ${ }^{18}$ It is therefore important to make sure that the recycling system for electronic products can also recover rare metals.

Plastics recycling rates lag far behind those of other materials, although post-consumer plastic recycling rates have been steadily increasing since the 1990s.

There are several reasons behind this trend. The production and use of plastics has a range of environmental impacts. The production of plastics requires significant quantities of resources, primarily fossil fuels, both as a raw material and to deliver energy for the manufacturing process. It is estimated that $4 \%$ of the world's annual oil production is used as a feedstock for plastics production and an additional 3-4\% during manufacture. ${ }^{19}$

In addition, plastics manufacture requires other resources such as land and water and produces waste and emissions. The overall environmental impact varies according to the type of plastic and the production method employed.

As the price of resources required for the production of virgin plastics increases, it is expected that recycling rates will further increase. Some of the benefits include:

- reduction of energy consumption;

- reduction of oil consumption;

- reduction of water usage;

- reduction of carbon dioxide generation;

${ }^{18}$ Hagelüken \& Meskers 2008

19 http://www.wasteonline.org.uk/ 
- reduction of usage of (hazardous) chemicals. ${ }^{20}$

\subsection{From consumer products to waste}

The average lifespan of computers in developed countries has dropped from six years in 1997 to just two years in 2005, while mobile phones have a lifespan of less than two years in developed countries. ${ }^{21}$ As the turnover of electronics consumed increase, so do the volumes of discarded electronics increase.

According to the 2005 UNEP report E-waste, the hidden side of IT equipment's manufacturing, 20 to 50 million metric tonnes of e-waste are generated worldwide each year. ${ }^{22}$ This waste includes lead, cadmium, mercury, and other hazardous substances. Up to 75 percent of the ewaste generated in Europe and around 80 percent of the e-waste generated in the United States goes unaccounted for. ${ }^{23} \mathrm{~A}$ vast amount of this ewaste is being exported to developing countries.

UNEP has estimated that consumers globally bought almost 900 million mobile phones in 2006 and over a billion in 2007. A considerable share of these devices end up in household waste-streams, or, as we shall see below, are waste-handled through environmentally unsound practices. The prediction is that by 2020 the amount of e-waste generated from mobile phones in China will be about seven times larger than it was in 2007.

\subsection{E-waste flow to developing countries}

Second-hand electronics and electronic waste are exported through illegal, legal and grey channels, from the EU, USA, Japan etc. to developing countries. Legal export involves functioning electronic products being exported for a second life in developing countries. However the lower costs for waste-management (or non-management) in developing countries is a powerful incentive to illegally export non-functioning equipment: the cost of for example glass-to-glass recycling of computer monitors in the US is ten times more than in China. It is also estimated that the waste-handling/recycling costs for PCs and mobile phones are ten times higher in the US or the EU than in India or Nigeria.

Furthermore, there are economic incentives for those on the receiving end of e-waste: through rudimentary techniques the informal sectors in developing countries can extract valuable substances such as copper,

\footnotetext{
20 See for example the British Plastics Federation, at http://www.bpf.co.uk/Sustainability/ Plastics_Recycling.aspx

21 Greenpeace 2009

22 UNEP 2005, p1. UNEP 2009, UNEP 2010

23 Greenpeace International 2008, p. 9
} 
iron, silicon, nickel and gold. In addition, in developing countries, used electronics such as computers are often refurbished and sold as second hand. ${ }^{24}$

In other cases, second hand electronics such as computers are sent to developing countries as charity. Even if the used electronics are intended as useful gifts, interviewees warned that they rapidly develop into a problem at end-of-life, releasing their hazardous constituents such as heavy metals and brominated flame retardants.

Due to the fact that, in general, neither the exporting countries nor the importing countries screen or test e-waste exported/imported there is a lack of information on the exact volume and composition of the ewaste flows. Some NGOs, however, have been studying parts of the flow. One study shows that in 2003 at least 23,000 metric tonnes of undeclared electronic waste was illegally shipped from the UK to the Far East, India, Africa and China. ${ }^{25}$ In Ghana a socio-economic assessment done within the context of the E-waste Africa Project, commissioned by the European Commission, found that between 10,000 and 13,000 metric tons of domestic and imported e-waste are treated annually in Ghana by the informal sector. ${ }^{26}$

\footnotetext{
24 For example, interviews with second hand electronic equipment businessmen in Accra, Kumasi and Tema in Ghana show that shipping costs for a forty foot container from the US costs about 5000 dollars, and each container can hold about 300 computers. A functioning Pentium 3 computer can be sold at almost 200 dollars in Ghana. Thus one will only need about 25 functional Pentium 3 computers to pay the costs of the shipping - the rest is dumped.

25 Greenpeace, 2009

26 Prakash \& Manhart 2010, p. 2
} 


\section{Handling of electronics and potential release of chemicals}

\subsection{Exposure to chemicals during production}

Workers, consumers and communities are exposed to chemicals in consumer electronics throughout their life cycle, from manufacture through use and disposal. The emphasis in discussions on health and environmental impacts from electronics is usually on the end-of-life phase, in particular during informal waste management.

However, problems occur during the production stages as well, but information on these chemicals and their health impacts are scarce at best. ${ }^{27}$ Studies have demonstrated high exposure to carcinogens and reproductive toxicants during production, including solvents, heavy metals and epoxy resins among electronics workers, ${ }^{28}$ and increased rates of spontaneous abortion and birth defects among women working in semiconductor fabrication. ${ }^{29}$ In addition, several studies over the past two decades have shown that electronics workers have a significantly elevated risk of lung, pharyngeal, nasal, breast, bladder, and brain cancers. ${ }^{30}$

Communities located near semiconductor manufacturing have suffered health impacts from direct contamination of their environment. Studies have been looking at the link between solvents and other chemicals leaked from semiconductor manufacturing plants in San Jose, California and increased rates of spontaneous abortions and congenital malformations among infants exposed during pregnancy. ${ }^{31}$

\subsection{Exposure to chemicals in the use phase}

In addition, evidence is growing that exposure to (hazardous) chemicals also occur during the use-phase of electronics. Sampling of household dust indicates that levels of dioxins and furans in indoor environments is increasing. Studies looking at house dust and office dust in Japan found

27 This study does not go deeper into the issue of problems associated with the use of chemicals in producing electronics. For more on the issue, see e.g. the Silicon Valley Toxics Coalition http://svtc.org/

${ }^{28}$ Alexander, $\mathrm{R}$

${ }^{29}$ Gray, 1993; Corn et al., 1993; Correa et al. 1996; LaDou et al. 1998

30 Beall et al. 1996; Bailar et al., 2000; Clapp 2006

31 Rudolph et al. 1986 
high levels of polybrominated dibenzofurans (PBDFs) in these environments. ${ }^{32}$

The authors found a correlation between polybrominated diphenylethers (PBDEs), and PBDFs and concluded that the PBDFs are a degradation product of PBDEs. 33 The connection to electronics present in these environments cannot be ruled out.

Other studies have looked at the debromination of flame retardants such as decabromodiphenylether, DecaBDE, a flame retardant used in a wide range of applications including electronics. For example, one study looked at the formation of PBDFs in flame-retarded plastics exposed to normal sunlight. 34

The researchers found that in high-impact polystyrene, HIPS, containing DecaBDE, the PBDF concentration increased by about 40 times after 1 week of exposure. Also, in TV casings with DecaBDE, PBDF concentrations increased continuously during the experiment. The researchers concluded that more attention should be paid to the fact that PBDFs are formed by sunlight exposure during normal use as well as disposal/recycling processes of flame-retarded consumer products. ${ }^{35}$

In addition, high levels of polybrominated dibenzodioxins (PBDDs) and polybrominated dibenzofurans (PBDFs) have been found in plastic TV housing, demonstrating the presence of dioxins and furans in the usephase of products containing plastics with brominated flame retardants. 36

It is very likely that a significant share of the exposure described above comes from the presence and use of consumer electronics. Such findings raise concerns for risks during the use phase as well as in waste-management.

\subsection{Formal and informal recycling}

At end of life, e-waste management and the recycling of electronics can roughly be divided into formal and informal handling. One should be aware that these terms can mean different things in different contexts. Informal activities are basically carried out by unregistered small scale businesses, groups of people or individuals. The extent of organisation varies greatly. In some countries such business activities are prohibited, while in others they are allowed by the public authorities. In some cases they operate in a legal grey zone where they are illegal in principle but accepted in practice.

As we shall see, in developing countries, the informal waste collection, reuse, repair and recycling activities are responsible for a large

32 Suzuki 2010a, Suzuki 2010b

33 Suzuki 2010b

${ }^{34}$ Kajiwara 2008

35 Kajiwara 2008

${ }^{36}$ Lundstedt 2009 
share of the waste management services. Informal waste pickers reduce the waste collection costs for municipalities and contribute to resource circulation. Even so, informal waste workers operate under difficult and often unhealthy conditions, and the value of the services they provide is generally not recognised.

Formal waste management on the other hand is mostly carried out in a more organised manner, by registered companies expected to comply with existing (applicable) laws and regulation.

The informal recycling of electronics that is common in developing countries uses simple recovery techniques and no protection of workers or the environment. It typically targets just a few valuable metals, such as gold and copper, while the materials that are difficult to recover or lack market value are usually improperly discarded. From a global perspective, the health risks and pollution caused by these operations are by far the most serious in the end-of-life treatment of electronics.

However, this does not mean that all "formal" recycling operations are safe, including e-waste recycling in OECD countries. Even recycling facilities that are equipped with appropriate technology for treating ewaste safely can generate occupational exposure and pollution. This can happen especially if management or staff lacks knowledge on risk prevention measures or do not have enough motivation or incentives to take appropriate action.

The distinction made here between formal and informal does thus not equate with safe vs. unsafe.

This section describes the e-waste handling practices in formal as well as informal sectors, as well as human health and environment impacts of these - in order to remedy these problems, one first needs to understand them.

Some might argue that the problem is not about chemicals/materials, but about inappropriate handling. It is however very difficult, in practice, to separate the two. Inappropriate handling practices may have very different environmental impacts depending on whether the handled products contain hazardous material or not.

\subsubsection{Recycling practices in the formal sector}

One can divide the recycling of PCs into three steps (see figure 5.2). In step one, collected PCs are manually dismantled into body (plastic, iron), CRT, unit parts (HDD etc.), cables and other components. At this stage, usable parts are separated, checked and reused as service parts. In step two, metal and unit parts are shredded and separated into iron, aluminium, copper, etc. Plastic parts are separated according to type of plastics. CRTs are dismantled manually and sorted into metals and glass. In step three, CRT glass is recycled to be reused in CRT displays by CRT manufactures. Gold, silver, and other precious material are refined from print- 
ed circuit boards by metal refineries. What is not used from the discarded printed circuit boards are recycled into road pavement materials.

Other electronics such as mobile phones are recycled in a similar fashion.

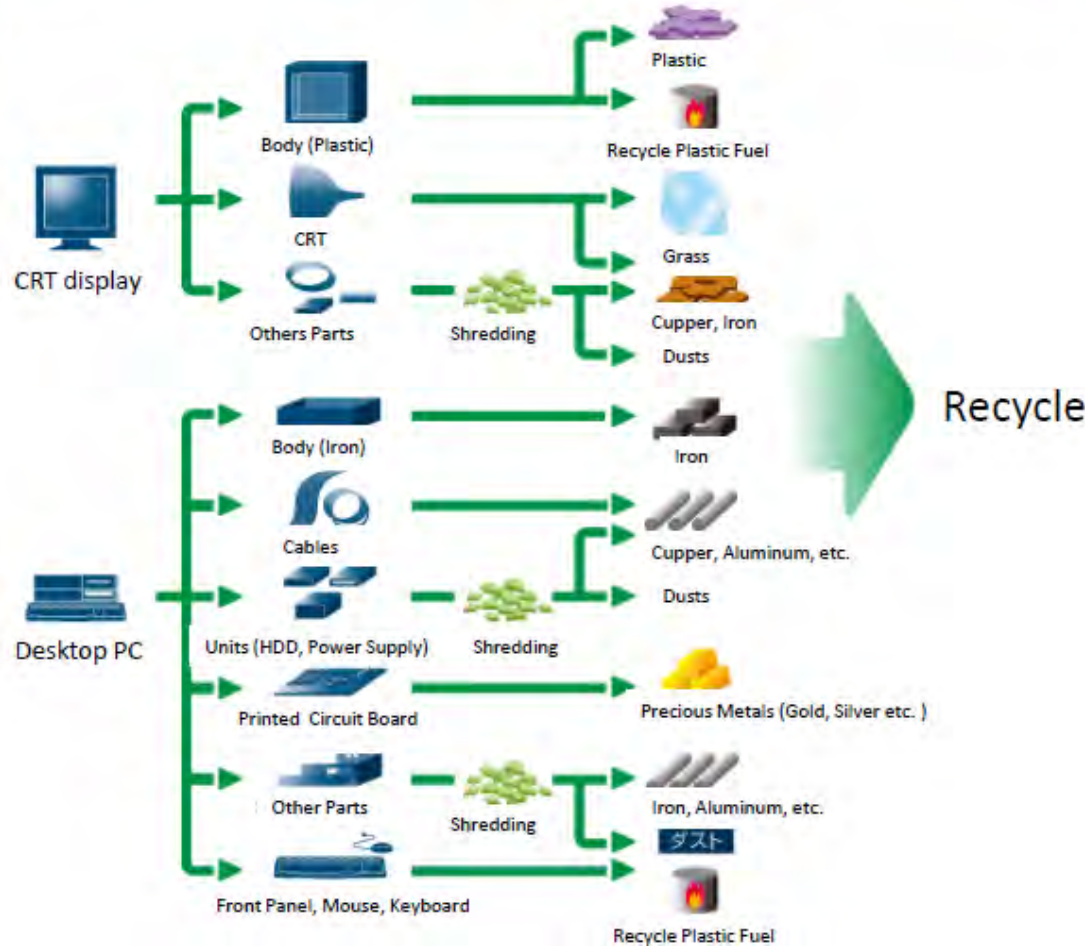

Figure 3.1. The Recycling Flow of PCs

Source: Pc3r Promotion Association, http://www.pc3r.jp/e/

\subsubsection{Recycling practices in the informal sector}

Most e-waste in developing countries is handled by the informal sector. In some countries this work is systematised to include waste pickers, collectors, small middlemen, and larger middlemen that sell the recyclable parts to the material recycling industry.

In other developing countries this informal work is not as organized but something that is done on a household level. It is a common feature of the informal waste sector in developing countries that it consists of the poor with little or no formal training.

The practices of e-waste management in developing countries as well as the impacts of such practices have been particularly well-documented for Guiyu in China, and the data referred to in the following sections is to a large extent constituted by, but not solely from, studies in Guiyu. The town is made up of several villages located in the Chaozhou region of Guangdong Province, 250 km northeast of Hong Kong. Since 1995, what 
was traditionally a rice-growing community has become a recycling centre for e-waste arriving from overseas.

It should be noted however, that as data is generated in other regions in developing countries where e-waste is an ever-increasing problem, similar pictures emerge. The interviewees in this report as well as previous studies describe elevated concentrations of heavy metals, dioxins and other hazardous substances in the dust, air, soil, fresh water and sediments surrounding sites and workshops where e-waste is treated in developing countries.

Guiyu is increasingly becoming the standard, rather than the exception.

Often, electronic waste is disassembled directly at dump-sites or small workshops in the informal sector, where there is no real control over the materials processed, the processes used, or the emissions and discharges from these facilities. ${ }^{37}$ The primary goal of such recycling operations is the recovery of valuable materials, such as gold and copper, and the goal is pursued with little or no regard for the environment or human health.

Fig. 5.6 shows recycling processes typically used in India and China for processing e-waste. However, similar recycling activities were described by all developing country interviewees involved in this study. 38 Most of the operations employ rudimentary techniques and are conducted by workers without protective clothing. The potentially hazardous recycling practices included manual disassembly of e-waste with little regard to its hazardous content, recovery of solder and chips from printed circuit boards, acid extraction of metals from complex mixtures, melting and extruding plastics, and burning of plastics to isolate metals.

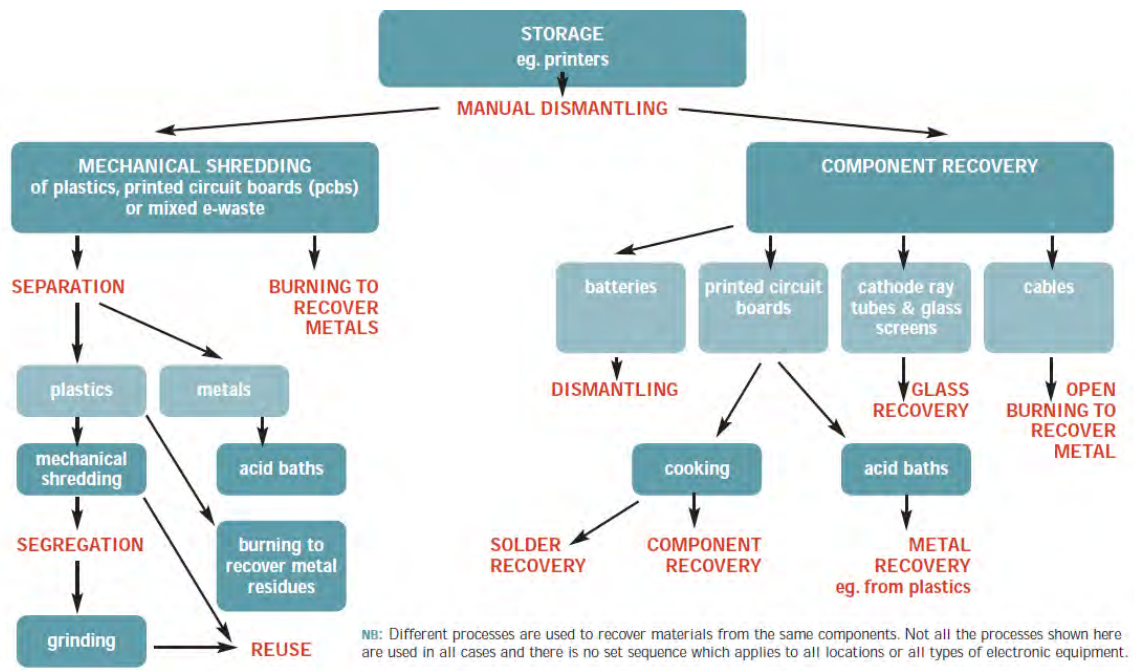

Figure 3.2. E-waste recycling processes in India and China Source: Brigden et al. 2005

37 BAN \& SVTC 2002; Brigden et al 2005; Brigden et al 2008

38 For further information see BAN \& SVTC, 2002; Brigden et al, 2005 


\subsubsection{Manual disassembly and recovery of valuables}

The recycling processes in the informal sector start with the manual disassembly of e-waste. The following components are separated for further recycling: materials containing copper (including motors, wires and cables, CRT yokes), steel (including internal computer frames, power supply housings, printer parts, etc.), plastics (including housings of computers, printers, faxes, phones, monitors, keyboards, etc.), aluminium (printer parts, etc), printer toners and printed circuit boards. At this stage, manual disassembly and recovery of valuable components from CRTs and printed circuit boards are of particular concern. ${ }^{39}$

In the manual disassembly process, CRTs are broken to remove copper yokes. This exposes the worker to the phosphor powder covering the inner surface of the front panel that contains heavy metals.

The common method to recover valuables and solder from printed circuit boards is by heating them until the connecting solder is melted. Heating is done using coal grills, propane torches, kerosene burners or other simple devices. Melted solder is then collected and individual components attached to printed circuit boards are manually removed. Valuable chips are sold or subject to acid digestion for precious metal extraction. Waste boards stripped of chips are further burnt or acid digested in order to recover the remaining metals.

\subsubsection{Acid extraction of metals}

Primitive hydrometallurgical processes are often used to recover metals from e-waste. ${ }^{40}$ Metals are dissolved in strong acid solutions and subsequently recovered from the solutions. In some cases, the workshops are situated in the open on the banks of rivers, while in other cases, this type of activity take place in small, enclosed workshops. ${ }^{41}$ Aqua regia (a mixture of $25 \%$ concentrated nitric acid and $75 \%$ concentrated hydrochloric acid) is often used in Guiyu for extraction of gold. ${ }^{42}$ Concentrated nitric acid and hydrochloric acids are also reportedly used for extraction of copper in similar operations in Delhi. ${ }^{43}$ Workers employed in the operations in general do not use equipment to protect them from inhaling toxic acid fumes. Various volatile compounds of nitrogen and chlorine are known to be emitted during such processes. The wastes acid solutions and sludges generated during the process are usually dumped onto open ground or into water streams.

${ }^{39}$ BAN \& SVTC, 2002

40 BAN \& SVTC, 2002; Brigden et al, 2005

41 Brigden et al, 2005

42 BAN \& SVTC, 2002

43 Brigden et al, 2005 


\subsubsection{Melting and extruding plastics}

Plastics are processed in similar ways in many developing countries. They are manually removed from e-waste and mechanically shredded. The next treatment step is either some kind of separation (e.g. by colour or density) and/or further grinding. These operations are often carried out in rooms with little ventilation and no respiratory protection. ${ }^{44}$

Many interviewees to this report describe how in developing countries e-waste parts are burned on open fires, at dumpsites as well as in workshops, to recover metals from the plastics in which they are encased. This includes plastic coated wires, other complex components as well as unwanted, discarded scrap. 45

\subsection{Exposure to chemicals during recycling}

There are severe, well-documented problems connected to the informal recycling of electronics, especially arising from open-fire burning of electronics components in developing countries. However, the release of e.g. additive brominated flame retardants, and subsequent human exposure to them, is not just restricted to informal e-waste practices, but occurs also in formal recycling processes.

\subsubsection{Formal}

Studies on release pathways and exposure to workers in recycling facilities in developed countries have documented the release of hazardous chemicals present in recycled e-waste. Studies have demonstrated higher levels of PBDEs in the blood of workers employed in the formal ewaste recycling sector, for example in e-waste recycling facilities in Sweden and Norway.46 Elevated levels of polybrominated diphenyl ethers, PBDEs and other brominated flame retardants have also been reported in air samples collected at a European plant involved in the recycling of e-waste, particularly in the vicinity of shredding equipment. ${ }^{47}$ The study found extremely high concentrations of tetrabromobisphenol A, TBBPA, in the indoor air. ${ }^{48}$ The brominated flame retardant decabromodiphenyl ether (DBDPE) was also tentatively identified in air samples from an e-waste recycling facility in Sweden. ${ }^{49}$ Furthermore, health hazards from the electronics recycling programme operated by the US Federal Prison Industries have been documented. ${ }^{50}$

\footnotetext{
44 BAN \& SVTC, 2002; Brigden et al, 2005

45 For further information see, Brigden et al., 2005 and Brigden et al, 2008

46 Sjödin et al. 1999; Thuresson et al. 2006; Thomsen, Lundanes et al, 2001

${ }^{47}$ Sjödin et al, 1999

${ }^{48}$ Sjödin, Carlsson et al. 2001; Morf, Tremp et al. 2005; Tollback, Crescenzi et al, 2006

${ }^{49}$ Pettersson-Julander, van Bavel et al, 2004

50 Jackson et al., 2006
} 
Such findings confirm that although informal e-waste management is in general carried out without consideration of human health and the environment, it does not mean that formal e-waste management is per definition safe.

Even under optimal circumstances, in modern facilities, there is a risk of exposure and e.g. dioxin formation when treating material containing hazardous chemicals, for example brominated flame retardants, (BFRs). Filtering the flue-gas from incinerators in order to capture fly-ash can be used to reduce escape of such chemicals. However the problem of how to handle and store the filters, to ensure that the captured dioxins are not released at a later stage, remains.

\subsubsection{Informal}

The rudimentary informal sector recycling techniques described above, coupled with the amounts of e-waste processed, have already resulted in adverse environmental and human health impacts in the developing countries receiving e-waste, such as China, India, Nigeria, the Philippines and Ghana.

For example, environmental pollution is a likely outcome of the breaking and handling of CRTs. The open-air storage and dumping of CRTs raise concerns regarding the possibility of lead contained in the CRT glass leaching out into the environment. 51

Heating of printed circuit boards for de-soldering and removal of chips undoubtedly exposes the worker to fumes of metals, particularly those in solder (often lead and tin), and other hazardous substances that can be potentially released during such treatment.

Since open fires burn at relatively low temperatures, which is most often the case when burning e-waste in open fires, the release of pollutants are significantly higher than in a controlled incineration process. Experimental studies have documented the formation of dioxins and furans through open burning of wires and printed circuit boards. 5253

Studies have shown that copper, which is present in printed circuit boards and cables, acts as a catalyst for dioxin formation when halogenated flame-retardants are incinerated. When incinerated at low temperatures $\left(600-800^{\circ} \mathrm{C}\right)$ these brominated flame retardants can lead to the generation of extremely toxic polybrominated dioxins (PBDDs) and PBDFs. ${ }^{54}$

Studies have shown that dust samples from e-waste workshops in China and India involved in de-soldering and disassembly of printed circuit boards contain extremely high concentrations of lead and tin.

\footnotetext{
51 BAN \& SVTC 2002; Brigden et al, 2005

52 Gullet et al, 2007

53 Leung et al, 2006

${ }^{54}$ EMPA 2009. http://ewasteguide.info/node/10
} 
Other metals found at elevated concentrations in the dust samples from the workshops in both China and India are tin, antimony, cadmium, copper, cobalt, chromium, lead, nickel, silver and zinc..$^{55}$

Elevated concentrations of metals such as cadmium, chromium, copper, nickel, lead, zinc, manganese and arsenic have also been observed in ambient air in Guiyu, ${ }^{56}$ as well as elevated levels of PBDEs. ${ }^{57}$ Furthermore, polycyclic aromatic hydrocarbons, PAHs, and PBDEs, chlorinated and brominated dibenzo-p-dioxins and furans (PCDD/Fs and PBDD/Fs) have also been detected at high concentrations in ambient air in Guiyu. 58

E-waste is known to contaminate the water system through the direct dumping of acid waste into streams and ditches, through the settling of airborne particles, or through the leaching of soils. For example, in Guiyu freshwater ecosystems have been affected by the intensive recycling activities taking place there, with the drinking water being contaminated. ${ }^{59}$ Excessive levels of metals such as dissolved arsenic, chromium, lithium, molybdenum, antimony, selenium, silver, beryllium, cadmium, cobalt, copper, nickel, lead and zinc have been attributed by researchers to acid leaching operations taking place along the rivers. ${ }^{60}$

In addition, a number of studies have assessed soil samples and found elevated levels of PBDEs and PCDDs/Fs, ${ }^{61} \mathrm{PAHs}^{62}$ and metals such as copper, lead and zinc.63

As described above, unregulated recycling activities generate workplace and environmental contamination by a wide range of chemicals. As a result, workers and local residents are exposed to the chemicals through inhalation, dust ingestion, dermal exposure, and oral intake (of contaminated food and drinking water). Due to the lack of access to running water, toxics are also transmitted orally via people's hands when they eat.

A number of studies have shown that inhalation and dust ingestion as particularly important routes of human exposure to dioxins, lead, copper, cadmium ${ }^{64}$ polybrominated diphenyl ethers, PBDEs, polychlorinated biphenyl, PCB, chromium. ${ }^{65}$

The exposure may have an effect on levels of thyroid-stimulating hormone and cause genetic damage, respiratory ailments, skin infections, and stomach diseases. ${ }^{66}$ In Guiyu, there has also been a surge in cases of leukemia. 67

\footnotetext{
55 Brigden et al. 2006; Leung et al. 2008

56 Deng 2007

57 ibid

58 Li et al 2007

59 BAN \& SVTC 2002

60 Wong et al. 2007

${ }^{61}$ Leung et al. 2007

62 Yu et al 2006

63 Wong et al, 2007

64 Huo 2007; Zheng et al. 2008

65 Deng et al. 2007; Li et al. 2007; Leung et al. 2008; Deng et al. 2007. Wen et al. 2008; Zheng et al. 2008; Li et al. 2008

66 Yuan et al. 2008

${ }^{67}$ Leung 2006
} 



\section{Overview of CiP information systems}

\subsection{Introduction}

Over the last few years a number of policy initiatives on chemicals in products and the end-of-life treatment of electronics have been developed. Most notable are the European Union's RoHS and WEEE Directives and the REACH regulations have impacted the way electronic products are designed, how they are collected and treated at the end-of-life, and how information on hazardous substances is generated and shared. Other regions and countries have since followed suit.

This chapter provides an overview of existing systems for sharing CiP information. The systems described are those referred to by the interviewees as the most influential on their CiP situation, or CiP information and management.

\subsection{International industry systems for sharing information}

Industry-wide initiatives have been set up which are international in their scope. These include the Joint Industry Guide (JIG), the International Electrotechnical Commission (IEC) material declaration standards and the Global Product Strategy (GPS) chemicals portal.

The JIG is a material declaration standard developed by and for the global electronics industry. It is a business-to-business communications tool which applies to products and subparts relevant for manufacturers in the electronics industry. 68 The aim is to facilitate reporting on material content information across the global electronics supply chain.

JIG lists materials and substances that may be present in the supplied electronic products, insofar as these chemicals constitute part of the finished product or subpart. The chemicals included are those that are subject to regulatory or market requirements.

JIG-101 states: 
"This Guide represents industry-wide consensus on the relevant materials and substances that shall be disclosed by suppliers when those materials and substances are present in products that are incorporated into electrotechnical products. The Guide benefits suppliers and their commercial customers by providing consistency and efficiency to the material declaration process and will promote the development of consistent data exchange formats and tools that will facilitate and improve data transfer along the entire global supply chain $[. .]$.

"This Guide contains:

- the lists of substances for disclosure when contained in electrotechnical products;

- the threshold levels for substances in electrotechnical products, equal to or above which the quantity of the substance must be disclosed;

- the regulatory requirements that establish threshold levels for electrotechnical products, where appropriate;

- a set of data fields for information exchange." 69

Founded in 1906, the IEC is the world's leading organization for the preparation and publication of International Standards for all electrical, electronic and related technologies. Adoption is voluntary, although the standards are often referenced in national laws or regulations around the world. IEC is developing a material declaration standard that is based on the JIG and the IPC data exchange format.

Through the GPS chemicals portal, chemical companies and associations voluntarily provide information about substances that are marketed to the public. The IT portal was launched by ICCA in 2010 and contains more than 1000 chemical safety summaries. The data are presented in a user-friendly format and information on use and potential exposure is included. In this regard, information on the chemicals portal is a complement to Material Safety Data Sheets (MSDS). GPS is further described in section 5.2.

\subsection{National/Regional regulation and initiatives}

Many of the waste-related policies introduced over the last few years have been based on the principle of extended producer responsibility (EPR). The idea behind this principle is that manufacturers have a responsibility for their products, and the environmental impacts related with these products, which goes beyond the production stage. The EPR principle stresses especially manufacturers' responsibility for the endof-life treatment of their products. This responsibility can manifest itself in different ways, but it usually includes either a physical responsibility to take back the product after its use, or a financial responsibility to pay

${ }^{69}$ Joint Industry Guide No. JIG-101 Ed. 3.1 
for recycling or waste treatment carried out by another company. The producer responsibility can also include a requirement for the manufacturer to disclose information needed for safe use, handling, recycling and disposal. This informative responsibility makes producers responsible for providing information on the product or its effects at various stages of its life cycle and could thus include CiP information. ${ }^{70}$

There is a double rationale behind the EPR principle. The first is related with financing and the second with product re-design. Traditionally, waste disposal and recycling has been paid for with tax money. By regulating that a certain kind of end-of-life treatment should be carried out and letting the producers pay for the establishment and operation of such a system, the costs will be internalised in line with the polluterpays principle. Some of these costs will then likely be carried by consumers through increased product prices. This is the direct effect of an EPR-based system. In the longer term, if manufacturers have to carry the financial burden for end-of-life treatment, they will have an incentive to modify the design of their products so that they are easier to recycle and the materials used can generate more income as secondary resources. ${ }^{71}$

\subsubsection{The European Union}

Although neither specifically focused on products nor any particular sector, the European Union REACH regulation on chemicals has since its adoption in 2007 had a global impact, on legislation in other part of the world as well as on how communication on chemicals and chemicalscontaining products is perceived, carried out and handled.

REACH obliges manufacturers and importers to register and provide basic information on the intrinsic properties of all chemicals produced or imported in volumes above one metric tonne per year on the EU market. The information requirements increase with the volume of the registered chemical.

Furthermore, REACH identifies and controls the use of high concern chemicals, through its Authorisation system as well as through Restrictions. REACH has also established provisions on data sharing, through its publicly accessible database and mandatory flow of information on the presence of chemicals in the supply chain as well as the intrinsic properties of these. ${ }^{72}$

With regards to information on Chemicals in Products, REACH introduces two types of information requirements.

First, there are requirements on manufacturers and importers to in certain cases make a notification or registration. If a product (or "article" in REACH terminology) contains any chemical that is to be intentionally re-

70 http://www.p2pays.org/ref/47/46204.pdf

71 OECD, 2001

72 For more on REACH, visit the European Chemicals Agency's website, http://echa.europa.eu/ 
leased from the product, it has to be registered with the European Chemicals Agency (ECHA). If the chemical is not to be intentionally released but is identified as of high concern (in REACH a "Substance of Very High Concern" or SVHC) and has a concentration above $0.1 \%$, then ECHA has to be notified. ECHA may then also require the chemicals to be registered. This is only necessary for chemicals that are produced or imported in volumes exceeding 1 tonne per producer or importer per year. There are other additional criteria which exempt chemicals from these requirements.

Secondly, there are requirements on suppliers to give information to professional customers ("recipients") and on request to consumers (the "right to know") about any SVHCs which constitute more than $0.1 \%$ of the product.. The information must be sufficient to allow safe use and as a minimum the name of the SVHC has to be given. There are neither volume limits for nor exemptions from these requirements. These provisions have an impact on the flow of information on high concern chemicals from producers/importers to actors further down the product chain. They also apply to products from recycled materials.

In order to manage the end-of-life phase of products, European countries and Japan have been at the forefront in introducing waste regulations based on EPR. As part of a legislative initiative to solve the problem of huge amounts of toxic e-waste, the EU Waste Electrical and Electronic Equipment Directive, WEEE, imposes EPR for a broad range of electronic products. It sets collection, treatment and recycling targets for electronic waste and places the financial responsibility for carrying the costs for recycling on the manufacturers and importers. It also mandates producers to disclose information needed for end-of-life treatment. Producers must provide reuse and treatment information for each type of new EEE within one year after the product is put on the market. The information shall identify, as far as it is needed by reuse treatment and recycling centres, the different EEE components and materials, as well as the location of dangerous substances and preparations in the product. Also, the WEEE symbol must be placed on concerned EEE, informing consumers not to dispose of the product as unsorted municipal waste but to collect it separately.

Although WEEE requires information sharing with recyclers, it has so far not been a priority for the public authorities of the EU countries to specify how this information disclosure should be carried out and what information should be included. The regulators seem to assume that there is a demand for information from the recycling industry and that requests from the recycling companies will determine what information is made available and in what format. ${ }^{73}$

Manufacturers have taken different approaches to fulfilling the information requirement. Some of them have developed datasheets with recycling information and made these sheets available on their websites.

73 Bengtsson et.al. 2009 
In some cases these sheets also include details on the recommended disassembly process, supported by photos. In a few cases, the recyclers need to submit a registration form in order to get a user ID and password to access the information. There are also manufacturers who request that recyclers contact them by email. ${ }^{74}$

Compared with the Japanese marking systems for home appliances, the European systems in general contain less information. In particular, detailed information on plastic components (additives and the use of recycled polymers) and on hazardous metals in circuit boards is lacking.

Closely linked to WEEE, the Restriction of Hazardous Substances Directive (RoHS), was adopted in February 2003 by the European Union. This directive restricts the use of six hazardous substances (lead, mercury, cadmium, hexavalent chromium, polybrominated biphenyls, and polybrominated diphenyl ethers (PBDEs) in the manufacture of various types of electronics.

\subsubsection{The United States}

In the US there is no federal law mandating recycling of electronics or to make the producers responsible for the end-of-life treatment of their products. More than a dozen individual states have recently introduced recycling regulations, but these regulations differ by state and the producers are facing a patchwork of requirements. None of these state regulations require producers to provide recyclers with product information.

Certification systems for recyclers such as the Responsible Recycle (R2) Practices and the E-steward Certification program have been introduced to ensure the responsible recycling of electrical equipment and electronic devices through the certification of reliable recyclers and the promotion of sound recycling. To comply, recyclers will have to increase their efforts to stay informed on the changes in composition of products and to develop appropriate and safe treatment methods.

The Responsible Recycling (R2) Practices is a set of guidelines for accredited certification programs to assess electronics recyclers' environmental, worker health and safety, and security practices. The voluntary R2 practices include general principles and specific practices for recyclers disassembling or reclaiming used electronics equipment including those electronics that are exported for refurbishment and recycling and also requires downstream tracking of materials. ${ }^{75}$

E-stewards sets up a system for responsible recycling for the whole recycling chain. It places restrictions on what waste and what hazardous material can go downstream. As part of the certification, the E-stewards recyclers must set up environmental management systems that also include

\footnotetext{
74 Bengtsson et.al. 2009

75 For more on the Responsible Recycle Practices, see http://www.epa.gov/osw/conserve/ materials/ecycling/r2practices.htm
} 
occupational health. The aim of the system is to promote reuse of electronics and to prevent hazardous material from travelling downstream without appropriate management, e.g. from OECD to non-OECD countries. Estewards encourages as well as disallows certain recycling activities. ${ }^{76}$

Sara Westervelt at E-stewards explains: "Devices containing hazardous components must be properly tested and only fully functional devices are allowed for export to non-OECD countries. Devices containing hazardous substances are not allowed for e.g. shredding, unless the toxic components are properly removed."

The EPEAT standard, which currently covers only computers, requires information disclosure for safe end-of-life treatment. EPEAT allows purchasers to compare the environmental performance of products based on these criteria. EPEAT is quite widely used, not at least for public procurement, and it therefore has significant influence on the industry. Products registered in EPEAT must meet a core of 23 environmental performance criteria. They are then rated Gold, Silver or Bronze based on the percentage of a further 28 optional criteria which they meet. The requirements include the confirmation and elimination of parts containing hazardous substances, and the identification of plastic parts by marking them. ${ }^{77}$

Although established in the United States, EPEAT, R2 and E-Stewards are all international in their reach.

\subsubsection{Japan}

Following the introduction by the EU of the WEEE Directive and RoHS Directive, and the REACH Regulation, efforts have been made in Japan to increase the control of information regarding chemical substances in products and to promote environmentally conscious product design,. The underlying idea is the Integrated Product Policy, IPP, which considers the life of products from the supply chain to the recycling chain.

With regard to electrical equipment and electronic devices, the Japanese industry consortium Joint Article Management PromotionConsortium, (JAMP), has developed an information system which facilitates the management of information on chemicals in the up-stream part of products' life cycles. In addition to MSDS, JAMP utilizes JAMP MSDSplus for the purpose of information control in the upstream and midstream processes concerning substances and preparations contained in the products. Article Information Sheets, AIS, are utilized for preparations in the downstream processes. The JAMP-Global Portal is being operated in order to share compiled chemical substance information among the upstream, midstream and downstream sides.

$76 \mathrm{http}: / / \mathrm{e}-\mathrm{stewards.org/}$

77 EPEAT 2011. http://www.epeat.net/ 
The Japan Green Procurement Survey Standardization Initiative (JGPSSI), a regional member of the JIG, has formulated Guidelines for the Management of Chemical Substances in Products on the initiative of the industries concerned. These guidelines provide methods of sharing information required for compliance with REACH. To this end JGPSSI forms are promoted.

Japanese manufacturers not only deal with the rules and regulations set by the EU, but also promote their own initiatives. In response to the Home Appliance Recycling Law, the Association for Home Appliance Recycling and other related organisations have established a system of assigning recycling marks that through labelling indicate the information on chemical substances used in the products and information on their disassembly, so that the disassembly process and resources recovery rate can be improved at the recycling stage.

In response to the RoHS Directive, JIS established the J-Moss standard for the marking of chemical substances contained in electrical equipment and electronic devices. J-Moss communicates information from downstream of the supply chain to the consumption stage and then on to the recycling chain. It sets the control criteria for RoHS-specified hazardous substances (see paragraph on RoHS, above) contained in PCs, air conditioners and other targeted products. When the content of a specified substance in a product is at a level beyond the set criteria, a "containing" mark is stamped on the product and the manufacturer is obliged to provide on its website information on the parts containing the substance, the level of content, etc.

Japan has recycling legislation based on EPR which cover PCs and large home appliances used by private consumers. These laws set recycling targets for each product category individually and require consumers and manufacturers to pay for collection and recycling. In contrast to the WEEE Directive, the Japanese EPR system does not include any requirement to disclose recycling information. However, unlike in Europe, many Japanese recycling companies are closely related to the manufacturers - in some cases they are owned by large industrial groups that also include electronics manufacturing firms.

The Waste Data Sheet (WDS) is only utilised in the recycling chain. In principle, a WDS is produced by the waste generators and describes for waste handlers the properties of the waste, such as its corrosiveness, explosiveness, flammability, ecotoxicity, and other stability and reactivity properties. A WDS also describes the content of specified hazardous substances in waste (e.g. lithium, magnesium, sodium, copper and other metals, mercury, PCBs). The main characteristic of a WDS is that it is transported together with varying types of industrial waste, and provides detailed information to the receivers of the relevant waste.

While information sharing concerning hazardous substances is promoted through JAMP, information on valuable substances, particularly gold, silver, indium and other expensive precious metals and rare met- 
als, has not yet been included in the scope of information collection, even in the supply chain.

Another shortcoming is that web-based databases concerning substances that are hazardous or have an environmental impact are only utilized in JAMP in the supply chain, and are not yet shared with consumers, recyclers or treatment businesses. In the case of recycling marks or J-Moss marks, which only include a limited number of chemical substances within their scope, it is considered feasible to implement marking or labelling for communicating information from the supply chain to the consumption stage, and then to the recycling chain.

\subsubsection{South Korea}

South Korea has recently introduced legislation similar to the EU WEEE Directive which includes similar information sharing requirements. The South Korean government is researching how to help its industries comply with the international trend towards chemical substances management, including the EU's REACH Regulation and RoHS Directive, and it plans to pass laws, set up systems and infrastructure, and improve the national chemical substances management schemes.

The government also introduced the Act for Resources Recycling of Electrical and Electronic Equipment and Vehicles in 2008, which has its roots in the preceding recycling system based on EPR. This act is aimed at the effective utilisation of resources and the sound management of valuable substances, and includes an environmental quality assurance system. The assurance system targets the systematic control of information on valuable substances and hazardous substances, by reducing waste generation from electrical equipment, electronic devices and vehicles, promoting product design that facilitates recycling, and reducing environmental impacts through the systematic control of the whole process from production to disposal. The underlying information control and operational system is called the Eco-Assurance System, EcoAS.

\subsubsection{China}

As with Japan and South Korea, the Chinese government is promoting the establishment of laws and regulations concerning valuable substances and hazardous substances contained in products, in response to REACH, RoHS and WEEE. The government has enacted laws regarding Administration on the Control of Pollution Caused by Electronic Information Products (China RoHS) in response to the RoHS Directive, and the Administration of the Recovery and Disposal of Discarded Electronic and Electrical Products (China WEEE) in response to the WEEE Directive, followed by a related technical ordinance, the Technical Policy for the Prevention of Pollution from Waste Electrical and Electronic Equipment. 


\section{CiP information in manufacture and use}

\subsection{Introduction}

This chapter contains a discussion of information systems on CiP from the perspective of stakeholders surrounding the manufacture and use of mobile phones and PCs. The authors do not claim that this discussion is completely comprehensive and representative of all stakeholders and their needs. Rather it represents a cross-section of informed stakeholders who were willing to participate in this project, and provides details and insights into their needs for information, the information systems they find valuable and relevant, the areas where they feel information gaps or obstacles exist, and potential means of addressing these gaps and obstacles. No companies that could clearly be categorized as "laggards" in the industry participated in this project.

Conversations and in-depth interviews with fifteen stakeholders form the basis of this chapter (see list of informants). The participating stakeholders included representatives from: (1) companies producing chemicals or materials used in the manufacture of mobile phones and/or PCs, (2) companies manufacturing components for mobile phones and/or PCs, (3) brand owner companies that sell finished mobile phones and/or PCs to other businesses or consumers, (4) non-governmental organizations, NGOs, and consumer interest organizations, and (5) consultants to the companies in this list.

Most stakeholders who were involved with creation of both mobile phones and PCs used the same information systems both for products and for chemicals and materials. Thus, no effort is made here to separate information systems into categories based on mobile phones, PCs, or their various components. Actors at different locations in the supply chain, namely producers of chemicals and materials and the downstream users of these products do however, reference different sets of information systems. These two broad groupings of business will be discussed separately.

Each section of this chapter will step through the perspectives of the various stakeholders according to their general order in the value chain. The following provides a simplified description of stakeholder functions and interactions within the chain:

- The chemical producers create the basic chemicals, blends of chemicals, and materials (e.g. plastics and polymers for product 
casings, plating chemicals, solvents, paints and coatings, and metal finishes) that form the basis of mobile phones and PCs.

- The above materials are supplied to the large web of components manufacturers, who make everything from moulded plastic casings to disc drives and circuit boards. There are commonly several tiers of suppliers in between the chemical producers and the brand owners.

- Components are assembled into finished products for brand owner companies who then sell the final products to other businesses and/or consumers.

- NGOs and consumer interest groups are active along this chain, for instance in informing brand owners about appropriate and safe selection of chemicals, and in helping consumers obtain the information they need to safely use or dispose of the final product.

Two additional notes about the above functions and interactions should be mentioned: In general, the chemical producers and components manufacturers supply chemicals, materials, and components for a much wider range of products than just mobile phones and PCs. Also, some of the aforementioned actors interact mainly with the actor adjacent in the supply chain, while others, in particular the brand owners, may be involved in numerous stages of product development and disposal.

All of the company representatives interviewed stated that their companies not only comply with regulations, but also go beyond them in restricting certain chemicals from their products. Thus, the information systems discussed in this section are not only regulatory-based, but also include voluntary systems that were created internal and external to the participating companies. The chemicals or chemical classes most commonly mentioned by company representatives as being of concern in their products were: lead, mercury, cadmium, hexavalent chromium, brominated and chlorinated flame-retardants, and PVC. Development of halogenfree products was a common goal among participating companies.

\subsection{Needs and access to CiP Information in the product chain}

The company representatives participating in this research said that their companies try to stay ahead of global regulations and voluntarily restrict chemicals they think may be regulated in the future. Because so many non-regulatory information systems exist from which they can try to predict future restrictions, it is not surprising that there is no one set of information that most actors find relevant and valuable in deciding which chemicals to restrict. Most interviewees mentioned a unique set of information systems they considered to be valuable. There was also some disagreement among actors about the value of certain systems. 
Several interviewees from various positions in the supply chain noted that there are many lists and systems developing in non-Western countries such as India and China. While these lists and systems are not completed or operational information systems that can be described in this report, it is important to note that such systems are evolving, and companies are monitoring the situation so that they can be prepared for possible restrictions or requirements that may emerge from these economies in transition.

Companies use $\mathrm{CiP}$ information in many ways. One of the most common and important uses cited by interviewees was to keep up to date on the latest information on chemical hazards and risks because it is "good for business." These companies prefer to stay at the forefront of the industry where they are able to develop new alternatives and substitutes of high quality within an adequate timeframe, rather than reacting to new regulations once they are enacted. Generally, the companies participating in this research adopt voluntary restrictions as opposed to waiting for regulatory action that may require restrictions, and they seek out available sources of information that will help them determine which chemicals may be of concern in the future. In the words of one components manufacturer: "It is usually more cost effective to be proactive than it is to wait until a requirement lands on your desk. So we try to be strategic. It's as simple as that." Such a strategy may also provide a point of differentiation from the competition by eliminating problem chemicals from their products before others do. In addition, seeking out information on chemical hazards may allow companies to restrict chemicals that they perceive to be dangerous, regardless of the potential for regulation.

A few interviewees from different locations in the supply chain mentioned that there is an "informal" type of information system or information exchange that occurs within the electronics sector through a networking approach. Actors at various points in the supply chain meet to talk about where the industry is heading in the coming years and which chemicals and materials will be needed or should be developed for future products. They also participate in standardisation committees and other industry associations to keep up-to-date and/or help guide the direction of the industry. This future planning or road mapping may occur among many actors from different companies and organizations throughout the value chain, between only a few specific actors, or within a single company. It can take many years to develop a new product or modify an existing one, so some companies see networking within the value chain as critical to their business, both in understanding other value chain actors' product needs and in learning about which chemicals should be avoided in products. 


\subsubsection{Producers of chemicals, chemical mixtures, and materials}

The producers of chemicals, mixtures, and materials are near the upstream end of the supply chain, so the emphasis here is on how they generate CiP information and make it available to downstream actors in the value chain. Some of the interviewees from this category stressed that they buy many of their basic chemicals from upstream actors and blend these chemicals into proprietary formulations; thus, they are not always the first actor in the value chain.

Chemical producers described two main ways of communicating information about their products. First, there is direct communication with their customers about specific products that the customers are interested in or have purchased. Information provided at this stage is referred to as a "push" type of information, since specific, detailed information is directed from the chemical producer to a particular customer. The second form of communication is not directed toward any particular actor, and is referred to as a "pull" type of information. Information communicated by this route is freely available to the public, so any person or group who wants it can obtain it, often via the Internet. Regarding dissemination of this information to interested parties, some interviewees noted that they do not know how far the information they provide to their direct customers travels down the supply chain, or exactly who uses the "pull" type of information.

The chemical producer's main communication is often with its first customer downstream in the value chain, e.g. the electronics components manufacturers who make items such as shell cases, but there is occasionally communication with actors farther downstream. For instance, retailers sometimes have questions about chemicals used in final products.

The chemical producers emphasised that it is very important to them that their immediate downstream customers have a full understanding of how to safely use and handle the chemicals or products they receive. The producers said that they risk assess every chemical or product they sell to create a set of acceptable uses in which the chemical or product will be safe. They then gain an understanding of each immediate customer's proposed use of the chemical or product before selling it to ensure safe use. Some producers also have web pages that their customers can access for specific information on the chemical products they purchase.

One company said that each of its chemical products for the electronics sector is designed for a specific use and there are rarely alternative applications for products. They require their distributors to sign agreements that the chemical products will only be sold for the uses that have been safety assessed, and they audit the distributors to ensure that chemicals are not being sold for unintended uses. This company said that there is not much of an ability for unintended uses of their products to occur in the electronics sector, so they have never had a situation 
where they have had to stop sales on products that were being used inappropriately. Further, this approach is tied to the company's business strategy because it hurts the business to have to pull products off the market or re-qualify to win a customer's business.

There are times when a customer may need information about a chemical mixture or product beyond what is typically provided to customers by chemical producers. If the desired information is proprietary or pertains to material formulae, chemical producers have different ways of dealing with such requests. Some will provide the requested information to the customer, provided that the customer signs a nondisclosure agreement, NDA. The producers said that this gives them some assurance that the customer will not simply provide the proprietary information to another producer and ask them to make the chemical product for a lower price. Others interviewees, however, said that they will not reveal the complete details of their formulations, but do share all risk information with customers. This approach can involve revealing most of the high-exposure or high-proportion chemicals, but describing the minority chemicals in generic terms.

Producers gave several examples of the "pull" type of information that is available to anyone who wants it and can find it. One example is the safety summaries provided through the GPS, which is written in language that is accessible to the layperson and reflect the information that the chemical producers consider to be "all relevant information on a chemical or a product." Safety summaries include information such as chemical identity; common and acceptable uses of a chemical or product; benefits of a chemical in specific applications; strength, resistance, and insulation properties; toxicity; transport, storage, and handling recommendations; recyclability; and levels of exposure expected in different applications. These summaries are more general than the specific, detailed documents provided to customers. Currently, the safety summaries are available only in English, but the goal is to eventually provide them in all languages. Interviewees also described "product finder" types of databases, which are also freely available on company websites and provide information about chemical properties and acceptable uses of chemicals and chemical products.

Material Safety Data Sheets, MSDS, are another main tool that producers of chemicals and chemical products use to communicate information about their products to customers and the public. MSDS can contain information about acceptable uses, toxicity, handling and storage, and physical properties. MSDS come in PDF or hardcopy, and are made available by chemical producers in every one of their customers' languages. They are provided to customers with purchased chemical products and are freely available to the public on some producers' websites.

There were dramatically differing opinions among producers and downstream users about the value of MSDS to stakeholders in the value chain. One chemicals producer said that MSDS are generally useful in 
providing good, concise information, but are very technical and not meant for the layperson. Interviewees from another producer agreed that MSDS are written for a technical audience rather than a lay audience. In addition, they said that MSDS provide more information about hazards than uses and potential exposure, and are attempting to satisfy the information needs of too many different audiences, with an unwieldy result which is not user-friendly. Downstream users called MSDS "inadequate" at best and "useless" at worst. Another downstream user explained that while MSDS can be useful in some handling and manufacturing issues, they are "meaningless for materials selection," and "completely missing the point." Despite such opinions, MSDS are widely available and sometimes the only information available about chemicals and chemical products, so many downstream users require that their suppliers provide them.

A materials producer said that other information systems that are used in design of its products are the restricted substance lists (RSL) provided by some of its customers. Sometimes these lists are from actors a few tiers up in the supply chain instead of the producer's direct customers. Also, particularly proactive brand owners will develop lists of substances they would like to phase out in the future, and seek out communication and collaboration with trustworthy materials suppliers to develop alternative materials that do not contain the undesired substances.

One supplier explained that it uses its customers' restricted substance lists, in addition to industry, government, and NGO lists, to create its own internal restricted substance list. This list is continuously being updated, and contains information about the chemicals they use as well as the ones they want to avoid. Thus, these information systems become a part of the materials supplier's policy on hazardous substances, which has three parts: (1) Reactive compliance, where chemical ingredients are removed from products because of legal requirements, such as those found in RoHS and REACH, (2) Proactive compliance, where certain chemical ingredients or degradation products are added to the company restricted substance list before they become legal requirements, such as the case with halogenated flame retardants, and (3) Proactive differentiation, where substances and/or materials that have a clear toxicological advantage are developed and offered to the industry as substitutes for conventional substances or materials.

In the last case, innovation of new formulations that do not contain hazardous substances occurs based on the perceived needs of the industry for such substitutes or on the impossibility of substitute products to eliminate the associated concerns (e.g. in the case of PVC).

The producers of chemicals, mixtures, and materials said that they do not receive questions from recyclers or other end of life waste handlers about chemicals in electronic products. One materials supplier, however, does work with brand owners to design their products for easy disas- 
sembly and recycling, including the ability to regrind plastic materials that can be sold back into the supply chain.

\subsubsection{Downstream Users: Components Manufacturers and Brand Owners}

Downstream users of chemicals have additional information systems and strategies that they use regarding CiP information. This group aims to comply with all relevant regulations. In addition, the representatives from the companies interviewed also said that they strive to go beyond regulations by voluntarily restricting certain chemicals that may be used in the electronics industry. A chemical may be voluntarily restricted for a variety of reasons, including negative public perception, a real threat of harm, or likely future regulation.

The relevant regulated and voluntarily restricted substances are typically found on companies' restricted substance lists, RSLs, which are usually updated annually, and often include substances that are banned or restricted from products as well as those that are in the process of being phased out. Each of the participating companies consult many of the information systems described in chapter 4 in deciding on which substances to include in their RSLs; each company uses a unique combination of non-regulatory information systems in deciding which substances to voluntarily restrict. One brand owner company said that it also performs a life cycle analysis on its products to help determine which chemicals to put on its banned and restricted lists. This analysis includes the acknowledgement that recycling can occur in substandard ways/conditions in some contexts, and products are designed to be safe based on this reality. Some RSLs are publicly displayed on company websites, but most are only shared with the companies' suppliers. It is likely that no two company RSLs are identical.

As one example, a components manufacturer listed the following information systems and sources as being important in helping it identify chemicals for its RSL:

- International conventions

- Laws and regulations

- Customer RSLs and other specifications and requirements

- Industry standards

- Information about possibly hazardous material contents provided by third-party organizations that inspect, verify, test, and certify materials

- NGO reports regarding hazardous substance control

- Reports from other experts or institutes dedicated to chemicals management 
The company has developed systems that are available on its website to train suppliers to use its RSL and to help them to understand relevant regulations such as RoHS and REACH. Suppliers can also access the RSL and other information about product requirements on the company's website.

To control the content of their products, downstream users usually operate in one of two ways:

1. An RSL is sent to all suppliers, who in turn must declare that none of the listed substances are contained within the products that they are supplying to the company that issued the RSL. If the suppliers are using a substance on the RSL, the downstream user may set a deadline by which its use must cease and ask what substance will be used as a replacement. Downstream users sometimes assist their suppliers in finding replacement substances. Periodic random testing is also used in parallel with the RSL to verify that the undesired chemicals are not in the products. The RSL is an example of a negative list; negative lists provide information about specific chemicals that must not be used in materials or products.

2. In addition to RSLs, two of the interviewed companies also want full materials disclosure of the chemicals used in all materials and components supplied to them. Both companies use the IPC $78-1752$ standard in collecting the data from their suppliers. When claims of proprietary information hamper this effort, the downstream user may sign a NDA with the supplier. This approach allows the downstream user to know what their products do contain, rather than knowing only what they do not contain. Importantly, it also allows downstream users to quickly assess their product ingredients and identify problem chemicals when new research or regulations emerge, without having to question multiple tiers of suppliers. Full materials disclosure is an example of a positive list; positive lists provide complete, or near complete, information on the content of chemicals in materials or products.

While approach 1 above is common among downstream users, use of approach 2 is more controversial, and interviewees were split in their opinions of its benefits. Opponents, e.g. most of the larger companies participating in this study, say that collecting full materials disclosure from all their suppliers is an overwhelming and expensive effort, which does not necessarily translate into safer products; having a list of chemicals contained in products is meaningless if one does not also have information about the hazards or risks of those chemicals in the given applications. Plus, detractors say, the company requiring full materials

${ }^{78}$ IPC was founded in 1957 as the Institute for Printed Circuits. As more electronics assembly companies became involved with the association, the name was changed to the Institute for Interconnecting and Packaging Electronic Circuits. In 1999, IPC changed its name from Institute for Interconnecting and Packaging Electronic Circuits to IPC. See http://www.ipc.org/ 
disclosure can never be sure that the collected information is completely accurate because it is not verified.

In addition, some suppliers are wary about revealing their proprietary information to downstream companies, which would be required for full materials disclosure. So, these suppliers might not actually provide proprietary information in the set of data that they disclose, making it somewhat less than full materials disclosure. For all of these reasons, opponents of full materials disclosure say that they would rather spend their resources on eliminating target materials from their products and supply chains rather than on trying to achieve full materials disclosure.

On the other hand, interviewees from two companies that are on the smaller end of the spectrum compared to the others participating in this study, see full materials disclosure as the way forward. Proponents make the following argument for full materials disclosure: Standardised, consistent data reporting requirements, and use of standard formats such as the IPC-1752, will simplify reporting requirements and reduce costs long-term for the entire industry. Electronic data exchange will speed the process of information reporting as well. Standardisation will also improve data quality, since suppliers can focus their time and resources on providing one standard set of information on their product(s) instead of splitting their time and resources between several sets that are required by different companies. Regarding suppliers' proprietary information, proponents firmly believe that any disclosed proprietary information can be fully protected and nondisclosure agreements can be respected.

On a related note, several downstream users said they would like to see an agreed upon definition in the industry of what actually constitutes proprietary information. Based on one interviewee's experience, some materials suppliers consider all of their formulations proprietary, even ones that are standard in the industry. As a result, downstream users may have very little information about which chemicals comprise their components or final products.

Downstream users were split in their opinions on the adequacy of current information systems, and several explained that while the current systems have much room for improvement, they "make the best of it." Participants from four companies specifically commented on whether or not the current information systems met their needs; two said it generally did, and two said it did not. Of the two in the former group, one uses a combination of full materials disclosure and random testing of components and materials to manage chemicals in its products, and the other uses an RSL and testing requirements. The reasons why the two other companies described the systems to be inadequate are included in section 5.4.

Regarding transfer of and access to information in the supply chain, several interviewed downstream users said that they passed on as much information as they received when the next actor in the chain requested 
it. Sometimes this required NDAs if the transferred information included proprietary information. Other downstream users focused more on transferring only the information about hazardous or regulated substances.

Several brand owners complained that they did not get accurate, complete, or sufficient information from their suppliers. Reasons given for this were that the suppliers did not understand what the brand owner was asking for, they did not actually have the information or did not understand how to provide it, or the requested information was proprietary. One brand owner also complained about the lack of information provided about chemical hazards by the chemical producers. The interviewee added that he did not think that chemical producers know how their products are being used farther downstream, and that there is a significant disconnect between the chemical producers at front end of the supply chain and the brand owners at the other end.

One of the brand owners interviewed described that an important issue is whether the data submitted by their suppliers is reliable. The company checks this data internally, measuring the data by "hitrate", meaning how much data submitted by suppliers is accurate with the data analysed (=hit). As it is impossible to check all information, a hit-rate of more than $80 \%$ is regarded as reliable information. Less than $50 \%$ is regarded non-reliable. In order to increase the hit-rate, the company provides support and training programs to companies within the group. However, there is no support program provided to external suppliers. Accordingly, low reliability of data is an issue.

All downstream user interviewees said that they provided all legally required information, and in some cases much more, to waste handlers and recyclers. However, the interviewees were sceptical that much of the information is actually used. The questions that recyclers ask tend to be at a very high level about basic materials content. A few downstream user interviewees said that in their many years in the industry, they were not aware of a recycler asking any questions about particular substances contained in their companies' products. Another brand owner said that recyclers have asked about metals contained in certain products that could make recycling difficult, basic information that the brand owner can easily provide.

All of the brand owners communicate with the public, customers, retailers, and other stakeholders about substances in their products through their websites. Several companies have posted MSDS and other information about how their products comply with regulations or voluntary restrictions related to chemicals. Some have developed userfriendly pages, such as environmental declarations, which answer typical questions they get from the public, their customers, and NGOs. 


\subsection{Consumers needs and access to CiP information}

The NGOs and consumer interest groups who were interviewed for this study described consumer access to $\mathrm{CiP}$ information as a dire situation. One interviewee said that the situation might be slightly better in the case of consumer electronics because, though most consumers are primarily interested in features, electronics magazines also include information about environmental and safety concerns in overall product assessments. Since electronics products tend to be more expensive than other daily use items, consumers might be more likely to seek out product reviews in electronics magazines, and will also see the information about environmental and/or health concerns.

In addition to information presented in electronics magazines, environmental excellence schemes such as the EU Eco-label may provide a useful "shortcut" for consumers to make informed product choices. The appropriate eco-label on a given product will signal to consumers that they do not need to look for information about possibly hazardous chemicals in the product. However, interviewees pointed to a current widespread problem of green-washing, which can make a dependence on ecolabels less than reliable for identifying products without chemicals-related environmental or health concerns.

RAPEX, the EU's rapid alert system for dangerous consumer products, was also mentioned by consumer interest groups as a helpful CiP information system. The number of RAPEX notifications related to chemical risk in consumer products continues to increase. However, this system was designed more for authorities and NGOs to know if certain products should be recalled or taken off the market due to serious health or safety risks than for use as a consumer tool for product selection. Further, consumers cannot access much of the information available on RAPEX.

REACH, on the other hand, was mentioned by two interviewees as being a disappointment. These interviewees do not feel that it is a useful information system in protecting consumers from hazards in products because they think its procedures are too lengthy and complex, and dissemination of chemicals data has not been as wide as was hoped.

Consumer interest group interviewees feel that consumers need clear, credible, up-to-date, easily available, and comparable information in order to make informed choices about the products that they purchase and use. This information can be provided in different forms, such as through warnings, instructions for use, third party labelling, and a list of ingredients. If hazardous chemicals are included in products, one interviewee also specified that consumers should have access to information about the function of the chemicals, the quantities in which they are used, if safer alternatives exist, and the results of any toxicological studies that have been performed, along with disclosure of the studies' authors. 
A fundamental problem is that most consumers expect products to be safe for their use and for the environment and assume that they are. If information about chemicals or possible product hazards is not given at the point of sale, consumers will not typically look for it. It is a burdensome task for consumers to find information about chemicals in products, and only the most informed consumers will actively search for chemicals-related information. The consumer group interviewees emphasized that consumers should not be obliged to inform themselves about product dangers before making purchases; information about dangerous products needs to become more transparent for consumers.

Interviewees from consumer organizations identify greenwashing as a significant problem today. The organizations are working on addressing this issue, but it is complicated; it is difficult to set guidelines and definitions about what constitutes a green claim or a misleading claim. Further, it is not easy to go after companies that make false claims.

The consumer organizations described two additional problems related to green claims. If consumers see an eco claim or eco label on a product, many will, perhaps incorrectly, automatically assume that chemical hazards are not a concern with the product. Also, many companies put statements such as "RoHS compliant" on the packaging of their products. This does not make any sense to the consumer; plus, because it merely communicates that a product meets the legal minimum requirements that it should nonetheless fulfil, it is not information that needs to be communicated to the consumer. When companies want to inform consumers about chemicals-related product safety, they should think about what kind of information actually makes sense to, and is appropriate for, the consumer.

As mentioned, since consumers assume that most products are safe they generally do not actively seek out CiP information.

\subsection{Gaps and obstacles to CiP information exchange}

Interviewees discussed numerous gaps and obstacles to exchange of CiP information. The main ones are discussed in the sections below.

\subsubsection{Proprietary information can disrupt flow of information in both directions}

Proprietary information was discussed in all interviews, and was often mentioned as an obstacle to flow of CiP information. Interviewees had strong opinions on proprietary information, and it was a controversial topic. While no consensus among stakeholders was reached for this report, the varying opinions are presented here to illustrate the differing views on the topic. 
Several companies, especially those toward the front end of the supply chain, said that protection of proprietary information is essential; it often takes them years to develop a chemical formulation or material, and revealing the whole formulation would allow competitors to simply copy their work without expending any resources on R\&D. It is this recipe or formulation that differentiates a company and its products from those of competitors and gives a company its competitive advantage. Another interviewee claimed, however, that a determined competitor could figure out a product formula using modern techniques of laboratory analysis.

Downstream users saw proprietary information as an obstacle to flow of chemicals information in the supply chain, saying that some of their suppliers refuse to submit information on chemicals for reasons of protecting proprietary information. Some downstream users said that this protection sometimes extended to basic formulations that were standard in the industry, and others suspected that claims of proprietary information were sometimes used to avoid filling out long forms for complex devices. Downstream users were sympathetic to upstream actors' unwillingness to disclose proprietary information to varying degrees, and they described different ways of dealing with proprietary information.

Some downstream users accept the fact that they will not get certain information from their suppliers, while others will sign NDAs with willing suppliers to get as much information as they can about product hazards and/or content. Another strategy is to require suppliers to verify that they are not using any of the chemicals on the downstream user's specification, which may include thousands of chemicals. A few downstream users emphasized the importance of forming close relationships with suppliers; based on their experiences, establishing trust can enable the downstream user to get the information they need, which could mean signing an NDA or obtaining other information that demonstrates product safety. In cases where a supplier's information is so sensitive that the supplier would be seriously disadvantaged if its formulation was leaked, another option is for suppliers to release the ingredients but not the formulation.

A chemicals producer noted that proprietary information could also be an obstacle in the other direction. This interviewee's company wants to understand how its chemicals are being used before selling them, but some downstream users claim their uses as proprietary. This can cause communication difficulties, but the chemicals producer can usually get enough information about the use and exposure to be able to confidently assess whether or not the downstream user's use is acceptable.

One interviewee explained that in the past, chemical identity and product content was not very important. Product designers focused more on function, cost, and availability of materials, and this combination of elements was what manufacturers claimed as their intellectual 
property. But now downstream users need CiP information, and a system needs to be established that allows companies to maintain their competitive advantages, while still providing information on chemicals used in products. A first step is to narrow the definition of what is "proprietary," so that the larger issue of adequate information flow can be addressed.

\subsubsection{A global standard for CiP information is needed}

Several companies stressed that a global reference for them to use in design of products would be incredibly useful and would lead to significant cost savings across the industry. Currently, discussions about chemical use are country-by-country, and it is difficult for global actors to keep up with the evolution of chemicals policies around the globe. A common standard for chemicals use and information transfer would simplify design, production, and distribution of electronics. Some interviewees noted that they thought the United Nations would be an appropriate organization to design such as system.

A few interviewees mentioned that some stakeholders are expecting REACH to provide direction for the global electronics sector, but that REACH does not actually serve that function. One interviewee explained, "REACH covers a very small fraction of what needs to be covered in terms of toxic chemicals and reporting on non-toxic chemicals in products. While it is a step in the right direction, it does not have application in a mass production environment."

If a global standard were to be created, an obstacle that must be overcome is that different actors in the value chain have different expectations as to what the standard would include or exclude. Even in these interviews, it was apparent that different actors have dramatically different ideas about which chemicals should not be used in products, how much information should be provided about product content, etc. For instance, one downstream user that is often at the forefront of phasing out undesirable chemicals from its products said that its proactive approach is frowned upon by some other industry actors that are not as enthusiastic about adding additional substances to their RSLs. Another downstream user stressed that the level of protection regarding allowable chemical use in products should be targeted at pregnant mothers, a level that other actors may not find appropriate. This interviewee also suggested that information about a chemical's toxicological profile should be provided to users in the supply chain. The point is that a global standard would need to have the support of at least a reasonable fraction of industry in order to be effective. 


\subsubsection{Global supply chains are huge and complex}

Several downstream users, especially brand owners, discussed the vast and complex nature of their supply chains. Brand owners often do not design and create all of their product components, and they may have several tiers of subassembly manufacturers involved in production of their goods. Thus, it may be difficult for them to control all of the chemicals used far upstream in the chain. An interviewee from one company gave a hypothetical example where a supplier using a hazardous chemical could be five or more tiers upstream in the supply chain, and information about use of this hazardous chemical may not be transmitted all the way back to the brand owner. Another brand owner commented that he does not think chemical manufacturers know how their products are being used farther downstream or in what final products they ultimately end up. He is not convinced that the hazards are understood for all chemicals in their final applications.

As related concern, a few downstream users said that even if they ask their suppliers for information about the chemicals contained in the supplied materials or components, there is no guarantee that the information provided is accurate. Companies were mixed in their opinions on whether testing of final products for certain chemicals is the best approach to verify information provided by suppliers. Some companies rely on testing, while others think it is a complex and costly procedure.

\subsubsection{Information can get lost between ODM and OEM}

Another factor to take into account specifically for the electronics industry is the emergence of the Original Design Manufacturer (ODM) model. An ODM is a company which designs and manufactures a product which is specified and eventually branded by another firm for sale. ODMs have grown in size in recent years and many are now sufficient in size to handle production for multiple clients, often providing a large portion of overall production. A primary attribute of this business model is that the ODM owns and/or designs in-house the products that are branded by the buying firm. This is in contrast to a contract manufacturer, CM.

This development can have an impact on the flow of information, as it can be lost between the ODM and the Original Equipment Manufacturer (OEM), or the ODM can choose to not forward all/parts of information due to resource or proprietary information issues. Given the size of ODMs they are increasingly have more power and OEMs often lack the power to demand information related to substances, as this is a cost/resource-intensive activity for the ODM. 


\subsubsection{Information does not easily or reliably flow through supply chains}

Regardless of whether a company is trying to manage chemicals using an RSL or full materials disclosure, there are many challenges associated with obtaining reliable data from the supply base. First, there is no guarantee that needed information on chemicals or materials will actually flow downstream, and there is no good way of collecting this data from suppliers. IPC-1752 is widely used, but it is currently just a data format. There is not a means for downstream users' database systems to communicate with those of actors upstream in the supply chain - data is usually transferred through a process in which downstream users manually enter into their own systems the data they receive from their suppliers.

The next challenge is getting accurate and reliable information from the suppliers; some suppliers are not used to having to provide information downstream and may not understand what the downstream user is asking for. Errors can creep into the data transmission process since people instead of databases are transferring the information at every step. And since many downstream users have their own customized forms, rather than using IPC-1752 or some other standard, the format and requirements may not be familiar to the supplier.

Many companies feel obligated to pass on chemicals-related information to the next actor in the supply chain, and some of these downstream actors require it. Often, however, this information is incomplete or undefined, and information pertaining to chemical content or hazard information, or both, are often lacking for materials and components.

\subsubsection{Operating in a system that is constantly evolving and changing}

As interviewees from one company explained, neither they nor their competitors know for certain what is coming next in terms of chemicals legislation or new research about chemical hazards. They are operating in a system where new information is continually being introduced by various actors in the value chain and chemicals regulations are evolving around the world. They said that companies must decide whether to be leaders or laggards, either acting on uncertain information reacting when regulations are enacted. Leaders must stay abreast of research on chemicals and materials, upcoming needs in various market segments, and possible future legislation. The question everyone in the value chain has is, "What chemical or substance will be regulated next?" 


\subsubsection{Product developers and materials scientists are not trained in environment and safety}

Product developers and materials scientists have historically been focused on performance, price and function. Information systems have developed around these three elements. Environmental performance and safety metrics are relatively new, and training/education has not kept pace with the demand for these new areas of knowledge. Currently, there are few universities that provide degrees related to the environmental performance of products, so product and material designers are typically not learning about environmental and safety aspects of design. Thus, lack of education in safety and environmental performance of products is a fundamental problem, and it will likely take some time to embed this new way of thinking in the supply chain.

\subsubsection{Companies can give information to e-waste handlers in developing countries, but these handlers may not understand it or be able to use it}

Companies can give information about chemical content to e-waste handlers in developing countries, but the handlers may not understand it or be able to use it. Even if these e-waste handlers know about the risks associated with their work in product disassembly and extraction of valuable materials, they may have no other work options and need the work to survive. Also, they may not have the resources to improve the ways they are currently handling e-waste.

\subsubsection{More information on chemical uses and safer substitutes is needed}

A few interviewees discussed information that could be helpful to downstream user companies. Two brand owners pointed out that many of the existing information systems used in the electronics industry fall short in two main ways. First, many of the lists of undesirable chemicals do not contain any indication of how the chemicals are used or in what types of products one might find them. For this reason, downstream users cannot easily use these lists to remove undesirable chemicals from their products. Second, the currently available lists do not provide recommendations for replacement chemicals or materials. Thus, the downstream user does not know if the chemicals or material they use as a replacement is any better than the original substance. 


\subsubsection{Some actors may not know where to look for "pull" types of information, and others may not be motivated to get it.}

Some chemical producers and downstream users provide chemicalsrelated information about their products that is freely available on the Internet. However, actors in the supply chain may not know where to look for the information, and others may not be motivated to find it. One chemicals producer mentioned that this type of outreach could be really difficult to achieve. Also of importance is providing this information in a way that people can understand and use it. Sometimes information on toxicity, handling, and storage, for instance, can be provided at a technical, complicated level that is too technical and complex difficult for lay people to understand and use properly.

\subsection{Potential means of addressing gaps and obstacles}

Interviewees had suggestions for addressing many of the gaps described above. These ideas are described in the following sections.

\subsubsection{The scope of "proprietary information" should be narrowed and defined}

Based on stakeholder comments in the interviews, there is a clear need for an agreed upon scope and definition of proprietary information. Numerous stakeholders mentioned proprietary information as a major obstacle to flow of CiP information. If claims of proprietary information are to be respected, the non-disclosed information should be restricted to that which is truly proprietary, and not an excuse to avoid the timeconsuming task of information provision. Overuse and misuse of proprietary information claims is not a new issue; it has been a topic of discussion regarding REACH as well as reform of the US Toxic Substances Control Act.

\subsubsection{A global standard and platforms for sharing information are needed}

Most of the companies participating in this study discussed a need for global standards for chemicals use and easier access to data on chemicals of concern. Sifting through all of the available information about chemical hazards and risks and trying to determine what is important is a time-consuming, resource-intensive and difficult process; a data pool or global system where companies can easily obtain all the needed and relevant chemicals-related information would be helpful. A harmonized global approach in the electronics industry could dramatically simplify product design and production. It would also bring laggard companies 
up to speed on chemicals restrictions since supply chains would be affected if/when the largest players adopted such a harmonised approach.

Two interviewees emphasized that in crafting any common information systems or standards, care should be taken not to over-specify product design. This can hamper innovation and can lead to unnecessary use of chemicals. For example, a blanket specification that flame retardants be applied to certain product types would lead to unnecessary chemical use if a company chooses to innovate and substitute new nonflammable materials for traditional ones.

Another interviewee said that it is important not to include chemicals that are not used in the electronics industry in the standard because this could require companies to do due diligence work to prove that those chemicals are not in their products, which takes a lot of time and effort.

Interviewees from one company that works in several sectors besides electronics explained that sharing information across sectors would be useful as well. These interviewees would like to see creation of common platforms where multiple industry segments could convene to openly discuss chemical issues and share information. Such platforms could be conferences, conference calls, or any regular forum that provides the opportunity for open exchange of information. The interviewees referenced the automotive industry's IMDS/GADSL system as an example of an industry sector's information system that has been successful. ${ }^{79}$

The recommendations interviewees in this study made regarding the details of a possible global standard fall into two main categories. These are discussed below as the Negative List approach and the Full Materials Disclosure approach.

\subsubsection{Negative List approach}

This approach has a goal of simplifying and harmonizing the current approach, giving companies fewer chemicals on which to report. The companies that would prefer this type of approach generally are not supporters of full materials disclosure, and want to focus on restriction of only a few chemicals at a time. Many of them also said that there are too many lists circulating, and they cannot keep up with all of them. As one interviewee noted, “We can't overwhelm suppliers by asking them if they use 300 substances all at once. We won't get accurate answers back. But if you ask about five at a time, that is more manageable for them." Similarly another interviewee suggested that the way forward should avoid use of the present "substance of the day" approach, which he thinks is neither effective nor efficient.

Companies had different ideas about what form a "negative list" type of system would take, but the general idea was to work with absence decla-

79 The IMDS/GADSL system is described in detail by Massey et al. 2008 and Kogg \& Thidell 2010 
rations. Suppliers would be provided with forms on which they could declare that they are not using any number of chemicals and/or that they are below certain levels of these chemicals in their products. Such a system would be simple and would allow companies to protect their proprietary information. The list of restricted chemicals on the forms for suppliers could be managed by an international body, such as UNEP.

Another company described the ideal approach as a "United Nations RoHS" which would be similar to the current EU RoHS Directive, and would be the only regulation or standard with which companies would have to comply. It could either be specific to electronics products or could include all products. Companies would have to indicate that their products do not contain certain chemicals, or that chemicals are above or below certain concentration thresholds, without having to prove that a multitude of chemicals are not present. The system could be harmonized for use of common materials, common exemptions, common testing, and mutual recognition of testing from international labs. Common IT tools and other information schemes could also be developed and/or endorsed by the UN. The interviewee said that having one global, unified process/system for everyone would be less work for companies and more straightforward, and could result in substantial cost savings for governments and industry.

Further, this interviewee said that a single system with its list of substance restrictions could be updated every few years with a few new chemicals. He thinks that a simple system that is periodically updated could be easily understood by all companies globally. Plus, he says, everyone would know what the requirements are and suppliers could not claim to not understand their compliance obligations. In addition, from a trade standpoint, the same product could be shipped to and sold in any country. A unified global standard would force all companies to design to the same levels of safety instead of having different standards for different countries based on what is legal. All products would be consistent with one set of rules, dramatically simplifying shipping and distribution logistics. Enforcement would also be easier since all companies would be designing to the same requirements.

In addition to a common "banned/restricted" list, another company would like to see an "approved" list, which specifies which substances can be safely used in electronics. However, the interviewee acknowledged that this would be a "huge and very difficult undertaking."

\subsubsection{Full Materials Disclosure approach}

Other companies advocated for a common system of full materials disclosure and mandatory laboratory test reports for verification of product contents. These companies explain that if all companies in the supply chain would adhere to one standard data format and provide full disclosure of their materials and products, high-quality, reliable CiP data could 
be more easily exchanged. Suppliers could put their time into creating only one accurate, credible, and complete data set (instead of several poor quality ones) that would be used to satisfy all customers. These proponents believe that this approach would tremendously improve the quality of data transmitted in the supply chain.

To make such a system work, clear standards for data format must first be adopted. As one interviewee said, "Standards are going to be required to drive transparency and credibility - otherwise, we can't communicate well." An example of a standard format that could be used is the IPC-1752, and software could be developed around the agreed upon format to allow for electronic exchange of the information. Companies could then receive and provide full materials disclosure data using this common system. Driving standardisation will allow actors throughout the supply chain to collect similar data and have better transparency and compliance. One interviewee said that such a system of exchanging materials content data will also lower costs and allow data to be shared much more quickly.

An example is provided here to illustrate how one company effectively communicates full disclosure of components without giving away its suppliers' secrets. This components manufacturer's successful system uses a small, isolated, quasi-third party to verify and review all incoming data. The system's structure makes it very difficult for these data experts to leverage any of the incoming data for other clients, and allows suppliers to be more confident that their proprietary data can be protected. For downstream customers who want full materials disclosure, the components manufacturer is able to provide a substantial amount of information. For those customers with whom they have NDAs, chemicals within a product can be reported without linking them to individual formulations or materials. This approach masks suppliers' proprietary formulations and prohibits the ability to reverse engineer formulations.

In addition, this components manufacturer does not see full materials disclosure as a detractor to a company's competitiveness, and is not aware of any problems associated with collection of full materials data; leaking proprietary information is bad for business. Still, transitioning to full materials disclosure can be a tough hurdle for some suppliers. But in the components manufacturer's experience, once suppliers understand the approach and how their formulations will be maintained as proprietary, they will provide the data.

Another company added that it was very hard to get materials declarations from suppliers at first. But now the suppliers have a better knowledge of their materials and components and do a better job; the quality of the data is improving daily. In addition, they are seeing increasing numbers of companies using the IPC-1752 standard for providing data, and trade secrets are becoming less common. 


\subsubsection{Changing the paradigm: the "Screening Hub" model}

One interviewee said that, ideally, the industry should be striving toward "full materials disclosure, where every supplier is openly sharing chemical constituents of every product that they ship." However, this interviewee does not think that the full materials disclosure approach is "practical, timely, or achievable in the next ten years." Not practical because there are currently too many claims of proprietary information, and manufacturers will not disclose this information as would be required for real full materials disclosure. Not timely because large brand owners have complex supply chains for products that are on six month turn-over schedules, and it would difficult for them to keep up with full materials disclosure when there are thousands of chemicals per product. Not achievable in the next ten years because it would require a massive shift in industry to a major, common reporting system. Further, based on this interviewee's experiences, even the chemicals-related information disclosed by trustworthy suppliers about their products is sometimes found to be incorrect upon testing; the problems usually result from the supplier basing its assessment on the wrong test method, provision of false information within the supplier's supply chain, or contamination of the product.

As a possible solution to the above issues, this interviewee has developed a conceptual model of a system that would give downstream users confidence that the chemicals they are using are safe for their desired applications, without requiring producers of chemicals and materials to reveal their proprietary information. The interviewee said that the approach would "incorporate a conscious decision-making process about which chemicals are going to be used and how, which is absent in every product today."

The proposed approach would completely reinvent previous CiP information system models with the introduction of an independent screening hub for confidential screening and evaluation of suppliers' chemicals and materials. Downstream users would have contractual requirements with their suppliers to use the screening hub as a condition of doing business together. The process would start with a chemicals or materials company paying the screening hub to evaluate a chemical or material it has created. Independent toxicologists at the screening hub would evaluate the safety of the chemical or material for each of several different likely end uses. Then the downstream user can see the evaluation of the chemical or material for the use it is interested in, and decide whether or not the chemical or material is acceptable/suitable for its intended use. Alternatively, the downstream user might have a different use in mind from the ones that were evaluated. To keep this use confidential, it can pay to have the screening hub evaluate the chemical or material for the alternative use. The screening hub would use a non-profit structure and would include administrative levels, an arbitration committee, a legal body, etc. 
The objective of the system described above is for downstream users to have enough data to make an informed choice about using one material over another, and to find chemicals and materials that are safe for their intended uses. Safety testing becomes part of the product development process, and dangerous chemicals are kept off the market. In this way, downstream users can avoid finding out several years later that they had been making products with carcinogens or other dangerous substances.

\subsubsection{Increased collaboration to influence chemical choices in supply chains}

Interviewees from four of the largest companies discussed the importance of cooperation and collaboration with each other. First, it would allow them to better predict where the industry is headed regarding product sustainability requirements prior to enactment of regulations. This is important because large companies cannot change their operations or product design/content very quickly. They need time to develop technical solutions and work them through their supply chains and inventories.

In addition, any chemical restrictions these large players decide to make can have significant impacts in supply chains and the industry as a whole because the companies have such a significant market presence and so many suppliers. As one interviewee noted, "If at least a few of the (largest) companies unite on which substances they are asking suppliers not to use, it is an automatic trigger for a lot of suppliers not to use those substances." In this way, a few companies' decisions to restrict certain chemicals can shift the entire industry.

\subsubsection{Use of "escort information" to improve information transfer}

In order to improve information transfer, the idea of escort information was mentioned by different stakeholders contributing to this report. Escort information is information that is attached to a product, and then follows the product all the way through its life cycle. With an appropriate technology, information is added and updated as the product travels along different stakeholders in a product chain. The aim is to gather and organise the information in such a way that all the necessary information is available during the whole product life cycle.

There are different technologies being developed to facilitate escort information. Information can be directly attached to the product or the product can be given an identity and relevant information stored elsewhere and read with suitable equipment. The information can be visibly written on a sticker in common language. The information can also be 
coded in a bar code sticker or programmed into a Radio Frequency Identification Device (RFID). 80

One chemicals producer explained that while her company provides a lot of information about chemicals to its customers, it does not know exactly what information its customers pass on to their customers, or how far that information makes it down through the supply chain. While the idea is not fully developed, she suggested the concept of placing a bar code on each component or product that is produced, such as shell cases, which would contain information about chemical content, how the product should be used, its toxicity, exposure concerns, etc. Each actor in the supply chain would add information to the bar code about its contributions to the product as the product travelled through the supply chain. Contact information for each contributor could also be included. Any downstream user, waste handler, or other stakeholder could then scan the bar code to obtain access to all CiP information related to the product. In this way, the last person in the value chain would be able to access the information provided by the first person in the value chain. The bar code idea could also be used by enforcement agencies and port authorities to map and control the flow of e-waste. An obvious limitation of this concept is that stakeholders would have to have access to the technology to scan the bar codes.

\subsubsection{Business model for e-waste handlers in developing countries}

One interviewee discussed at length the problems she sees with the typical current system of e-waste management in developing countries. She feels that companies can inform the informal recyclers that there are hazards involved with the way they are performing their tasks, but these people often need this work for money to survive; it is unlikely that they will cease their work because someone tells them it is dangerous, and they may not have the resources to change their mode of operation. So, while CiP information should still be provided, creation of a new business model is also necessary.

A new business model would demonstrate to waste handlers and recyclers how to do their jobs more safely and effectively. Certain changes to the current waste-handling model could reduce environmental and human health hazards, and allow for increased profits as well. For example, plastic casings of electronics products are often burned to access the metals contained inside, and hazardous air pollutants are emitted as a result. Instead, she argued that the recyclers could be taught how to safely dismantle electronics, collect the plastics, and sell them as a fuel source, e.g. to power a water treatment plant. They can also continue to

${ }^{80}$ Luttropp 2009 
sell the metals that are removed from the electronics products, as they do today.

\subsubsection{New standards allowing comparison of products on environmental and human health performance}

Standards allowing for comparison of electronics products' environmental performance may incentivise more manufacturers to focus on the human health and environmental effects of every chemical chosen for their products. Standards for labels and information pertaining to energy efficiency currently exist for electronics products, allowing consumers to compare products and make choices according to their preferences. Similar types of standards could be created pertaining to chemicals, including information on recyclability, chemical toxicity, and lifecycle issues, all of which could be included on labels and used by consumers to compare products. Such a standard could help companies that prioritize health and environmental performance compete on such product characteristics and realise an advantage in the market. It would also clearly define health and environmental performance goals for companies that are not currently focused on such performance in their product design. A standard and labelling system that allows for comparison of products based on environmental impact of chemicals should also make it possible for companies to make economic arguments for use of environmentally preferred chemicals.

The Green Chemistry Institute of the American Chemical Society, in partnership with the standards development organization NSF International, will soon introduce a new standard that represents a good first step in this direction. The standard will help companies reduce their use of hazardous chemicals and materials in their products and motivate industry to make choices resulting in reduced impact on the environment and human health. The standard would be voluntary, and companies could demonstrate their adherence to the standard through different levels of certification. 81

\subsubsection{Regulations for ecolabels and "green" claims}

Greenwashing has become a significant problem, and regulations are needed to provide guidelines on ecodesign and to prevent companies from making misleading green claims. Product labels should not refer to a product's compliance with legal requirements - this confuses consumers, since any product being sold should already be compliant with any relevant legal requirements.

${ }^{81}$ For further information see Taylor 2010 pp. A254-A257 
Ecolabels should strive to maintain credibility by ensuring that certified products meet high standards of excellence. The environmental or health significance of the certification should also be clearly represented to avoid misleading consumers and to allow them to use ecolabels as shortcuts to finding products with the features they desire.

\subsection{Summary and conclusions}

A cross-section of informed stakeholders in the product chain were interviewed to obtain details and insights into their needs for CiP information, the CiP information systems they find valuable and relevant, the areas where they feel information gaps or obstacles exist, and potential means of addressing these gaps and obstacles. All of the company representatives interviewed stated that their companies not only comply with regulations, but also go beyond them in restricting chemicals of concern from their products. Thus, the information systems discussed in this section are not only regulatory-based, but also include voluntary systems that were created internal and external to the participating companies. The stakeholders involved in this study each described a different set of CiP information systems that they find valuable in trying to advance product safety. No two stakeholders referred to identical sets of information systems, though there was more overlap in the sets between stakeholders at similar locations in the supply chain.

Based on the CiP information systems they find valuable, each interviewed company created its own restricted substance list to keep undesirable chemicals and materials out of its products. A few companies required full materials disclosure from their suppliers, in addition to using an RSL. Interviewees had differing views on the practicality and value of full materials disclosure.

Many of the interviewed companies tend to interact primarily with the adjacent actor in the supply chain, while others, in particular the brand owners, may be involved in numerous stages of product development and disposal. While companies at the front end of the supply chain said they were providing their customers with necessary CiP information, some companies farther downstream in the supply chain complained of CiP information deficits, signalling possible obstructions in flow of CiP information in the supply chain.

Interviewees discussed numerous obstacles and possible solutions to overcome them. A key issue is the absence of an agreed definition of what constitutes proprietary information. Many stakeholders said that claims of proprietary information often blocked their ability to understand product contents or chemical uses, and they suspected frequent misuse of the claims. These stakeholders stressed the need for a narrowed and defined scope of proprietary information. 
Most companies discussed the need for a harmonized global standard as well as platforms for sharing CiP information. The common theme among interviewees was that there are too many information systems and too many lists available, making it difficult to keep up with all of the information and make decisions about which chemicals are actually of real concern in products. Companies want a common list of chemicals to be avoided in supply chains and products, a common data collection format, software and systems for electronic data transmission, and platforms for open exchange of information. Presently, companies' views diverge on the shape the ideal harmonized approach should take.

Information seems to be lost as it travels through the supply chain, and some downstream actors find it difficult to get the CiP information they need. Creation of an escort information system could solve this problem by tracking product contents as they move through the supply chain, providing all stakeholders in the value chain with complete information about product contents. Such a system would be especially useful and powerful if it included information about chemical properties and toxicity.

Stakeholders acknowledged that simply providing reams of CiP information to e-waste handlers in developing countries was not the most effective approach. In addition to providing CiP information, some companies are designing the content of their products for the reality of waste handling operations in developing countries, for instance, by leaving out chemicals that can create hazardous pollutants when burned inappropriately. Others suggest development of a new business model that would demonstrate to waste handlers and recyclers how to do their jobs more safely, effectively, and profitably.

Finally, chemicals-related standards, similar to those for energy efficiency, that allow for comparison of electronic products' environmental performance may incentivise more manufacturers to focus on the human health and environmental hazards posed by their products. The ability to easily compare labels of different products would allow consumers or customers to make product choices according to their preferences. Some stakeholders also discussed the problem of green-washing and the need for regulations and/or guidelines to prevent companies from making misleading green claims. In addition, ecolabels should strive to maintain credibility in order to serve as reliable "shortcuts" for consumers in choosing products that have the health and environmental features they desire. 



\section{CiP information at end of life}

\subsection{Introduction}

This part of the study elaborates on how information on substances contained in electronic products is generated, transmitted and used by various actors at the end of the product life cycle. The chapter covers information related to both hazardous substances and valuable materials. Research as well as feedback from various stakeholders indicate that the flow of information on these two groups of substances is currently insufficient and that improved information exchange could have environmental as well as overall economic benefits. ${ }^{82}$

The chapter is divided into two parts. The first part looks at the formal recycling and management of electronic waste, with a focus on the situation in developed countries. The second part studies the informal handling of e-waste in developing countries.

As described in chapter 3, there is not always a clear distinction between formal and informal waste management, and the terms can mean different things in different contexts. The distinction we use is between more formally organised, registered companies, expected to comply with existing legislation ("formal" waste management) and unregistered small-scale businesses, groups of people or individuals ("informal" waste management).

\subsection{Recycling in the formal sector}

A bulk of the information in this section based on IGES' research with a particular focus on the situation in Japan. The empirical research on waste management practices in Japan consists of document analysis and face-to-face interviews with 14 representatives of the recycling industry, electronics manufacturers and industry associations. ${ }^{83}$

In addition, two in-depth interviews have been conducted with representatives of the recycling industry in Sweden.

82 Bengtsson, M, Hayashi, S. et al, 2009

83 IGES, 2009; IGES, 2010 


\subsubsection{Recyclers' needs and access to CiP information}

Access to information on chemicals in e-waste is very much dependent on how active the recycler is at searching for this type of information. In general, there is little information readily available on chemicals content relevant for recycling, guidance on disassembly and recycling etc. If the information is available, it is often fragmented and split up among different actors further up the supply chain, and thus difficult and timeconsuming to access. If information is published in places such as the websites of producers, it is usually not detailed enough for recyclers. In such cases, there is thus still a need to contact producers directly.

However, to deal with the lack of information on chemicals in ewaste, some recyclers strive at building up internal knowledge on the materials they process, by conducting their own analysis and setting up internal lists. To find out the presence of e.g. bromine in components received, $\mathrm{x}$-ray fluorescence (XRF) scanners are used. However these only indicate the presence of bromine, not whether any detected bromine is in a form restricted by regulation or policy, the brominated flame-retardants restricted through RoHS.

Because demand for recycled material of increasing purity is going up, interviewees expressed increasing pressure from the next link in the recycling and waste treatment chain to be able to declare what substances are in the material they pass on. For example, plastic recyclers increasingly want information on content and have strict requirements, especially on metals and the use of halogenated substances, such as bromine and chlorine.

Japanese interviewees said that brand-owners often send their staff to recycling plants and provide opportunities to hear recyclers' opinions on disassembling their products, in order to promote Design for Environment (DfE). However the Japanese situation seems rather unique in this respect. In general, it seems very rare for recyclers to interface with manufacturers about information needs around chemicals in products. As described e.g. in chapter 5, the experience of the brand-owners is that recyclers at most request very high level information about basic materials content. (This is described further below in the section on obstacles.)

Many recyclers are doubtful about the usefulness of sharing information about chemical substances contained in products. This is mainly due to the low awareness of environmental risks among recyclers. It is common for recyclers to assume there is no environmental risk as long as they comply with the existing laws and regulations. Large-scale recyclers have established their own know-how concerning information on chemicals in products and do not think they need to ask the manufacturers to disclose additional information on the substances contained in what they recycle. Recyclers also point out that there are products of various brands at the entry point to the recycling process, and that it is difficult to identify the relevant products, even if information about them is provided by the manufacturers. 
At the moment, very few products carry marks or labelling aimed at the recycling process. Some recyclers consider that, if a cross-industrial information system is established in the future, and if there is an increase in the proportion of end-of-life products that have the relevant information attached, then information concerning chemicals in products will be utilized efficiently in the waste treatment and recycling processes. At the recycling sites, opinions have been expressed that labelbased information-sharing concerning chemical substances in products may have a certain level of usefulness, and the promotion of relevant initiatives on a cross-industrial basis was identified as an item to be addressed.

With regards to the contents of such an information system, recyclers suggested the need for information concerning the risks and properties of the chemical substances, rather than just their names. There were also opinions that criteria should be established for recycled products, in order to guarantee their quality in the supply chain.

Manufacturers have concerns about the stable procurement of resources and are therefore strongly interested in the recycling of valuable substances contained in their products, particularly valuable or rare metals. In many cases, manufacturers have data on the parts that they use, but do not own the information concerning the metals contained in the respective parts. They have started to identify the contents of valuable metals contained in their products through chemical analysis and other means for the purpose of establishing the appropriate price for selling their products.

Recyclers (intermediate treatment plants) are interested in information concerning valuable substances contained in products, but such information is very seldom provided by the manufacturers. Recyclers are not very enthusiastic about identifying the relevant information, either. Some recyclers expect that the relevant information will be communicated from the supply chain. They mainly want such information for the purpose of calculating the price for selling items to resource collectors (such as metal refineries) in the downstream stage of the recycling chain.

Among the metal refineries that operate in the downstream stage of the recycling chain, some companies actually collect valuable or rare metals from compacted electronic equipment and other products. They have established their own know-how concerning the valuable metal content of products to a certain degree. Because they do not have an incentive to share such information with their competitors, they keep detailed information on the metal content to themselves as a trade secret. Metal refineries are less interested in detailed information on product parts that contain valuable metals, and instead are primarily concerned as to which parts contain the metals they are looking to retrieve. 
These findings indicate that information concerning valuable metals contained in products is very seldom shared throughout the product life cycle. This remains with the raw material suppliers in the upstream stage of the supply chain, or at refineries in the downstream stage of the recycling chain.

REACH does not regulate waste. However, REACH does apply to recovered waste, once it ceases to be waste and recovery companies are considered under REACH to be manufacturers. They may therefore have obligations around registration and providing information for downstream users. So far, recyclers of e-waste do not seem to be fully aware of this. Once they do understand this fact, it is expected that the information needs of the recycling chain will increase drastically.

One likely reaction is that recyclers will request product manufactures to provide notification of any hazardous chemicals in their products and improve their ability to separate hazardous chemicals contained in products.

Recyclers are also becoming more concerned about the quality control of recovered materials as they will soon face requirements to be able to declare that recycled material does not contain substances of concern.

In this context, a concern was expressed that the REACH provisions on information-sharing on the presence of high concern chemicals above the $0.1 \%$ limit would not ensure a sufficient flow of relevant information to recyclers, if the limit would be applied on a whole complex product instead of on its parts (i.e. the products it has been assembled from).

\subsubsection{Gaps and obstacles in CiP information exchange}

This study indicates that there is a gap between manufacturers and recyclers in their recognition of chemical substances contained in products. Manufacturers are required to ensure accuracy in the control of information concerning chemical substances in products, and strive at corporate awareness of information control from the viewpoint of corporate social responsibility and risk management. On the other hand, recyclers have a relatively low awareness of environmental risks, which has resulted in a lower demand for information.

In general, there are no laws or regulations that apply exclusively to working environments in the recycling process. As long as recyclers adhere to general regulations on workers protection or waste management and other general laws and regulations, many recyclers consider that end-of-life products are being treated safely, and that there is no particular risk to the environment or human health in the recycling process. Some also consider that no special attention needs to be paid to hazards in the recycling process as long as parts that contain hazardous substances (e.g. liquids in liquid crystal displays, lithium ion batteries and solder in circuit boards) are removed from products at end of life. 
In general, contact with manufacturers is, as described above, rather rare. Besides low risk awareness, an important obstacle to informationsharing is the fact manufacturers are often located abroad creating geographical and language barriers in the way of communication.

An additional, related issue described is that the general level of education among staff at recycling plants is low. Both technical literacy and the ability to communicate freely in a foreign language, e.g. English, is low, limiting the chances of information exchange and dialogue. In the plants represented there are for example very few white-collar employees and the administrative capacity is low. The majority of staff are operators, many of them short-term workers employed via staffing companies.

Regarding producers' consideration of the recycling and waste treatment phase, interviewees said that producers generally do not seem to investigate the consequences of product design changes for the recycling chain. Producers are seen to have limited knowledge of recycling, and recycling and waste treatment seem in general not to be part and parcel of the design phase of products. Considering recycling at the design phase would, however, save time for recyclers, making e.g. preprocessing more precise, and potentially generating recycled material of such quality that it could fully substitute for virgin material.

As described above many stakeholders expressed the need for relevant information on the presence of valuable material, such as precious metals. However, information on the content of precious metals in products is in principle owned solely by the parts manufacturers and a limited number of metal collectors, and they do not have the incentive to share such information with other stakeholders.

\subsubsection{Means of addressing gaps and obstacles}

The stakeholders contributing to this report have described a number of solutions that they see would remedy some of the problems which hinder information flow around chemicals in electronics at end of life.

Firstly, there are recommendations for introducing or improving legislative frameworks. Key in such initiatives is enhancing EPR for information about chemicals in products. Legislative frameworks should also require product manufacturers to disclose enough information to recyclers for safe and efficient recycling. Furthermore, regulation on occupational health should be applied specifically to recycling activities.

Secondly, recommendations are proposed aimed at introducing certification systems. Interviewees call for the certification of products with an expanded list of chemicals restricted in electronics, such as the RoHS directive (through marking/labelling). In addition, the development of a positive list of substances/materials, easy to be separated/ recycled/disposed is seen as useful, complemented by recycling marks of those substances/materials. 
Related suggestions include criteria for recovered substances/materials. This could be in the form of a declaration that materials or products do not contain hazardous substances such as those restricted under RoHS or REACH SVHCs. Systems for certification or licensing of recyclers for handling of e-waste (collection, transportation, treatment, and final disposal), such as the E-Stewards program, are seen as constructive.

Thirdly, information systems in developed countries need to be further developed. Expanding the list of chemicals in products including valuable substances in the supply chain and providing this information to each stakeholder through product labelling would facilitate safer recycling, as would access to on-line database systems.

\subsubsection{Summary and conclusions}

The recycling industry needs more information on the products they are treating. At present, the flow of information on hazardous ingredients as well as precious materials is currently insufficient. Improved information exchange could potentially have environmental as well as overall economic benefits.

For example, it is expected that by improving information exchange between producers and recyclers, recycling operations could become not only safer but also more effective. Benefits would include:

- safer recycling and waste treatment operations;

- higher overall recycling ratio;

- higher use value of recycled material - with better knowledge of which substances are used in products, recycling operations can produce secondary materials that are less contaminated.

Different stages of the recycling chain have different needs for information. For example, the information needed for safe and efficient disassembly is not the same as the information needed for the recovery of precious and rare metals from printed circuit boards. Furthermore, information provided by the producers may only be accessible at the disassembly stage; after a product has been disassembled it is usually not possible to identify from which type of product and from which brand the different parts come. For this reason, it may be needed to develop information systems consisting of two separate parts: one for information from the producers to the disassembling companies and another for information from the disassembly stage to the following stages of the recycling chain. The format of these two systems and the information contained may need to be different.

In addition to providing relevant information to the recyclers, it is also important to improve product design. Design changes can make recycling easier, safer and more effective. For example, printed circuit boards 
are normally treated in integrated smelters. These facilities are capable of treating complex mixes of metals and up to 20 elements can be recovered at high rates. The presence of hazardous metals, such as lead or mercury, is normally not a problem for these processes. However, before entering the smelting and refining processes the circuit boards have to be shredded into small pieces. At that stage hazardous substances could be emitted.

Recyclers do not normally have two parallel treatment routes - one for boards containing certain hazardous substances and another for non-toxic boards. Improved product design across the proverbial board is needed here.

However, information systems must also facilitate communication upstream as well as downstream. In order to be able to make the right changes, electronics designers need to know more about how recycling is done and what problems the recyclers are facing when treating the existing products. Feed-back from the recyclers to the manufacturers is therefore another key element towards improved management of products containing chemicals and thus reducing risk from these. Training sessions involving electronics designers and recyclers facilitates information exchange, helping e.g. producers better understand how recycling is carried out and what challenges recyclers are facing.

Increased availability of product information from manufacturers will have only a limited effect unless efforts are made also to increase the demand for such information. In this respect, the development and effective dissemination of information about the risks associated with ewaste handling as well as information on safe technologies and practices among recyclers is needed.

\subsection{Recycling in the informal sector}

This section looks at information on chemicals in electronics from the perspective of e-waste and developing countries. The research laying the basis for the section consists of document analysis and in-depth interviews with stakeholders engaged in the e-waste issue in Nigeria, Ghana, Thailand and the Philippines. In addition, input has been provided by Public Interest Organisation members of the International POPs Elimination Network, IPEN.

Unless otherwise referenced quotes in this section are derived from these interviews, conducted for the purpose of this study in November December 2010. 


\subsubsection{Needs and obstacles to CiP information and potential means of addressing these}

In general, all interviewees pointed to large gaps in CiP information in developing countries. Formal information systems are in general not designed to cover particular needs in developing countries and access to industry systems and databases is limited. In the event that information is present it is often not in the appropriate national language. Since information about chemicals in products is limited or inaccessible, many stakeholders are not even aware of the need for this information.

A common feature of the developing countries receiving e-waste is the lack of environmental regulation. This was confirmed by all of the interviewees in this study. Legal frameworks do not exist to manage the in-flow of waste, nor is the appropriate technology or infrastructure available. The lack of environmental laws in combination with cheap labour are important incentives to dump e-waste in developing countries, much of it brought in illegally.

Interviewees point to a number of needs in terms of CiP information.

Firstly, there is a need for basic information for identifying chemicals in products. To ensure informed use and appropriate waste management, a need is expressed for the chemical components in products to be identified and communicated. The identified components should include metals as well as chemical substances.

In this context, interviewees propose the development of a publiclyaccessible global database of information on chemical components of products.

More importantly, however, the interviewees called for information on hazardous chemicals in products, their health risks, and alternatives. This information on toxic chemicals in the supply chain needs to be communicated all the way to actors engaged in the end-of-life phases of electronic products, such as recyclers and waste handlers, including the informal sector which often handles this type of waste in developing countries. Workers dealing with recycling of electronic products also need to know more about toxic releases into the environment during low tech e-waste burning and the health effects of toxic chemicals.

Consumers in developed countries also need to be made aware of hazardous substances in products. This information can help drive the market toward products with safer constituents by permitting consumer choice.

Other information related to $\mathrm{CiP}$ and handling of e-waste which is requested is manufacturer name and contact information. This information is needed to implement the producer responsibility principle in life cycle management. EPR is perceived as applying in developed countries, but not in the developing countries engaged in handling of e-waste.

Other information needs are not exclusively targeted at chemicals composition, but are nonetheless seen as relevant from a chemicals 
management perspective. These include guidelines for refurbishment, repair or dismantling in developing countries.

Connected to this is information to consumers about how to return or safely dispose of electronic products when they become waste. The challenge is to distribute information in a manner that people can understand. This is particularly true in developing countries, where literacy rates are in general low. CiP information systems used further up the supply chain must be adapted to meet the needs and circumstances in developing countries. It is particularly difficult to spread this information in countries where e-waste management is done at the household level. Interviewees in this study have mentioned channels such as radio, TV, film and pictures as appropriate means to communicate CiP information and best practices for refurbishment, dismantling and waste management of electronics.

An important way emphasised by interviewees to distribute CiPinformation and related information on waste-handling is through running workshops. These are described as useful platforms to strengthen the capacity of developing countries to manage electronic waste in an environmentally sound manner. This includes waste generated domestically as well as from illegal trans-boundary movements.

Furthermore, workshops and trainings can be aimed at providing more information on hazardous chemicals in electronics, as well as demonstrate how poor recycling and waste handling lead to workers, consumers and the environment being exposed to hazardous substances.

NGOs and governments have an important role to play here, but interviewees also expressed a desire for brand-owners to engage in organising such workshops in developing countries. This is seen as being in line with Individual and Extended Producer Responsibility, and as a way to make sure that the right type of information, such as on content and handling, reaches the right target audience in an appropriate fashion.

One interviewee states "the Basel convention centers as well as NGOs and the government are important stakeholders when it comes to dissemination of information". But his view is also that industry could be a source of awareness and disseminate information at various levels. "We need case studies to ensure best practices, local pilot centers on for example sustainable collection, under the guidance of the Basel Center. At the moment we are talking with Hewlett Packard. We invite other companies such as DELL, Acer etc. to contribute to developing an integrated collection system in Nigeria. [...] There is a need for Corporate Social Responsibility and producer responsibility. CSR is now lacking in Africa and companies do not seem to care about what is happening to their products. The industry has a role to play in securing a sustainable collection of their products. And the companies should not only collect their products in Europe, but also in Africa." 
Means of addressing the issue in addition to CiP information systems In many cases, workers in the informal e-waste sector do not know or understand the health implications of their waste handling practices. In other cases, they know the work is dangerous. However they continue the hazardous work. As their livelihood depends on the work they perform in the informal sector, these people have little choice but to continue with inappropriate practices unless safer alternatives are introduced.

Several interviewees explained that the people managing the waste know the work affects their health but not the extent to which it does. They stress that it is important that the workers receive information about the hazardous substances in waste and their effects. But, as one interviewee explains, "since these people are poor and uneducated this kind of information will probably not prevent them from doing the hazardous work. Their first concern is how to get money to stay alive. That is why the Government also needs to give some economic support to get equipment that will prevent the unsafe working methods that the workers use to retrieve as much metals as possible."

A similar situation is described for the Philippines: the workers are in general aware that burning has negative human side effects. But like in other developing countries the workers in the informal sector in the Philippines continue despite the awareness of the consequences of the hazardous work as there are usually no other options to earn a living. According to interviewees it is not enough to tell people that burning is harmful, they have to be provided with alternatives.

The authors of this report understand that the solutions described below do not automatically fall under the heading CiP information. However, access to available relevant CiP information is oftentimes a prerequisite to reaching an awareness of problems and solutions related to chemicals in products. CiP information contributes to the ability to make informed choices on chemicals in products as well as products containing chemicals (such as electronics), to develop the incentives needed to put such solutions into practice.

The result is improved risk management of the chemicals in electronic products, thus the link to improved flow of CiP information is undeniable.

\section{Establish a formal sector}

One way forward is to establish formal waste sectors by increasing the capacity of these countries to manage waste in an appropriate manner. A number of stakeholders have pointed to the importance of integrating the informal sector in this process. ${ }^{84}$

A representative for the Toxics Department at Ghana's Environmental Protection Agency states: "We are looking for support to build a

${ }^{84}$ Prakash et al. 2010 
demonstration plant where we can show the informal operators how to do $e$-waste recycling in a proper way. With proper legislation in place we will be able to control the movement of the materials from abroad. If we manage to do that, I think that we will be able to get the e-waste problem under control."

Engaging the informal sector in an emerging formal e-waste management system ensures continued livelihood for this informal, but often considerable economy. Furthermore, it avoids a situation where an emerging formal economy has to compete on uneven terms with an informal sector employing often inappropriate, unsound and cheaper methods of waste-handling.

According to a report issued by UNEP, China's lack of a comprehensive e-waste collection network, combined with competition from the lower-cost informal sector, have held back state-of-the art e-waste recycling plants. ${ }^{85}$ However a pilot to transform informal e-waste collection and management in Bangalore, India has been successful.

The report states that due to the relatively small size of the informal e-waste sectors in Brazil, Colombia, Mexico, Morocco, and South Africa these countries are cited as places with great potential to introduce state-of-the-art e-waste recycling technologies. Furthermore Kenya, Peru, Senegal, and Uganda would benefit from capacity building in socalled pre-processing technologies such as manual dismantling of ewaste. Today these four countries handle relatively low volumes of ewaste but this is likely to change. ${ }^{86}$

\section{Legislation}

A number of stakeholders have suggested that regulation of e-waste would be an important way forward. Legislation should help prevent the in-flow of non-functional electronics into developing countries, phaseout inappropriate waste-handling practices and ensure producer responsibility.

In India, a core group comprising of Toxics Link, Greenpeace, Manufacturers Association Of Information Technology and the Deutsche Gesellschaft für Technische Zusammenarbeit (GTZ) has taken the lead on drafting some new rules. These rules broadly encompass the framework of EPR and RoHS. ${ }^{87}$

NGOs interviewed called for the use of hazardous chemicals to be minimised and for EPR to push producers to change the substances in their products.

As an interviewee explains: "Companies and governments in the developed countries should stop dumping electronic waste in developing countries because they do not have the resources to manage them. On top

85 UN News Centre 2010

86 ibid. 2010

${ }^{87}$ Satish 2010 
of this the producers' responsibility should be expanded to include the developing countries.'

In addition, interviewees call upon the exporting countries to take responsibility for the e-waste being shipped to poorer countries. An NGO in Ghana proposes that the exporting countries conduct the necessary tests and document that all electronic equipment that is exported as second hand goods are functional. They recommend that anything that arrives as second hand should be certified as working. At ports in Ghana the equipment should be tested as well. "If the equipment is not working we recommend that it is re-exported at the expense of the importer" said one interviewee.

To minimise the export of used computers that are closer to their end-of-life, one can for example apply minimum technical specifications on computers for reuse.

In addition, take-back systems can ensure that computers at their end-of-life are exported back to a recycling facility in a OECD country.

Such suggestions are very much in line with the E-Stewards program described earlier in this report, which aims at ensuring cleaner recycling and export of electronics from OECD countries.

\subsubsection{Summary and conclusions}

From a global perspective some of the most severe problems associated with e-waste are caused by inappropriate recycling and waste-handling carried out in developing countries. These unregulated, and in some cases illegal, activities are causing serious, and in many cases irreversible, problems to human health as well as the environment.

Although many of the solutions often discussed to address these dangerous activities seemingly go beyond CiP information systems and information flow, the availability of such information, e.g. on hazardous substances in electronics serves as a cornerstone for developing solutions promoting improved products and waste management and reduced risks from electronics throughout the entire lifecycle.

It is a common feature of the informal waste sector in developing countries that it consists of poor people with little or no formal education; many informal waste workers are illiterate. This is relevant to bear in mind regarding information and education on the presence of hazardous material and how to manage these.

As interviewees have pointed out, information is important to stop primitive, highly unsustainable, and unsafe working methods in the informal sector. What is also needed is intervention and economic support to transform the informal sector into a formal sector where sustainable ways to retrieve valuable metals are introduced. Furthermore, awareness about the inappropriate but commonplace handling of e-waste must be secured at the design-phase of products, encouraging the phaseout of hazardous material early in the production stage. In order to facil- 
itate such awareness, information on how and where the products end up must be communicated upstream.

Improved waste management facilities, systems and structures in combination with safer product design will improve not only the toxic foot-print of products at end of life, but will also secure a higher recovery of valuable materials and rare elements.

Stakeholders in developing countries emphasise the need to incorporate the present workers in the informal sector in the future formal sector. As e-waste management is their livelihood they would likely continue the work if a formal sector was established without them being involved in it. This would result in an unfortunate competition between the formal and informal sector where humans and the environment would continue to suffer.

In addition to national action from the authorities in the developing countries to implement legislation and set up collection and management systems, stakeholders in developing countries also call for action in the e-waste exporting countries, from companies and the domestic public:

- Companies and governments in the developed countries are called to stop the exporting obsolete electronic products to developing countries;

- Exporting countries are requested to conduct the necessary tests to ensure that all electronic equipment exported as second hand is functional;

- The amount of hazardous chemicals in the products should be minimised by aiming for toxic use reduction throughout the product chain;

- EPR should be expanded to include developing countries in order to maximise recycling;

- Consumers should change their consumer behaviour, use electronic products as long as they can, and be aware of how to recycle it properly. Also, consumers in developed countries must be made aware of how their e-waste is being managed when exported to developing countries. 



\section{Discussion and recommendations}

Hazardous chemicals used in the electronics sector contribute to negative consequences for human health and the environment. This is especially, but not exclusively, true in the case of the inappropriate e-waste handling that is prevalent in many developing countries, where hazardous chemicals used in electronics often end up were they were not intended, leading to detrimental effects to the health of workers, their communities and the environment. As the prices of virgin materials, metals, and minerals increase and their availability decreases, it is becoming apparent that recycling of valuable materials must be made more efficient and effective. However, although informal waste handling is usually the focus when discussing any adverse environmental impacts of electronics, there are well-documented problems associated also with formal recycling in modern facilities.

The production phase is also problematic, often leading to exposure and health problems for workers and the environment. All of these problems are exacerbated by the fact that there has been a rapid increase in sales of electronics products in the past several years, making e-waste one of the fastest growing waste stream in the world. Information on the presence of hazardous chemicals in electronics is key in order to tackle these problems.

This report has studied some of the problems related to the presence of chemicals in electronic products, as well as the uses and needs of CiP information among stakeholders surrounding the electronics sector. The report has identified gaps and obstacles in the flow of CiP information, studied different stakeholders access to CiP information in relation to their particular needs, and identified possible ways forward.

The report has been conducted within the SAICM CiP project, with the ultimate objective of finding ways of improving CiP information systems for chemicals in products, where needed.

It is important to bear in mind that the aim must not be to improve information systems for the sake of information systems. As many of the interviewees to this study have pointed out, the overarching objective must be to reduce the risks associated with chemicals in electronics, to ensure improved human and environmental health. Considering the restraint in resources for all stakeholders concerned, it might even be counterproductive to focus on the development of information systems, if these are not connected to the goal of achieving an overall improved risk management of chemicals in products. 
In short, any system promoted must be in accordance with the spirit of SAICM, which underlies this project. The SAICM overall objective is to achieve the sound management of chemicals throughout their lifecycle, with the goal of ensuring the minimisation of significant adverse effects of chemicals on human health and the environment by 2020. Thus any information system set up or further developed must be connected to measures that solve identified problems and lead to improved risk management and handling of electronics and e-waste.

\subsection{Needs for improved flow of CiP information}

In order for stakeholders in different stages of the life cycle of products to adapt their handling of a product in an appropriate manner, and thereby minimise any potential risks to human or environmental health, there is a need for awareness of chemicals present in electronics. This includes production, use, appropriate waste handling and recycling.

Increased communication among actors along the life cycle is needed in order to identify unmet information needs, what information is required, and on what format and through what media the information should be provided.

Companies expressed a need for increased flow and transparency to help reduce their costs when planning, designing and carrying out production. There is a need to be able to foresee any potential future business risks as well as opportunities which is dependent on the availability of sufficient CiP information. This can include upcoming regulation on chemicals used in production, future preferences, demands and expectations of customers and consumers, future challenges in performance of their products, in the manufacture of their products, the availability of materials and components for their products and any present or future liability for the fate of these products. Protection of the workforce is also largely dependent on an understanding of the chemicals present in production.

Sifting through all of the available information about chemical hazards and risks and trying to determine what is important is a timeconsuming, resource-intensive and difficult process. It requires specialist knowledge held by few of the actors along the life cycle of electronics and related stakeholders. Agreement on what chemicals should be reported, and what information should be made available, would in many cases help companies obtain the needed and relevant chemicals-related information.

Authorities such as customs officials need access to relevant information in their efforts to control the flow of discarded electronics. In addition, in order to develop appropriate policies and measures authorities need information about which chemicals are contained in products on the market. 
Recyclers extracting valuable material from e-waste need to know where hazardous chemicals can be found in the products they receive, as well as information on the content of valuable material. At end of life, improved information can contribute to increased as well as more environmentally sound recycling and more efficient extraction of valuable metals. It should be noted that often the awareness of environmental risks is low among recyclers. Accordingly, there is a need for awarenessraising on the chemicals present in products, associated hazards and risks, and the role recyclers might have in contributing to or addressing problems related to chemicals in products.

Consumers in general assume that the products they purchase and use are safe for them as well as for the environment. Therefore, consumers in general might not feel an urgent need for CiP information. However, as their assumption that all products on the market are perfectly safe throughout the life cycle is incorrect, information increasing the awareness of hazards and risks from chemicals in products provides consumers with the opportunity to make informed choice on the products they buy.

Additionally, such information gives other stakeholders, such as designers, companies in the supply chain and public purchasers, the ability to make informed choices about the products they purchase.

In addition, a strong need has been expressed by upstream actors for information about where their products end up and how they are handled. Accordingly, improved information flow upstream through the product life cycle as to how products are used and handled at all stages must be promoted in order to help designers and formulators make informed decisions when designing, developing and improving products. With better information on exposure, the development of products with improved environmental performance is promoted, which contributes to less toxic material to handle in recycling and decreased release of toxics into the environment.

\subsection{Gaps and obstacles in the flow of information on chemicals}

As described in this report, there are overarching, industry-wide systems developed to facilitate exchange of information. The companies interviewed in this study take part in such joint collaborations. There are also regional and national rules and policies that regulate the flow of information on chemicals in electronics. However, as many companies feel that these systems are not sufficient to meet their particular information needs, they often develop their own approach, complementing the joint industry systems and regulatory frameworks with internal systems for substance restrictions, information exchange, supply chain 
management etc. In other words, as part of their daily business, they try to close this gap.

Others might not try to close such gaps, and may unwittingly contribute to increasing risks from chemicals in electronics. Some might be fully aware of such risks but due to lack of regulation or absence of economically feasible alternatives, in combination with lacking information on chemicals ingredients and recommended handling, continue harmful practises such as inappropriate waste handling.

A number of gaps and obstacles in the flow of information on chemicals have been described in this report. Below, the following gaps are discussed:

- The gap between upstream manufacturers of chemicals and the information needs further downstream;

- The gap along the supply chain to the final brand owners;

- The gap between the production-phase and the recycling phase;

- The gap between the formal product chain and informal wastehandlers in developing countries;

- The gap between information provided for intended use and the information needs arising from unintended use;

- The gap between what information is needed (relevant) and what information is available.

The obstacle constituted by different understandings of what is proprietary information.

1. This study has encountered an interesting paradox in the flow of information on chemicals in electronics. In general, upstream manufacturers of chemicals and material pass on the information they consider relevant, but they seem to have limited knowledge on applications and downstream exposure pathways. This might also hamper the ability to judge what information is actually relevant to feed into the system and pass on. Thus downstream manufacturers often feel that there is a gap at the beginning of the product chain, where the information made available and fed into the system is not relevant or sufficient information. Therefore, the information flow along the supply chain must also be guided by downstream demand, coming from the brand owners, rather than suppliers.

2. In addition, upstream actors described how they provided their customers with relevant information about their products, but actors farther downstream felt that needed data was unavailable, indicating that communication of data or information needs may be obstructed through the supply chain. To a large extent, information is lost in the supply chain, i.e. the numerous steps in the product chain between the chemicals industry and OEMs/brand-owners. Thus in spite of global industry systems designed to improve information sharing between companies, such as JIG, many perceive that the supply chain is a major gap where important information is often lost. 
3. Another major gap identified is between brand-owners and recyclers/waste-handlers. From the perspective of manufacturers, the general perception is that feedback is not communicated from recyclers on the needs they might have, and information requests from the recyclers are very rare.

Recyclers on the other hand express that producers often seem to have limited knowledge on recycling and that end of life considerations are not incorporated in the product design and material composition of electronics. They are also saying that the availability of information is limited, that much of the information which is available is not in a format that meets their needs, and that they have difficulties in approaching the brand-owners with requests for information,

4. Furthermore, the gap between the formal product chain and informal waste-handlers in developing countries hinders the flow of information to relevant stakeholders in developing countries. As mentioned, information systems are in general not designed to take into account the particular circumstances which exist in developing countries. Information to, for example, workers engaged in informal recycling in developing countries must take into account factors such as low level of literacy, formal education or organization.

5. The acknowledgement that recycling of electronics occurs in substandard conditions on a large scale has been expressed by brandowners contributing to this report. This acknowledgement must also be made by all other actors in the product chain, in particular the upstream chemicals manufacturers who, because they can control the information that is made available and fed into the system, are in a key position. A focus as described in chapter 5 is that information made available is primarily based on intended uses.

However simply dismissing the e-waste handling practices prevalent in many parts of the world as "this is not the way it is supposed to be done" will not solve any problems. Describing an annual flow of millions of tonnes of discarded electronics to inappropriate waste handling in developing countries as "not being intended use" will not contribute to reducing the risk of chemicals in electronics. Rather, stakeholders upstream must sincerely contribute to mitigating and reducing the environmental impact of informal recycling. (It is more in tune with reality to view this phase of the electronics life cycle as a "likely" or "probable" fate).

Accordingly, the type of CiP information that is fed into the system upstream should take into account information needs that arise from unintended but highly-probable handling.

6. In order not to overwhelm providers as well as recipients of information, stakeholders have been emphasising that the information provided should only be the relevant information. However, the information that is relevant for one actor in the life cycle is often different from what is relevant for other actors located elsewhere in the life cycle. Due to for example the gaps in information flow described above, information that 
is relevant to a particular actor in the life cycle might not be available at that point in the lifecycle. What is to be considered needed or relevant is largely defined by each individual actor and is dependent on e.g. perceived needs, on applications, type of use, interaction and combination with other ingredients and components, legal requirements, image/branding considerations, company policies and values etc. A challenge is how to ensure that relevant information is available where needed at every step of the life cycle.

7. A number of stakeholders have pointed out that proprietary claims at times create obstacles to acquiring or accessing essential CiP information. Sometimes such claims are vital to a company's business interest, but sometimes, interviewees have described, such claims are not particularly well founded, but arise from a lack of engagement, understanding or resources to deal with information requests.

As noted in e.g. section 5.4, claiming proprietary information also constitutes an obstacle to important information that needs to be communicated upstream, e.g. on uses and exposure.

While understanding the necessity for businesses to protect sensitive information, interviewees have discussed examples of how to nonetheless deal with sensitive information in a manner that assures the needs of providers as well as recipients of information.

A sincere and open discussion is needed among stakeholders about what really is and is not proprietary. Recipients need to be able to show suppliers that data can be protected. In order to tackle problems that can arise from the presence of chemicals in products, ways also must be found to provide the information needed by different actors to conduct proper risk management in their particular stage of the life cycle.

It should be noted that, as stated in chapter 1, according to Objective $15 \mathrm{C}$ of the SAICM Overarching Policy Strategy, information related to the health and safety on humans and the environment should not be regarded as confidential.

\subsection{Key requirements for information systems}

The stakeholders interviewed for this case study agree that there is room for improvement regarding the current CiP information systems in the electronics sector. Broadly speaking, they would like to see improved flow of CiP information through the value chain. There are different information needs related to chemicals in products depending on where a company or individual is situated in the product chain. Information systems must thus be designed or further developed accordingly. A set of key characteristics of well-functioning information systems for chemicals in products were pointed out: 
- Information must flow down the product chain, but also travel up the product chain.

- Relevant information must be available when the particular need for that particular type of information arises.

- The information generated and provided must take into account not only the intended use or handling of a product, but also the likely or probable fate of that product.

- The information provided must be comprehensible, accessible and appropriate for the particular stakeholder who needs the information for safe handling of the product in the particular stage of the life cycle of that stakeholder.

\subsection{Recommendations}

To improve the current situation and mitigate and reverse the negative consequences stemming from the use of chemicals in products, stakeholders need to collaborate and cooperate to tackle these issues in a meaningful way. The stakeholders involved in this study recognise this need for cooperation.

Two groups of actors have a particular role to play in this process; the manufacturers of chemicals and materials and the brand-owners.

The manufacturers of chemicals and materials are at the starting point in the product chain, and to a large extent function as gatekeepers of CiP information. Their ability to control what information is fed in to the system carries with it particular responsibility to also make this information available.

The brand owners, responsible for placing products on the market, play a key role. Many companies interact primarily with the adjacent actor in the product chain while brand owners may be involved in numerous stages of product development and manufacture. Due to this position in the value chain, information requirements on the product developed, produced and used are oftentimes driven by the brandowners. In addition, in terms of liability and responsibility for products, the eyes of regulators, consumers and upstream suppliers are usually on the actor placing the products on the market.

Companies throughout the product chains have described a need for a common list of chemicals of concern to be agreed upon which could simplify design and operation and reduce costs throughout the industry. Such a list should include what chemicals to provide information on as well the content of such information. In order to provide any added value, the list should go beyond merely listing already banned or otherwise regulated chemicals, but also take into account broader needs for CiP information among companies and other stakeholders such as authorities.

It should be noted that some of the problems and solutions discussed in this report do not fall automatically under the heading of CiP infor- 
mation, but seem to go a step beyond pure information systems. However, available, relevant information on the presence of chemicals in products is oftentimes a prerequisite for identifying potential problems associated with chemicals in products and develop solutions to these problems. Access to CiP information is a precondition for stakeholders to make informed choices and is an essential tool for stakeholders to adapt production, consumption, use and handling of products in order to minimise adverse effects to human health and the environment.

The following table contains recommendations expressed by the stakeholders contributing to this study for a more sustainable path forward.

\begin{tabular}{|c|c|c|}
\hline $\begin{array}{l}\text { Measures for improved flow of CiP } \\
\text { information }\end{array}$ & Potential Benefits & Comments \\
\hline $\begin{array}{l}\text { 1. A joint effort by major players } \\
\text { in the electronics industry to } \\
\text { define the scope of "proprietary } \\
\text { information" for the sector. }\end{array}$ & $\begin{array}{l}\text { Minimise obstruction of } \mathrm{CiP} \\
\text { information flow. } \\
\text { Facilitates planning and design. } \\
\text { Reduces costs. } \\
\text { Reduces business risks. }\end{array}$ & $\begin{array}{l}\text { Proprietary information } \\
\text { claims are seen as a com- } \\
\text { mon obstacle to information } \\
\text { flow. }\end{array}$ \\
\hline $\begin{array}{l}\text { 2. Agreement in the electronics } \\
\text { industry on which chemicals that } \\
\text { must be reported by suppliers in the } \\
\text { supply chain when being used in their } \\
\text { products, the infor-mation to be } \\
\text { communicated, and above what } \\
\text { thresholds they must be reported. } \\
\text { Downstream users should communi- } \\
\text { cate their anticipated uses of chemi- } \\
\text { cals, as well as in-formation on likely } \\
\text { or probable fate of the products, to } \\
\text { upstream actors to assist in determin- } \\
\text { ing which chemicals are "of concern". }\end{array}$ & $\begin{array}{l}\text { Provides a common set of chemi- } \\
\text { cals, that stakeholders consider } \\
\text { relevant from a CiP information } \\
\text { perspective. } \\
\text { Facilitates planning and design. } \\
\text { Reduces costs. } \\
\text { Reduces business risks. } \\
\text { Enables brand-owners to communi- } \\
\text { cate to consumers and end of life } \\
\text { actors on chemicals in their prod- } \\
\text { ucts. } \\
\text { Enables appropriate risk assessment } \\
\text { and risk reduction measures. }\end{array}$ & $\begin{array}{l}\text { Include regulated and unregu- } \\
\text { lated chemicals. } \\
\text { Regulated chemicals as a } \\
\text { minimum base-line, however } \\
\text { also covering the non- } \\
\text { regulated chemicals that } \\
\text { different stakeholders see as } \\
\text { relevant for their respective } \\
\text { information needs. }\end{array}$ \\
\hline $\begin{array}{l}\text { 3. Introduce mandatory obligations } \\
\text { to provide information on chemi- } \\
\text { cals present in electronics } \\
\text { throughout the life cycle. } \\
\text { E.g. by further introducing and } \\
\text { applying legislation on EPR for } \\
\text { Electronics Producers. }\end{array}$ & $\begin{array}{l}\text { Introduces informative responsibil- } \\
\text { ity, making the producer responsi- } \\
\text { ble for providing information on the } \\
\text { product or its effects at various } \\
\text { stages of its life cycle. }\end{array}$ & $\begin{array}{l}\text { EPR must also be promoted in } \\
\text { developing countries, where } \\
\text { much of the e-waste ultimately } \\
\text { ends up. }\end{array}$ \\
\hline $\begin{array}{l}\text { 4. Further development of certifi- } \\
\text { cation systems for recycling. These } \\
\text { must include tracking of materials. }\end{array}$ & $\begin{array}{l}\text { Increases transparency in the waste } \\
\text { phase, facilitates tracking of materi- } \\
\text { als. } \\
\text { Increases awareness among recy- } \\
\text { clers. }\end{array}$ & $\begin{array}{l}\text { Measures needed to ensure } \\
\text { that these apply to all actors } \\
\text { on the market. }\end{array}$ \\
\hline $\begin{array}{l}\text { 5. Agreement on an industry } \\
\text { standard format for collecting } \\
\text { chemicals-related data in the } \\
\text { electronics sector. For example, } \\
\text { the common IPC- } 1752 \text { standard } \\
\text { could be used, or a new standard } \\
\text { could be created. This system } \\
\text { would cover chemicals used by } \\
\text { actors in the supply chain. Down- } \\
\text { stream users should clearly com- } \\
\text { municate the information that they } \\
\text { need so that it can be included in } \\
\text { the standard. }\end{array}$ & $\begin{array}{l}\text { Increases the quality and reliability } \\
\text { of information. } \\
\text { Reduces costs. } \\
\text { Facilitates access to data. } \\
\text { Saves time and resources. }\end{array}$ & $\begin{array}{l}\text { Important tool for information } \\
\text { sharing. }\end{array}$ \\
\hline $\begin{array}{l}\text { 6. Creation of software packages } \\
\text { tailored to a standard data format. }\end{array}$ & $\begin{array}{l}\text { Allows for easy transmission of data } \\
\text { among actors in the supply chain. } \\
\text { See point above. }\end{array}$ & $\begin{array}{l}\text { Important tool for information } \\
\text { sharing. }\end{array}$ \\
\hline
\end{tabular}


7. Further development of escort information systems to allow product contents to be tracked as it move through the supply chain.
Provides all stakeholders in the value chain with complete information about product contents.
To be most effective, the system should include information about chemical properties, risks associated with various applications, and toxicity. Downstream users should communicate about the amount and type of information that would be useful for upstream actors to contribute.

\begin{tabular}{|c|c|c|}
\hline $\begin{array}{l}\text { Measures for reducing risks from } \\
\text { chemicals in electronics }\end{array}$ & Potential Benefits & Comments \\
\hline $\begin{array}{l}\text { 8. Collaboration among large } \\
\text { actors in the electronics sector } \\
\text { on a list of chemicals of con- } \\
\text { cern to be avoided in products, } \\
\text { including agreed upon exemp- } \\
\text { tions, allowed contamination } \\
\text { levels, and testing methods. } \\
\text { The actions of a few large, } \\
\text { concerned players in the } \\
\text { industry will be sufficient to } \\
\text { shift supply chains. }\end{array}$ & $\begin{array}{l}\text { Promotes a common ap- } \\
\text { proach. } \\
\text { Facilitates planning and de- } \\
\text { sign. } \\
\text { Reduces costs. } \\
\text { Reduces business risks. }\end{array}$ & $\begin{array}{l}\text { A Master RSL List. } \\
\text { This list would include both } \\
\text { regulated and unregulated } \\
\text { chemicals. }\end{array}$ \\
\hline $\begin{array}{l}\text { 9. A common list of chemicals of } \\
\text { concern to avoid in products that } \\
\text { is agreed upon by all major } \\
\text { players in the industry. } \\
\text { Similar to the Avoidance list in the } \\
\text { point above, however deeper } \\
\text { consolidated among a larger } \\
\text { constituency in the sector. }\end{array}$ & $\begin{array}{l}\text { Promotes a common approach. } \\
\text { Facilitates planning and design. } \\
\text { Reduces costs. } \\
\text { Reduces business risks. }\end{array}$ & $\begin{array}{l}\text { A Master RSL List. } \\
\text { This list would include both } \\
\text { regulated and unregulated } \\
\text { chemicals. }\end{array}$ \\
\hline $\begin{array}{l}\text { 10. Support and use in the } \\
\text { electronics sector of new systems } \\
\text { of standards and labels such as } \\
\text { the standards produced by the } \\
\text { Green Chemistry Institute and } \\
\text { NSF International. } \\
\text { Improvement and expansion of } \\
\text { such standards and labels. }\end{array}$ & $\begin{array}{l}\text { Allows for comparison of prod- } \\
\text { ucts based on environmental and } \\
\text { human health performance. }\end{array}$ & $\begin{array}{l}\text { Increased CiP information can } \\
\text { facilitate the development of and } \\
\text { agreement on such standards and } \\
\text { labels. }\end{array}$ \\
\hline $\begin{array}{l}\text { 11. Development of regulations } \\
\text { and/or guidelines on eco-design } \\
\text { and environmental claims. }\end{array}$ & $\begin{array}{l}\text { Promotes use of less hazardous } \\
\text { material. } \\
\text { Prevents greenwashing and } \\
\text { misleading "green" claims. }\end{array}$ & $\begin{array}{l}\text { Dependent on CiP information } \\
\text { being made available. }\end{array}$ \\
\hline $\begin{array}{l}\text { 12. Information campaigns aimed } \\
\text { at consumers on CiP, appropriate } \\
\text { waste handling and how e-waste } \\
\text { is commonly is exported and } \\
\text { inappropriately managed in } \\
\text { developing countries. }\end{array}$ & $\begin{array}{l}\text { Raised awareness among con- } \\
\text { sumers on CiP and the potential } \\
\text { fate of electronics can contribute } \\
\text { to improved take-back as well as } \\
\text { help consumers make informed } \\
\text { choices on the environmental } \\
\text { profile of the products they buy. }\end{array}$ & $\begin{array}{l}\text { Dependent on CiP information } \\
\text { being made available. }\end{array}$ \\
\hline $\begin{array}{l}\text { 13. Information campaigns in } \\
\text { developing countries, aimed at } \\
\text { authorities and waste handlers, } \\
\text { on CiP information, human and } \\
\text { environmental health impacts of } \\
\text { e-waste handling and appropriate } \\
\text { waste management practices. }\end{array}$ & $\begin{array}{l}\text { Improved waste handling practic- } \\
\text { es, aiming at improved efficiency } \\
\text { as well as reduced human health } \\
\text { and environment impacts. }\end{array}$ & $\begin{array}{l}\text { E.g. workshops, or through } \\
\text { channels such as radio, TV, etc } \\
\text { taking into account the needs of } \\
\text { the target audience. }\end{array}$ \\
\hline $\begin{array}{l}\text { 14. Development of business } \\
\text { models for safe and profitable } \\
\text { e-waste handling in developing } \\
\text { countries. }\end{array}$ & $\begin{array}{l}\text { Transform e-waste in develop- } \\
\text { ing countries from problem to } \\
\text { opportunity. }\end{array}$ & $\begin{array}{l}\text { Increased CiP information } \\
\text { facilitates the development of } \\
\text { such models. }\end{array}$ \\
\hline
\end{tabular}





\section{Abstract}

Many chemicals used in the electronics sector have negative consequences for human and environmental health. These include chemicals such as lead, mercury, cadmium, halogenated flame retardants and phthalates. Handling of electronic waste in developing countries is often detrimental to the health of workers, their environment, and their communities. There are also well-documented problems associated with formal recycling in modern facilities. The production- and use-phases are often problematic as well. Also, recycling of valuable materials must be made more efficient as the price of virgin materials, metals, and minerals increases and their availability decreases.

The problems are exacerbated by the rapid increase in sales of electronics in the past several years, making e-waste one of the fastestgrowing waste streams today. A vast amount of e-waste generated in developed countries such as the US, the EU and Japan is being exported to developing countries. The lower cost of waste handling in developing countries is a powerful incentive for this export.

In order to minimize any potential risks to human or environmental health, electronics stakeholders in different stages of the life cycle of products need information on what chemicals are present in products, their properties, use and potential risks.

The aim of the report is to describe the extent to which existing information systems meet the needs of different stakeholder groups, highlight information gaps, and identify obstacles and potential solutions to optimize flow of information. The report is carried out within the UNEP project on Chemicals in Products, and is based on literature research and 38 interviews with stakeholders surrounding the electronics sector.

Regarding information needs, companies express a need for increased flow and transparency to help reduce their costs in planning, designing and carrying out production. There is a need to be able to foresee any potential future business risks as well as opportunities. Protection of the workforce is also largely dependent on an understanding of the chemicals present in production.

Also other stakeholders need information on chemicals: To develop appropriate policies and measures, authorities need information about the chemicals used in products on the market. Recyclers need to know where hazardous chemicals can be found in the products they receive, as well as information on the content of valuable material. Upstream actors need information about where their products end up and how they are handled. 
A number of gaps and obstacles in the flow of information on chemicals are discussed in this report. For example the information gap between upstream manufacturers of chemicals and the information needs further downstream, the gap along the supply chain to the final brand owners and the gap between the production-phase and the waste-phase. Also, there are gaps between the information provided for intended use and the information needs arising from unintended use as well as a gap between what information is needed (relevant) and what information is available.

The report discusses the usefulness of a harmonized global standard as well as platforms for sharing information on chemicals in products. Companies express a need for a common list of chemicals of concern, going beyond merely listing already restricted chemicals to be agreed upon which would simplify design and operation and reduce costs throughout the industry.

Obligation to provide information on products and their effects throughout their life cycle, certification systems for recycling as well as improving the tools to facilitate transfer of information on chemicals are other solutions discussed. 


\section{References}

Alexander, R. Electronics Industry Fraud: Cancer and Birth Defects, A Public Report, Alexander, Hawes \& Audet, LLP

Bailar et al. 2000, Open Letter to the Health and Safety Executive. Int J. Occup Environ Health 2000: 6 (1), 71-72

BAN \& SVTC, 2002. The Basel Action Network and Silicon Valley Toxics Coalition. Exporting harm: the high-tech trashing of Asia. Seattle WA, USA http://www.ban.org/films/ExportingHarm.html

Beall et al. 1996. Brain tumors among electronics industry workers. Epidemiology. 1996: 2:129

Becker, M. Monica Becker \& Associates Sustainablility Consultants. 2009. Survey of SAICM Focal Points on the Need for Information on Chemicals in Products. Rochester, New York.

Bengtsson, M., Hayashi, S., et.al. 2009. Towards Improved Information Exchange for Safe and Effective Treatment of E-waste. Presented at the Life cycle Management. IGES.

Brigden K., Labunska I. et al. 2005. Recycling of electronic wastes in China and India: workplace and environmental contamination. Greenpeace Research Laboratories, Department of Biological Sciences, University of Exeter, UK

Brigden K., Labunska I., et al. 2008. Chemical contamination at e-waste recucle and disposal sites in Accra and Korforidua, Ghana. Greenpeace Research Laboratories, Department of Biological Sciences, University of Exeter, UK

Brigden, K., Santillo, D., et al. 2006 The toxic legacy: e-waste recycling in China and India. Public Service Review: International Development1: 84-86

Chan, Jenny. Haan, Esther de. et al. 2008. Silenced to Deliver: Mobile phone manufacturing in China and the Philippines. p.16, MakeITFair SOMO and SwedWatch

Clapp, R.2006. Mortality among US employees of a large computer manufacturing company: 1969-2001 Environ Health. 19 Oct 2006, http://www. ehjournal.net/content/5/1/30

Corn et al. 1993. Prospective Exposure Assessment Supplement to the Final Report, Johns Hopkins University School of Hygiene and Public Health, Baltimore

Correa et al. Ethylene Glycol Ethers and Risks of Spontaneous Abortion and Subfertility. Am. J. Epidemiology 1996:143 (7), 707-717

Cui, J., Forsberg E. 2003. Mechanical recycling of waste electric and electronic equipment: a review. Journal of Hazardous Materials 99 (3), 243-263.

Deng W. J., Zheng J.S., et al. 2007. Distribution of PBDEs in air particles from an electronic waste recycling site compared with Guangzhou and Hong Kong, South China. Environment International 33, 1063-1069.

Gray. 1993. Final Report Retrospective and Prospective Studies of Reproductive Health among IBM Employees in Semiconductor Manufacturing, Johns Hopkins University School of Hygiene and Public Health, Baltimore

Greenpeace International 2008. Toxic Tech: Not in Our Backyard. http:// www.greenpeace.org/international/en/publications/reports/not-in-our-backyard/

Greenpeace 2009. Where does e-waste end up? http://www.greenpeace.org/ international /en/campaigns/toxics/electronics/the-e-waste-problem/wheredoes-e-waste-end-up/

Gullet B. K., Linak W. P., et al. 2007. Characterization of air emissions and residual ash from open burning of electronic wastes during simulated rudimentary recycling operations. Journal of Material Cycles and Waste Management 9, 69-79 
Hagelüken, C., Meskers, C. 2008. Mining Our Computers - Opportunities and Challenges to Recover Scarce and Valuable Metals from End-of-Life Devices.

Huo X., Peng L., et al. 2007. Elevated blood lead levels of children in Guiyu, an electronic waste recycling town in China. Environmental Health Perspectives 115, 1113-1117.

IGES Instiute for Global Environmental Strategies, 2009 and 2010. Tekisei-na kokusai-shigen-jyunkan wo mezasita seihin-chu no yuuyou busitsu oyobi yuugai busitsu no kanri no arikata ni kansuru kenkyu. (Research on management of valuables and hazardous materials in products aiming for environmentally sound international resource circulation). (K2166) Hayama, Japan

Kajiwara, N.,Noma, Y. Takigami, H., 2008, Photolysis Studies of Technical Decabromodiphenyl Ether (DecaBDE) and Ethane (DeBDethane) in Plastics under Natural Sunlight. Environ Sci Technol 42(12), 4404-4409

Kogg, B., Thidell Å. 2010. Chemicals in Products. UNEP

LaDou, Joseph and Timothy Rohm. 1998. The International Electronics Industry. International Journal of Occupational Environmental Health, Vol 4, No. 1, Jan-Mar 1998

Leung A., Cai Z.W. \& Wong M.H. 2006. Environmental contamination from electronic waste recycling at Guiyu, Southeast China. Journal of Material Cycles and Waste Management 8, 21-33.

Leung A., Luksemburg W.J., et al. 2007. Spatial distribution of polybrominated diphenylethers an polychlorinated dibenzo-p-dioxins and dibenzofurans in soil and combusted residue at Guiyu, an electronic waste recycling site in Southeast China. Environmental Science and Technology 41 (8), 2730-2737

Leung A., Duzgoren-Aydin N.S., et al. 2008. Heavy Metals concentrations of surface dust from e-waste recycling and its human health implications in Southeast China. Environmental Science and Technology 42 (7), 2730-2737.

Li H., Yu L., et al. 2007. Severe PCDD/F and PBDD/F pollution in air around an electronic waste dismantling area in China. Environmental Science and Technology 41, 5641-5646.

Li H., Xu X., et al. 2008. The hazard of chromium exposure to neonates in Guiyu of China. Scince of The Total Environment 403 (1-3), 99-104.

Lundstedt, S. 2009, Emission, omvandling och bildning av bromerade ämnen vid olycksbränder, Umeå University.

Luttropp, C., Johansson, J. 2009. Improved recycling with life cycle information tagged to the product, Journal of Cleaner Production

Massey, R. I., Hutchins, J. G. et al. 2008. Toxic Substances in Articles: The Need for Information. Tema Nord

Minde P., Liljeholm R. 2005. Flaskhalsar i Aitik koppargruva. Master Thesis, Luleå Tekniska Universitet, Luleå.

OECD 2001, Extended Producer Responsibility, A Guidance Manual for Governments, OECD Publishing.

Prakash, S., Manhart, A. 2010. Socio-economic assessment and feasibility study on sustainable e-waste management in Ghana. Öko-Institut e.V.

Rudolph et al. Reproductive hazards in the microelectronics industry. State-of-theart reviews. Occup. Med. 1986 (1),135-143

Satish, S. 2010. Sustainable E-waste Management. Toxics Link

Sepulveda, A., M. Schluep, et al. 2010. A review of the environmental fate and effects of hazardous substances released from electrical and electronic equipments during recycling: Examples from China and India. Environmental Impact Assessment Review 30(1): 28-41.

Suzuki, G., Someya, M., Takahashi, S., Takigami, H., Sakai, S. Tanabe, S. 2010a, Dioxinlike compounds in Japanese indoor dusts: Brominated dibenzofurans strongly contribute to dioxin-like activity evaluated by In Vitro bioassay. Proceedings of the 5th International Symposium on Brominated Flame Retardants. April 7-9 2010, Kyoto Japan. 
Suzuki, G.,Someya, M.,Takahashi, S.,Tanabe, S.,Sakai, S.-i. Takigami, H., 2010b, Dioxinlike Activity in Japanese Indoor Dusts Evaluated by Means of in Vitro Bioassay and Instrumental Analysis: Brominated Dibenzofurans Are an Important Contributor. Environmental Science \& Technology.

Taylor, D. A. 2010. Principles into Practice: Setting the Bar for Green Chemistry, Environmental Health Perspectives, vol. 118 no. 6.

UN news centre, 2010. As e-waste mountains soar, UN urges smart technologies to protect health.

http://www.un.org/apps/news/story.asp?NewsID=33845\&Cr=waste\&Cr1

UNEP 2005. E-waste, the hidden side of IT equipment's manufacturing and use. http://www.grid.unep.ch/product/publication/download/ew_ewaste.en.pdf

UNEP 2006. Strategic Approach to International Chemicals Management -SAICM texts and resolutions of the International on Chemicals Management. http://www.saicm.org/documents/saicm\%20texts/SAICM_publication_ENG.pdf

UNEP 2009. Recycling- from E-waste to resources. http://www.unep.org/PDF/ PressReleases/E-Waste_publication_screen_FINALVERSION-sml.pdf

UNEP 2010. Urgent Need to Prepare Developing Countries for Surge in E-Wastes. http://www.unep.org/Documents.Multilingual/Default.asp?DocumentID=612\&Art icleID $=6471 \& \mathrm{l}=\mathrm{en} \& \mathrm{t}=$ long

Wen S., Fang FX., et al. 2008. Elevated levels of urinary 8-hydroxy-2\#deoxyguanosine in male electrical and electronic equipment dismantling workers exposed to high concentrations of polychlorinated dibenzo-p-dioxins and dibenzofurans, polybrominated diphenyl ethers, and polychlorinated biphenyls. Environmental Science and Technology 42 (11), 4202-4207.

Wong C.S.C., Duzgoren-Aydin N.S., et al. 2007. Evidence of excessive releases of metals from primitive e-waste process in Guiyu, China. Environmental Pollution 148 (1), 61-72

Wong C.S.C., Wu S.C., et al. 2007. Trace metal contamination of sediments of an e-waste processiong village in China. Environmental Pollution 145 (2), 434-442

Yu X. Z., Gao Y., et al. 2006. Distribution of polycyclic aromatic hydrocarbons in soils at guiyu area of China, affected by recycling of electronic waste using primitive technologies. Chemosphere 65 (9), 1500-1509

Yuan J., Chen L.,et al. 2008. Elevated serum polybrominated diphenyl ethers and thyroid-stimulating hormone associated with lymphocytic micronuclei in Chinese workers from an e-waste dismantling site. Environmental Science and Technology 42 (6), 2195-2200.

Yoshida, A., Tasaki, T. and Terazono, A. 2009. Material Flow Analysis of Used Personal Computers in Japan. Waste Management 29 (5), 1602-1614

Yoshikawa, M. 2008 Urban miners look for precious metals in cell phones. Article in Reuters

Yoshida, A. 2010. 7.8 UNEP-DTIE-IETC Regional Workshop on E-waste / WEEE Management. http://www.unep.or.jp/Ietc/spc/news-jul10/Mitsui\%20Final_(Ms.Masui).pdf

Zheng L., Wu K., et al. 2008. Blood lead and cadmium levels and relevant factors among children from an e-waste recycling town in China. Environmental Research 108 (1), 15-20 



\section{Sammanfattning}

Många kemikalier som används i elektronik har en negativ inverkan på naturen och människors hälsa. En stor del av dessa problem är kopplade till avfallshanteringen i utvecklingsländer, där primitiva och skadliga metoder ofta används i återvinningsprocessen. Miljö- och hälsopåverkan förekommer även vid moderna avfallsanläggningar, samt i samband med produktion och användning av elektronik.

I februari 2006 antogs det internationella ramverket SAICM (Strategic Approach to Intenational Chemicals Management) inom FN. Det övergripande målet med detta ramverk är att kemikalier skall användas och produceras på ett sådant sätt att deras negativa påverkan på miljö och hälsa minimeras.

2009 startades ett projekt inom SAICM, med fokus på information om kemikalier i varor (Chemicals in Products, vilket inom projektet förkortas CiP). Fallstudier inom fyra produktområden genomfördes, och resultaten av studien om elektronikindustrin redovisas i denna rapport. De övriga fallstudierna har fokus på leksaker, textilier samt byggnadsmaterial.

Syftet med denna rapport är att:

Beskriva i vilken utsträckning befintliga informationssystem tillgodoser behoven hos olika aktörer för att minimera potentiella risker kopplade till kemikalier i elektronikprodukter. Belysa brister i informationen.

Identifiera hinder och möjliga lösningar för att optimera informationsflödet.

Intervjuer med 38 aktörer med koppling till elektroniksektorn har genomförts inom studien. En stor del av dessa är tillverkare och producenter av mobiltelefoner och/eller datorer. Detta fokus valdes främst på grund av att dessa produkter ligger i framkant vad gäller teknisk utveckling och innovation. Marknadens efterfrågan på nya produkter med den senaste tekningen är stor, vilket resulterat i en hög omsättningen av dessa produkter. Dessa produkter är således mycket betydelsefulla ur ett avfalls- och återvinningsperspektiv.

\section{Kemikalier i elektronik}

De viktigaste farliga ämnen som förekommer i elektronikprodukter är bly, kvicksilver, kadmium, zink, yttrium, krom, beryllium, nickel, bromerade flamskyddsmedel, antimontrioxid, halogenerade flamskyddsmedel, tenn, polyvinylklorid (PVC) och ftalater. Elektronikprodukter innehåller även värdefulla metaller som guld och koppar, vilka är attraktiva för 
återvinningsföretag att utvinna. Återvinningen av plast ökar också stadigt.

\section{Volymer och avfallsflöden}

Enligt UNEP köptes nästan 900 miljoner mobiltelefoner år 2006 och över en miljard år 2007, globalt sett. En betydande andel av dessa produkter hamnar bland i hushållsavfallet, och en stor del av avfallet hanteras med metoder som är skadliga ur miljösynpunkt. Upp till 75 procent av elektronikavfallet i Europa och runt 80 procent i USA försvinner bortom myndigheternas kontroll. En stor mängd av avfallet exporteras till utvecklingsländer. De lägre kostnaderna för avfallshantering i utvecklingsländer är ett kraftfullt incitament för denna export. Det uppskattas att avfallshanteringen för datorer och mobiltelefoner är tio gånger högre i USA eller EU än i t.ex. Indien eller Nigeria.

\section{Utsläpp av kemikalier}

Studier har visat att arbetare i elektronikindustrin är mycket utsatta för cancerframkallande och reproduktionstoxiska kemikalier. Det rör sig bl.a. om lösningsmedel, tungmetaller och epoxihartser. Andra studier har visat eventuella utsläpp av t.ex. polybromerade dibensofuraner (PBDF) i användningsfasen av elektronik. PBDF är nedbrytningsprodukter av polybromerade difenyletrar (PBDE), som ofta används som flamskyddsmedel i elektronik. Hanteringen av elektroniskt avfall som ofta förekommer i utvecklingsländer, i kombination med de stora volymerna elektronikavfall har redan lett till skadeverkningar för miljön och människors hälsa i t.ex. Kina, Indien, Nigeria, Filippinerna och Ghana.

\section{Översikt över informationssystem}

Under de senaste åren har ett antal politiska initiativ utvecklats med fokus på kemikalier i elektronik och avfallshantering. Inom EU har RoHS- och WEEE-direktiven samt REACH-förordningen haft stor inverkan på hur elektronikprodukter är utformade, hur de samlas in och återvinns, och hur information om farliga ämnen genereras och sprids. Andra regioner och länder såsom USA, Sydkorea, Kina och Japan har sedermera gått i samma riktning.

Branschgemensamma, ofta internationella, initiativ har införts, bl.a. JIG (the Joint Industry Guide), IEC:S standard deklaration och webbportalen GPS. 


\section{Behov av information om kemikalier i varor}

De företag som deltagit i denna studie försöker ligga steget före globala regler och frivilligt begränsa kemikalier som de tror kommer att regleras i framtiden. Ett av de vanligaste och viktigaste användningsområdena för information är att hålla sig uppdaterad på den senaste informationen om kemikalier, dess faror och risker. Alla intervjuade beskrev olika uppsättningar informationssystem för CIP som de finner värdefulla för att öka produktsäkerheten och baserat på dessa skapar varje företag sin egen ämnesförteckning över begränsade kemikalier för att undvika oönskade kemikalier och material i sina produkter. Dessutom kräver ett fåtal företag att deras leverantörer redovisar information om alla kemikalier i levererade komponenter och produkter, så kallad Full Material Declaration.

Många av de intervjuade företagen interagerar främst med aktörerna närmast sig i distributionskedjan. De stora varumärkena däremot är ofta inblandade i flera steg i produktutvecklingen och - hanteringen. Uppströmsaktörer beskrev hur de förser sina kunder med relevant information om sålda produkter, men aktörerna längre nedströms känner att väsentlig data inte finns tillgänglig, vilket talar för att information går förlorad i distributionskedjan.

För att minimera eventuella risker för miljö och hälsa, behöver aktörer i alla steg av elektronikprodukternas livscykel information om vilka kemikalier som förekommer i produkterna, deras egenskaper, användning och potentiella risker.

Företagen uttryckte ett behov av ett ökat informationsflöde och ökad öppenhet för att minska sina kostnader vid planering, utformning och genomförande av produktion. Man behöver kunna förutse eventuella framtida risker och möjligheter. Detta inkluderar kommande lagligkrav på kemikalier som används i produktionen, eventuella preferenser, krav och förväntningar från kunder och konsumenter, framtida krav på produkters prestanda, tillgång till material och komponenter och nuvarande eller framtida produktansvar. För att säkra arbetarskyddet krävs kunskap och förståelse för de kemikalier som används i produktionen. Allt detta är beroende av tillgången till adekvat CIP information.

Överenskommelser om vilka kemikalier som skall rapporteras, och vilken information som bör göras tillgänglig, skulle i många fall hjälpa företag att få nödvändig och relevant kemikalier-relaterad information.

Myndigheter, såsom tulltjänstemän, behöver tillgång till relevant information för att kunna kontrollera flödet av elektronik avfall. För att kunna utveckla lämpliga strategier och åtgärder, behöver myndigheter information om de kemikalier som används i produkter på marknaden.

För att utvinna värdefullt material från elektroniskt avfall måste återvinningsföretag veta var farliga kemikalier finns i de produkter som de tar emot, samt få information om förekomsten av värdefullt material. 
I avfallsledet kan förbättrad information bidra till ökad och mer miljövänlig återvinning, med effektivare utvinning av värdefulla metaller.

I allmänhet är avfallshanterare inte medvetna om eventuella miljörisker i deras verksamhets, vilket resulterar i minskad efterfrågan på information. Återvinningsföretag verkar tro att så länge de följer allmänna bestämmelser finns det inte någon särskild risk för miljö eller hälsa i återvinningsprocessen. Därför finns det ett behov av att öka medvetenheten om de kemikalier som finns i varor och vilka faror och risker de utgör, för att återvinningsföretag ska kunna bidra till att minska problemen som rör kemikalier i varor.

Den låga medvetenheten om riskerna gäller särskilt för avfallhanterare i utvecklingsländer. Åtgärder och ekonomiskt stöd krävs för att skapa alternativ till den ofta farliga avfallshanteringen som är vanlig inom den informella sektorn.

Konsumenter utgår från att de varor de köper är säkra för dem och miljön och anser sig därför inte ha ett akut behov av CIP information. Information om faror och risker från kemikalier i varor kan emellertid ge konsumenterna möjligheten att fatta välgrundade beslut om de varor de köper.

Kunskap om förekomsten av farliga kemikalier i varor skulle också ge formgivare, företag i leveranskedjan och offentliga upphandlare möjlighet till mer miljövänliga inköp.

Aktörer uppströms uttryckte ett starkt behov av information om var deras produkter hamnar och hur de hanteras. Därför skulle förbättrat informationsflöde uppströms om hur produkterna används och hanteras på alla stadier hjälpa tillverkare och formulerare att fatta välgrundade beslut vid tillverkning, utveckling och förbättring av produkter. Med bättre information om exponering kan produkter med förbättrad miljöprestanda främjas, vilket bidrar till mindre giftiga material att hantera vid återvinning och minskade utsläpp av gifter i miljön.

\section{Hinder för flöde av CIP information}

Det finns övergripande, branschgemensamma system som har utvecklats för att underlätta utbytet av information. De intervjuade företagen i studien deltar i sådana gemensamma samarbeten. Det finns också regionala och nationella lagar och regler som reglerar flödet av information om kemikalier i elektronik. Eftersom många företag upplever att dessa system inte är tillräckliga för att tillgodose deras informationsbehov, utvecklar de ofta sina egna strategier, som komplement.

Ett antal brister och hinder för flödet av information om kemikalier tas upp i rapporten.

Klyftan mellan uppströmstillverkare av kemikalier och informationsbehov nedströms. Uppströmstillverkare av kemikalier och material vidarebefordrar den information de anser vara relevant, men de verkar ha 
begränsad kunskap om behov nedströms och olika exponeringsrutter. Nedströmstillverkare känner ofta att det finns ett gap i början av produktkedjan, där den informationen som görs tillgänglig och matas in i systemet inte relevant eller tillräcklig.

Gapet längs distributionskedjan till de slutliga varumärkesägarna/produ-centerna. Aktörer uppströms beskrev hur de gav sina kunder relevant information om kemikalier i produkter, men aktörerna nedströms känner att relevant data inte finns tillgänglig, vilket tyder på att överföringen av relevant information hindras i produktkedjan. Det är troligt att en del information går förlorad i de många stegen mellan kemiindustrin och sluttillverkare/ varumärke-ägare.

Klyftan mellan produktionsfasen och återvinningsfasen. Den allmänna uppfattningen bland tillverkarna är att återvinningsföretag i allmänhet inte efterfrågar information. Återvinningsföretag å andra sidan anser att producenter ofta verkar ha begränsad kunskap om återvinning och att hänsyn inte tas till avfallsfasen vid utformning och materialsammansättning av elektronik.

Klyftan mellan den formella produktionskedjan och avfallshanteringen i den informella sektorn i utvecklingsländer. Informationssystem är i allmänhet inte utformade med hänsyn till förhållandena i utvecklingsländer. För att tillhandahålla information till exempelvis arbetstagare som sysslar med återvinning i utvecklingsländer måste faktorer såsom låg läskunnighet, bristande formell utbildning eller bristande organisation beaktas.

Skillnaden mellan information som tillhandahålls för att tillgodose behov vid avsedd användning av varor och informationsbehov som uppstår till följd av icke avsedd användning. I allmänhet tillhandahålls information med hänsyn till den avsedda användningen av produkter. Med tanke på de stora volymerna av elektroniskt avfall som hanteras på ett miljöfarligt sätt, bör även hänsyn tas till icke avsedd hantering av produkterna då man utformar den typ av CIP information som matas in $\mathrm{i}$ systemet uppströms.

Skillnaden mellan vilken information som behövs (relevant information) och vilken information som finns tillgänglig. På grund av brister i informationsflödet finns den information som är relevant för en viss aktör i livscykeln inte alltid tillgänglig för den aktören. En utmaning är därför att säkerställa att relevant information finns tillgänglig där det behövs i varje steg av livscykeln.

Ett av hindren för CIP information som diskuterades av de intervjuade var bristen på enighet om vad som utgör företagskänslig information (proprietary information). Det är vanligt att information inte delas av leverantörer med motiveringen att den informationen skulle kunna skada leverantörens affärsverksamhet. Flera aktörer uppgav att sådana åberopanden hindrar dem att bedöma en produkts kemikalieinnehåll. De misstänker också frekvent missbruk av sådana åberopanden. Sådana åberopanden för att hindra informationsdelning försvårar också kommunikation uppströms av 
information. Väl medvetna om nödvändigheten för företag att skydda känslig information, har de intervjuade diskuterat exempel på hur man ändå kan hantera känslig information på ett sätt som tillgodoser behoven hos leverantörer såväl som mottagare av information. En öppen diskussion behövs mellan olika aktörer om vad som verkligen är och inte är företagskänslig information. Mottagarna måste kunna visa leverantörer att data kan skyddas. Dessutom måste också vägar hittas för att tillhandahålla den information som behövs av olika aktörer för att säkra en korrekt riskhantering i alla faser av livscykeln.

\section{Viktiga krav på informationssystem}

Ett antal nyckelegenskaper för fungerande informationssystem för kemikalier i varor beskrevs av intervjupersonerna:

Information måste flöda nerströms längs varukedjan, men även flöda uppströms.

Relevant information måste vara tillgänglig när behov av just den typen av information uppstår.

Informationen måste genereras och lämnas med hänsyn till inte bara den avsedda användningen och hanteringen av en vara, men också den varans sannolika eller troliga öde.

Den information som lämnas skall vara förståelig, tillgänglig och anpassad till olika aktörers olika behov för säker hantering av produkten i varje led av varans livscykel.

\section{Rekommendationer}

De intervjuade företagen diskuterade nyttan av en harmoniserad global standard för utbyte av CIP information. Det gemensamma temat var att det finns för många informationssystem och alltför många listor, vilket gör det svårt att ta till sig all information och fatta beslut om vilka farliga kemikalier i varor är relevanta.

Företag i samtliga led i varukedjan har beskrivit behovet av en gemensam förteckning över farliga kemikalier. Det skulle underlätta produktion och tillverkning och minska kostnaderna för hela branschen. En sådan lista bör omfatta såväl vilka kemikalier som man skall lämna information om som innehållet i den informationen. För att tillföra ett mervärde bör en sådan lista gå längre än att bara innehålla redan förbjudna eller på annat sätt reglerade kemikalier, utan även ta hänsyn till företags och andra aktörers bredare behov av CIP information.

En annan lösning som diskuterats är att införa en skyldighet att informera om en varas hälso- och miljöpåverkan i alla skeden av livscykeln, inklusive relevant information om kemikalier. Ett exempel är reg- 
ler om utökat producentansvar, vilket skulle omfatta ansvar att tillhandahålla relevant information.

Dessutom föreslås system för certifiering av återvinnare som ett sätt att spåra material, öka insynen i avfallshanteringen och öka medvetenheten om kemikalier i avfallshanteringen. Andra lösningar som föreslås är att förbättra de verktyg som krävs för att underlätta överföringen av information. Dessa inkluderar den fortsatta utvecklingen av standardformat för datainsamling och programvara som stödjer sådana standarder, och eskort informationssystem för att spåras produktinnehåll genom produktkedjan.

Ytterligare lösningar som diskuteras med är på gemensamma listor över vilka kemikalier som bör undvikas inom sektorn, normer och etiketter för eko-design, informationskampanjer riktade till konsumenter, informationskampanjer för aktörer i utvecklingsländer och åtgärder för att främja en säker och lönsam avfallshantering av elektronik i utvecklingsländer. Även om vissa av dessa lösningar till synes går bortom informationssystem för CIP, är tillgång till CIP information en förutsättning för att utveckla de lösningar som krävs för att minska miljöpåverkan av elektronik under hela livscykeln. 



\section{Informants and interviewees}

\begin{tabular}{ll}
\hline Melanie Bausen & BASF \\
Greg Bond & Dow \\
Greg Dripps & Dow \\
Michael Gribble & SGCl Chemie Pharma Schweiz \\
Brian Martin & Seagate \\
Tamim Sidiki & DSM \\
Fredrik Petit & DSM \\
Foxconn Technology Group & \\
Anonymous IT company & \\
Pontus Alexandersson & Sony Ericsson Mobile Communications AB \\
Mats Pellbäck Scharp & Sony Ericsson Mobile Communications AB \\
Markus Stutz & Dell \\
Representative from HP & \\
Michael Kirschner & Design Chain Associates \\
Sylvia Maurer & The European Consumers' Organization, BEUC \\
Christian Schaible & European Environmental Bureau, EEB \\
Sepanso & France Nature Environment Aquitaine \\
International POPs Elimination Network, IPEN & \\
Mikael Lekbeck & Sims Recycling Solutions AB \\
Sverker Sjölin & Stena Technoworld AB \\
Richard Gutierrez & Basel Action Network (Philippines) \\
Walaiporn Mooksuwan & Ecological Alert and Recovery (Thailand) \\
John Pwamang & Toxics Department of Ghana's EPA \\
Yaw Amoyaw-Osei & Green Advocacy Ghana, GreenAd \\
Oladele Osibanjo & Basel Convention Coordinating Centre (Nigeria) \\
Representative(s) from Hitachi & \\
Sarah Westervelt & E-Stewardship Policy Director, Basel Action Network \\
&
\end{tabular}




\section{norden}

\section{Nordic Council of Ministers}

\section{Ved Stranden 18}

DK-1061 Copenhagen K

www.norden.org

\section{Information on Chemicals in Electronic Products}

A study of needs, gaps, obstacles and solutions to provide and access information on chemicals in electronic products

Many chemicals used in the electronics sector have negative consequences for human and environmental health. These include chemicals such as lead, mercury, brominated flame retardants, halogenated flame retardants, polyvinyl chloride (PVC) and phthalates. Typical electronic waste handling practices in developing countries are detrimental to the health of workers, their environment, and their communities. There are issues associated also with formal recycling in modern facilities, and the production phase is often problematic as well, with electronics workers potentially being exposed to carcinogens and reproductive toxicants. In addition, it is becoming apparent that recycling of valuable materials must be made more efficient as the price of virgin materials, metals, and minerals increases and their availability decreases.

The problems are exacerbated by the fact that there has been a rapid increase in sales of electronics in the past several years, making e-waste one of the fastest-growing waste streams today.

In order to minimize any potential risks to human or environmental health, electronics stakeholders in different stages of the life cycle of electronic products need information on what chemicals are present in the products, their properties, use and potential risks.

This report studies the extent to which existing information systems meet the needs of different stakeholder groups, highlights information gaps and obstacles and discusses potential solutions to optimize the flow of information on chemicals in electronics. The report is carried out within the UNEP project on Chemicals in Products. 